\title{
MOLECULAR BASIS OF SUBSTRATE RECOGNITION IN BJAI, AN AHL SYNTHASE FROM BRADYRHIZOBIUM \\ JAPONICUM
}

by

Nicole Cornell

\author{
A thesis \\ submitted in partial fulfillment \\ of the requirements for the degree of \\ Master of Science in Chemistry \\ Boise State University
}

May 2017 
(C) 2017

Nicole Cornell

ALL RIGHTS RESERVED 


\section{BOISE STATE UNIVERSITY GRADUATE COLLEGE}

\section{DEFENSE COMMITTEE AND FINAL READING APPROVALS}

of the thesis submitted by

Nicole Cornell

Thesis Title: Molecular Basis of Substrate Recognition in BjaI, an AHL Synthase from Bradyrhizobium japonicum

Date of Final Oral Examination: 11 November 2016

The following individuals read and discussed the thesis submitted by student Nicole Cornell, and they evaluated her presentation and response to questions during the final oral examination. They found that the student passed the final oral examination.

Rajesh Nagarajan, Ph.D.

Henry A. Charlier, Ph.D.

Eric Brown, Ph.D.
Chair, Supervisory Committee

Member, Supervisory Committee

Member, Supervisory Committee

The final reading approval of the thesis was granted by Rajesh Nagarajan, Ph.D., Chair of the Supervisory Committee. The thesis was approved by the Graduate College. 


\section{ACKNOWLEDGEMENTS}

I am grateful to each of the members of my dissertation committee for they have provided me personal and professional guidance through this life changing event. I would especially like to thank Dr. Rajesh Nagarajan, the chairman of my committee, for being my mentor the past few years and always willing to give advice while enjoying a cup of coffee with me. Thank you Dr. Matthew King for volunteering your time to collect computational data and design professional pictures for the BjaI mutant chapter.

I also want to thank my parents and my grandma for supporting me through this pursuit and always encouraging me to reach for the stars. Finally, to my loving husband, who supported me through all the ups and downs and believed in me even when I did not; I could not have done this without you. Вечно и всегда, твой Ангел. 


\begin{abstract}
Resistance to antibiotics has become a major challenge in today's society for treating bacterial infections. Inhibition of quorum sensing has a potential to be a nonantibiotic based therapeutic that could be used to fight these bacterial infections. Quorum sensing is a cell density dependent, intercellular communication mechanism that bacteria use to synchronize behavior such as virulence and resistance to antibiotics. If this switch from planktonic to communal behavior can be inhibited, the bacteria will be less virulent. One possible way to accomplish this is by inhibiting the enzymes that are responsible for making the quorum sensing signaling molecules in Gram-negative bacteria - acylhomoserine lactone (AHL) synthases. Since AHL synthases are mostly uncharacterized, understanding how these enzymes recognize its acyl-substrate would be beneficial to designing effective quorum sensing inhibitors. The focus of this thesis is to investigate the substrate recognition mechanism in BjaI, an acyl-homoserine lactone synthase found in soybean symbiont Bradyrhizobium japonicum. BjaI was chosen because it can be used to highlight the differences between acyl-ACP vs acyl-CoA utilizing AHL synthases. We found that all of our single point mutations within either of the substrate binding pockets, S-adenosyl-L-methionine and isovaleryl-CoA, were detrimental to enzyme activity. Kinetic constants were measured for the native and other similar non-native acyl-CoAs as well as their respective alkyl-CoA inhibitors. For too long (> six carbons) and too short (< four carbons) acyl-CoAs, we found that BjaI rejected nonspecific substrates at the binding step. However, for substrates that are structurally similar to isovaleryl-CoA, BjaI uses a
\end{abstract}


combination of both the binding and catalytic steps to reject the nonspecific substrate. The tools used in this study should open new doors to designing effective quorum sensing inhibitors. 
TABLE OF CONTENTS

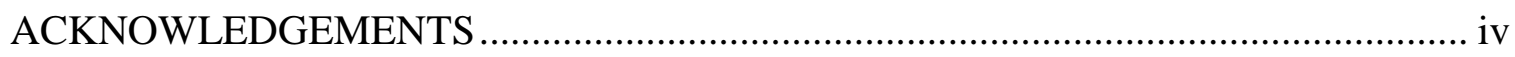

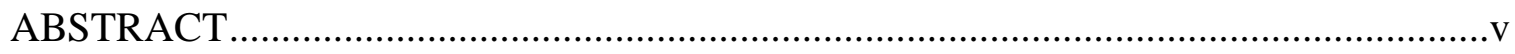

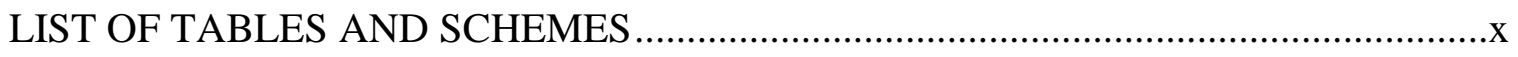

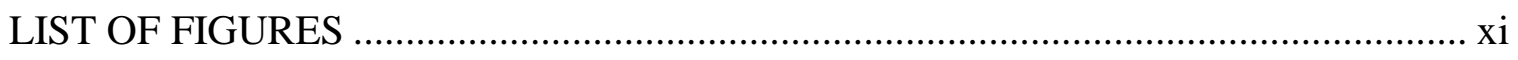

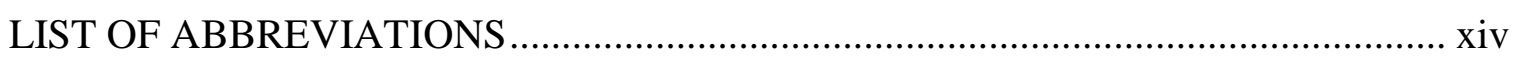

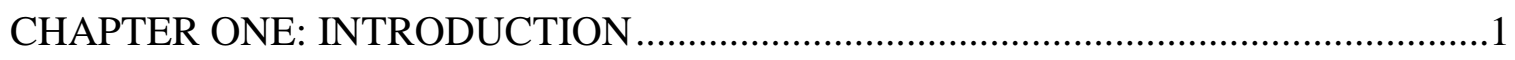

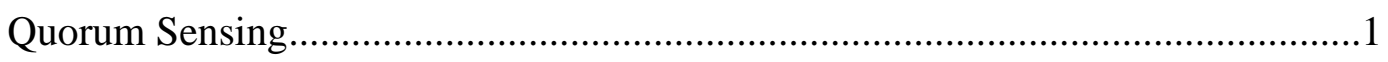

BjaI, an AHL Synthase found within the bacteria, Bradyrhizobium japonicum .....6

AHL Synthases are Bisubstrate Enzymes .........................................................

Crystal Structures of LasI, EsaI, and TofI .....................................................10

Michaelis-Menten Enzyme Kinetics ...............................................................12

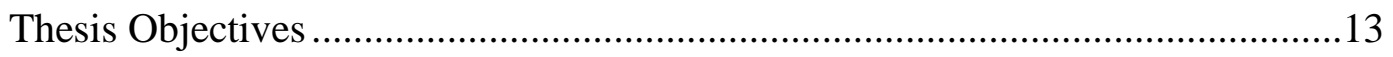

Chapter 2: SAM Synthesis .................................................................14

Chapter 3: BjaI Mutants .......................................................................14

Chapter 4: BjaI Substrate Specificity ........................................................14

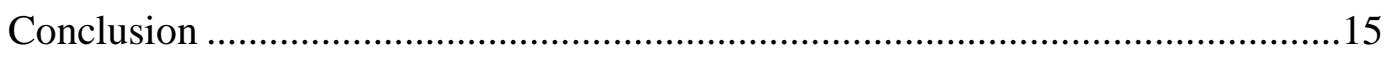

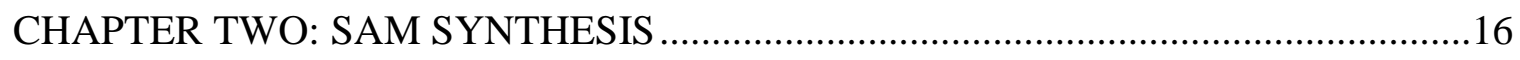

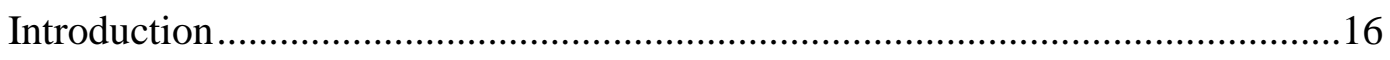

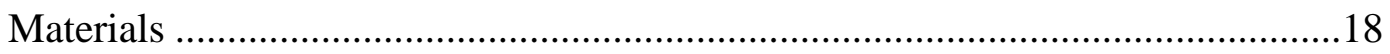


Methods.

MetK Transformation ......................................................................19

MetK Growth, Lysis, and Purification..............................................19

Enzymatic SAM Synthesis using MetK .............................................20

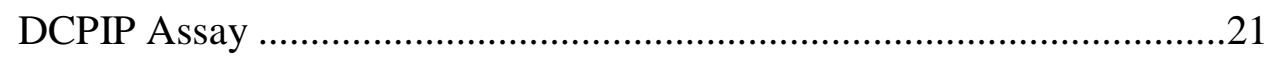

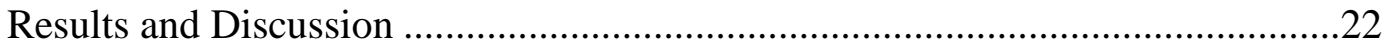

Issues with MetK Precipitation .........................................................22

Issues with SAM neutralization for use in DCPIP Assay ........................24

Conclusion ..............................................................................................25

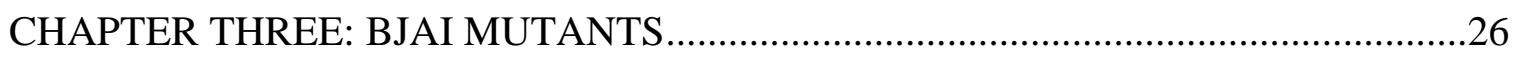

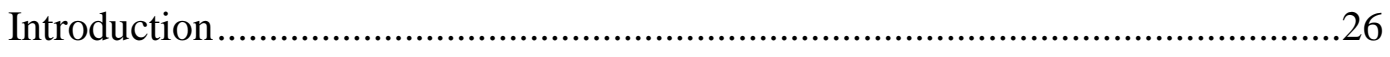

Mutagenesis Experiments with EsaI and LasI ....................................22

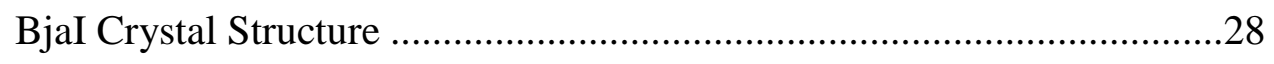

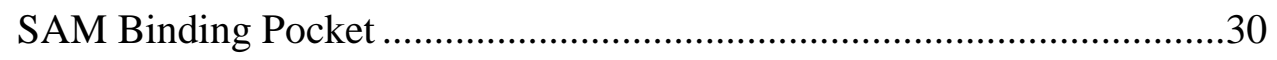

Isovaleryl-CoA Binding Pocket ..................................................... 31

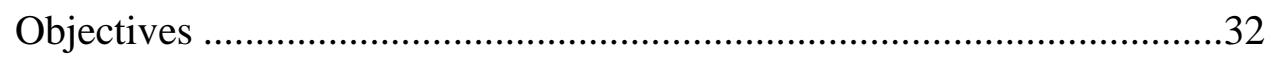

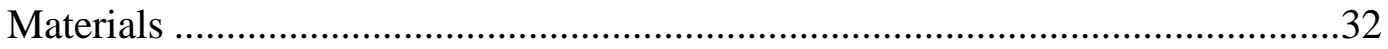

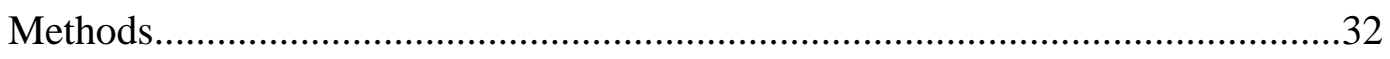

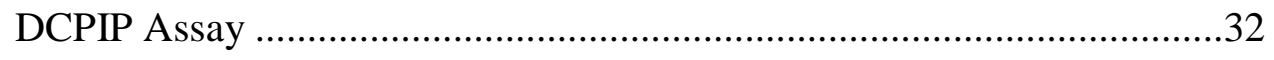

Molecular Dynamic Simulations .....................................................33

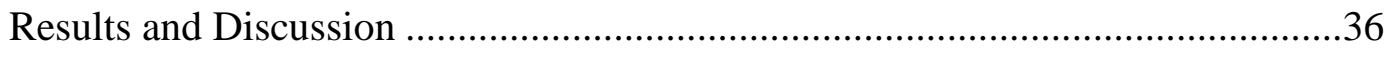

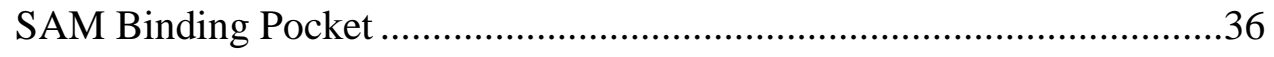

Isovaleryl-CoA Binding Pocket .......................................................39 
Conclusion

CHAPTER FOUR: SUBSTRATE SPECIFICTY IN BJAI............................................45

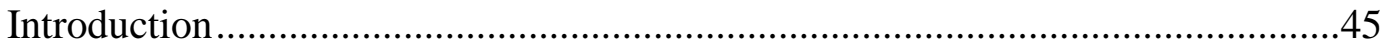

Michaelis-Menten Enzyme Kinetics and Inhibition ...................................48

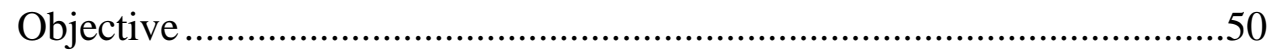

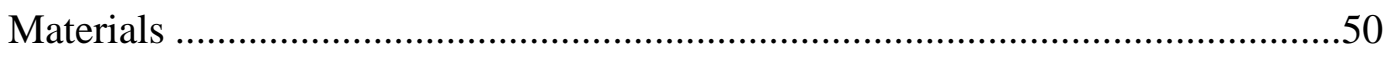

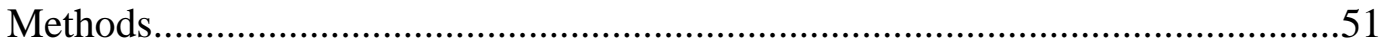

Wildtype BjaI Growth, Expression, and Purification .................................51

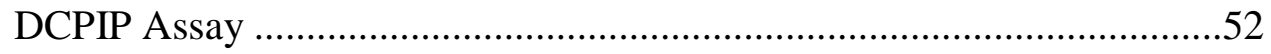

DCPIP Assay for Inhibition Studies .......................................................52

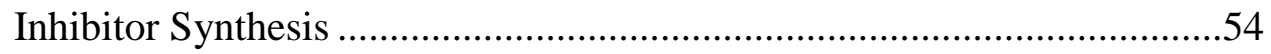

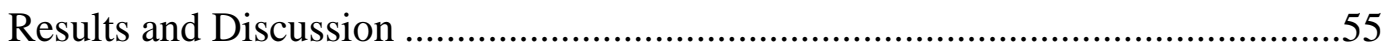

Confirming BjaI and Alkyl-CoA Synthesis .............................................55

Substrate Specificity in BjaI ..................................................................57

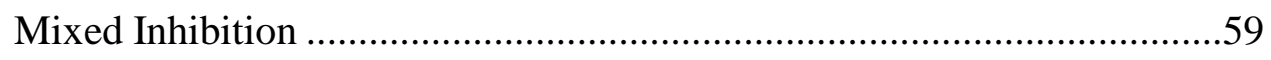

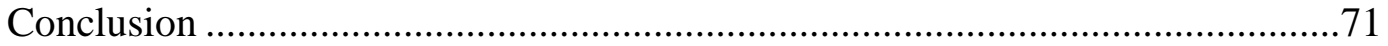

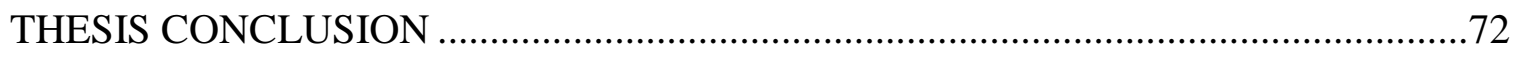

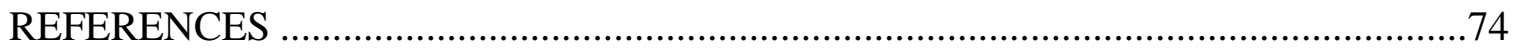

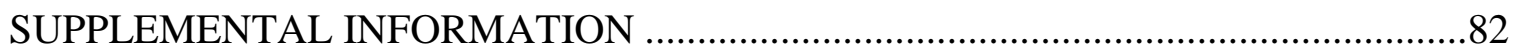




\section{LIST OF TABLES AND SCHEMES}

Table 1. Comparing enzyme rates of Sigma SAM with Synthesized SAM in Tris-

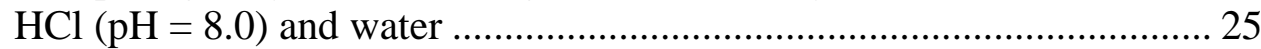

Table 2. Kinetic constants for BjaI single-point mutants.................................. 38

Table 3. Kinetic constants of various acyl-CoA substrates measured with fixed

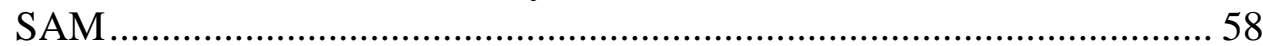

Table 4. Kinetic constants determined from Prism 6.0 using the mixed inhibition

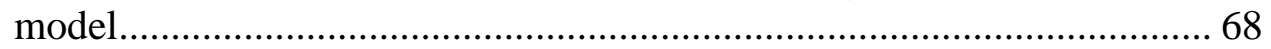

Scheme 1. Representative kinetic scheme showing possible enzyme forms for inhibitor binding. 


\section{LIST OF FIGURES}

Figure 1. Quorum sensing with bacterial cell density ............................................. 1

Figure 2. Autoinducer system for Gram-negative bacteria ....................................... 3

Figure 3. Specific acyl-substrates for certain acyl-homoserine lactone synthases..... 4

Figure 4. Autoinducer system for Gram-positive bacteria ……................................ 5

Figure 5. Examples of autoinducers in Gram-positive bacteria and structure of

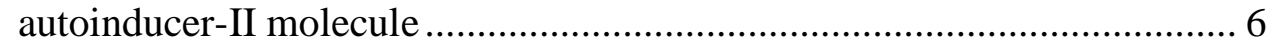

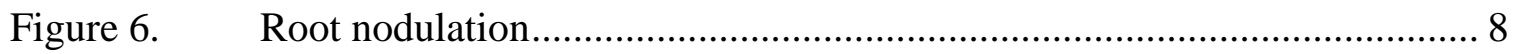

Figure 7. Proposed chemical mechanism for AHL synthases................................. 10

Figure 8. Crystal Structures of two acyl-homoserine lactone synthases - LasI and

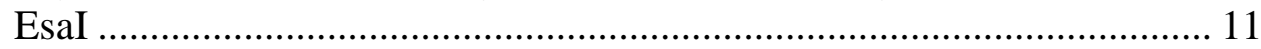

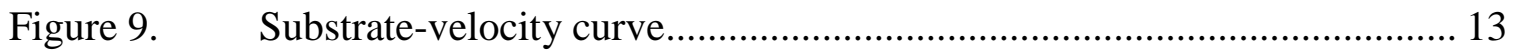

Figure 10. Problems with SAM degradation....................................................... 17

Figure 11. Enzymatic reaction to form SAM using MetK …………………............ 18

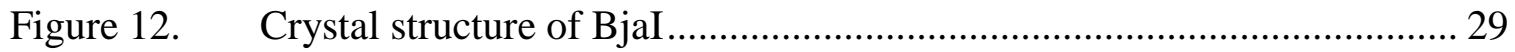

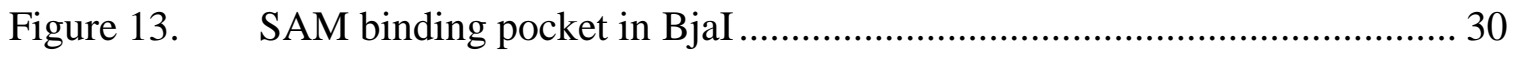

Figure 14. Isovaleryl-CoA binding pocket in BjaI.................................................... 31

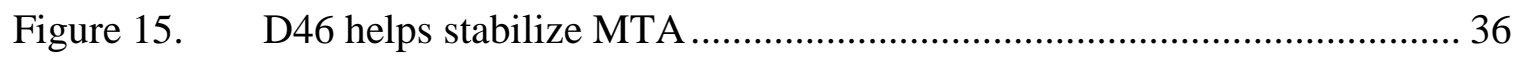

Figure 16. Interactions with polypetide backbone of R103 and T104 _..................... 37

Figure 17. Substrate-velocity curves for BjaI mutants............................................. 39

Figure 18. Overlay of wildtype BjaI with W101F mutant ......................................... 41

Figure 19. W142 and W143 indole platform with isopentyl-CoA ............................. 42 
Figure 20. Possible future amino acid mutations

Figure 21. Three possible enzymatic steps where BjaI can differentiate between native and non-native substrates ..................................................... 46

Figure 22. Structures of various acyl-CoAs and alkyl-CoAs ............................... 48

Figure 23. Lineweaver-Burke plots can be used to determine mode of inhibition .... 50

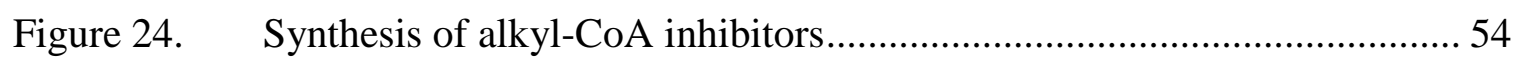

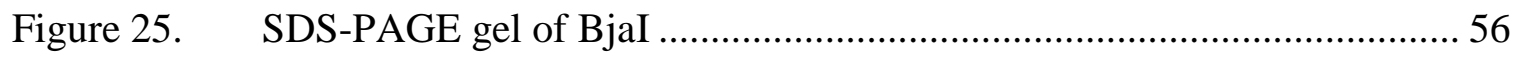

Figure 26. Overlapping HPLC chromatograms of various alkyl-CoAs .................... 57

Figure 27. Substrate-velocity curves for various acyl-CoAs .................................. 58

Figure 28. Bar graph of kinetic constants for various acyl-CoAs .......................... 59

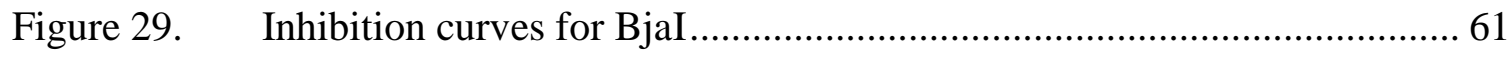

Figure 30. Double-reciprocal plot of all six inhibitors studied with BjaI ................. 62

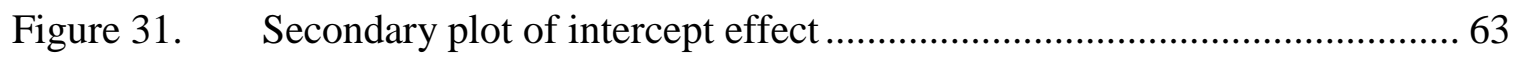

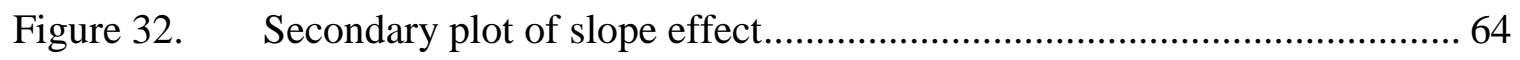

Figure 33. Common structure between substrates and products for BjaI ................. 67

Figure 34. Bar graph of inhibition constants for various alkyl-CoAs ...................... 69

Figure 35. BjaI bound with various alkyl-CoAs ............................................ 70

Figure S1. HPLC spectra of ATP and SAM separation ...................................... 82

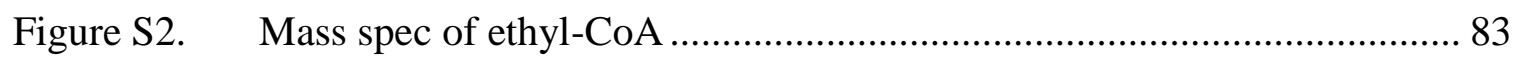

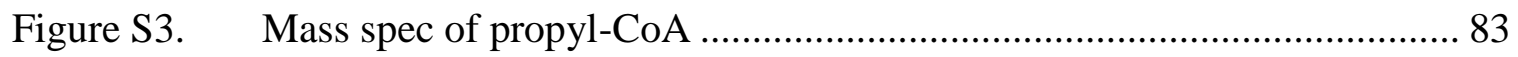

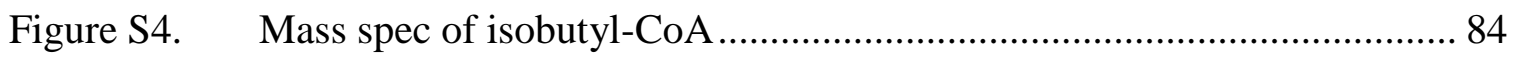

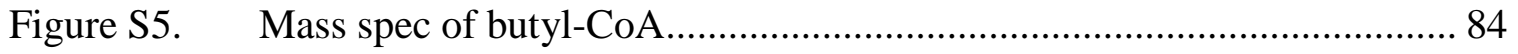

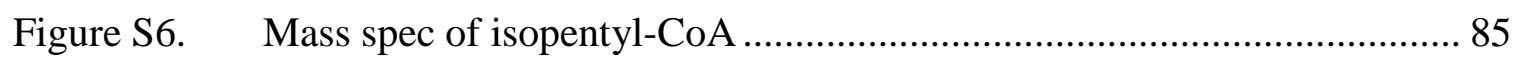

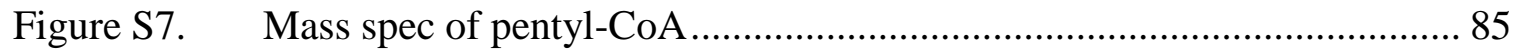




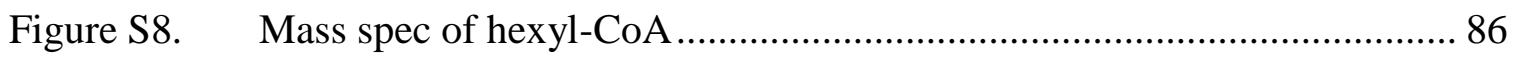

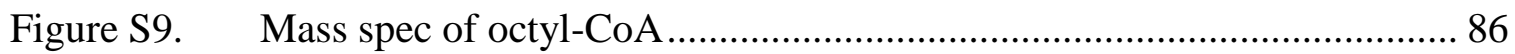

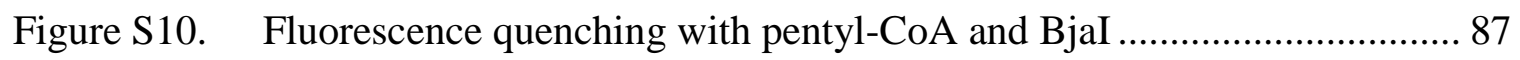




\section{LIST OF ABBREVIATIONS}

$\mathrm{ACN}$

ACPYPE

Acyl-ACP

Acyl-CoA

AHL

AI

AI-1

AI-2

AIP

ATP

BAR

BjaI

BmaI

C2-CoA

C2-I-CoA

C3-CoA

C3-I-CoA

isoC4-CoA

isoC4-I-CoA

C4-CoA
Acetonitrile

Antechamber pythin parser interface

Acyl-Acyl-Carrier Protein

Acyl-Coenzyme A

Acyl-Homoersine Lactone

Autoinducer

Autoinducer-1

Autoinducer-2

Autoinducer Peptide

Adenosine Triphosphate

Bennett's acceptance ratio

Bradyrhizobium japonicum Initiator

Burkholderia mallei Initiator

Acetyl-Coenzyme A

Ethyl-Coenzyme A

Propionyl-Coenzyme A

Propyl-Coenzyme A

Isobutyryl-Coenzyme A

Isobutyl-Coenzyme A

Butyryl-Coenzyme A 


$\begin{array}{ll}\text { C4-I-CoA } & \text { Butyl-Coenzyme A } \\ \text { IV-CoA } & \text { Isovaleryl-Coenzyme A } \\ \text { isoC5-CoA } & \text { Isovaleryl-Coenzyme A } \\ \text { isoC5-I-CoA } & \text { Isopentyl-Coenzyme A } \\ \text { C5-CoA } & \text { Valeryl-Coenzyme A } \\ \text { C5-I-CoA } & \text { Pentyl-Coenzyme A } \\ \text { C6-CoA } & \text { Hexanoyl-Coenzyme A } \\ \text { C6-I-CoA } & \text { Hexyl-Coenzyme A } \\ \text { C8-CoA } & \text { Octanoyl-Coenzyme A } \\ \text { C8-I-CoA } & \text { Octyl-Coenzyme A } \\ \text { CoA } & \text { Coenzyme A } \\ \text { DCPIP } & \text { 2,6-Dichlorophenolindophenol } \\ \text { GNAT } & \text { GCN5-N-Acetyl Transferase } \\ \text { HCl } & \text { Hydrochloric acid } \\ \text { HPLC } & \text { High-Pressure Liquid Chromatography } \\ \text { HSL } & \text { Homoserine Lactone } \\ \text { LINCS } & \text { Linear constraints solver } \\ \text { LJ } & \text { Lennard-Jones } \\ \text { MD } & \text { Molecular dynamic } \\ \text { MES } & \text { MetK }\end{array}$


Canonical ensemble: constant Number of particles, Pressure and Temperature

NVT

Canonical ensemble: constant Number of particles, Volume and

Temperature

QS

Quorum Sensing

SAH

S-adenosyl-L-homocysteine

SAM

S-Adenosyl-L-Methionine

TIP-3P

Transferable intermolecular potential 3-point

Tris

Tris(hydroxymethyl)aminomethane

UV-Vis

Ultraviolet Visible light

vdW

Van der Waals 


\section{CHAPTER ONE: INTRODUCTION}

\section{Quorum Sensing}

Fighting off bacterial infections is becoming more challenging as antibiotics develop resistance faster than they are being discovered. ${ }^{1,2}$ Finding an alternative route to fight off pathogenic bacteria is critical to addressing the drug resistance problem in antibacterial therapy. Quorum sensing inhibition is a potential method that can aid in controlling bacterial virulence without aggravating drug resistance.

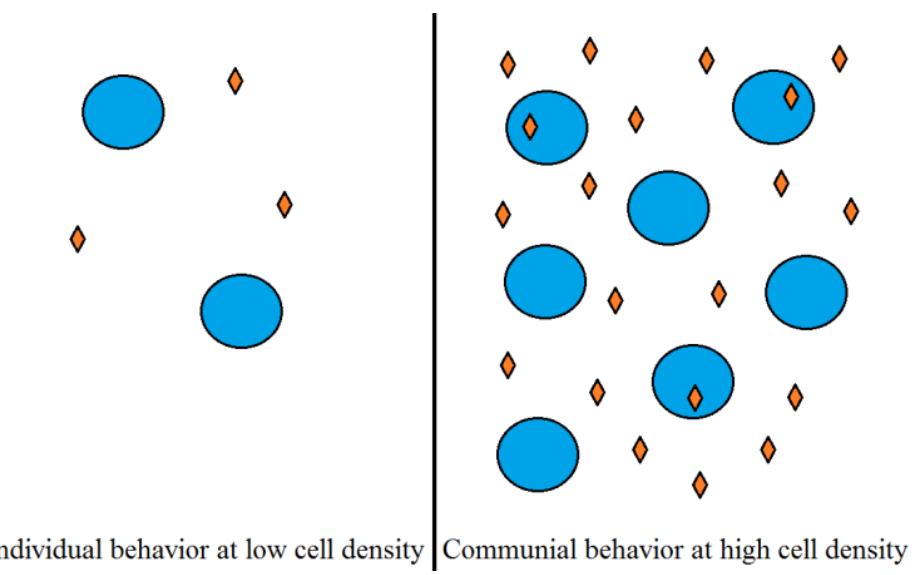

Figure 1 Quorum sensing with bacterial cell density. A high concentration of autoinducers is indicative of a higher population density of bacterial cells. When this quorum has-been reached, the bacterial cells start behaving as a group entity instead of a single cell.

Quorum sensing (QS) is a form of cell-to-cell communication that allows bacteria to act as a multicellular organism..$^{3-5}$ Using small molecules, known as autoinducers, bacteria can "count" how many other bacterial cells there are in its vicinity where a high concentration of autoinducers is indicative of a high population density (Figure 1). These cell-permeable autoinducers allow the bacteria to coordinate gene expression, which in 
turns regulates group behavior, including virulent gene expression, biofilm production, and antibiotic resistance. ${ }^{6,7}$ Preliminary data suggests that inhibition of quorum sensing does decrease the virulence of that bacterium and has the potential to be used as a therapeutic drug. ${ }^{8-11}$ What makes quorum sensing particularly interesting for antibacterial therapy is inhibition of QS would not directly kill bacteria thereby exerting less pressure for the microbe to develop drug resistance. Since autoinducers are species-specific, QS inhibitors are attractive as tools to discover novel antibacterial drugs that do not promote drug resistance.

Quorum sensing was first discovered in Vibrio fischeri during the 1970s, where the bacteria offers bioluminescence as protection for a bobtail squid. ${ }^{12}$ The squid would use the bioluminescent bacteria to hide its shadow and become more invisible to its predators. ${ }^{13,14}$ To be successful, the bacteria would have to become luminescent all at once in a controlled manner, which is accomplished through quorum sensing. The expression of the luciferase operon, which is responsible for bioluminescence, is controlled by two proteins, LuxI and LuxR. ${ }^{3}$ The autoinducer, synthesized by the initiator enzyme (LuxI), binds to the receptor protein (LuxR) to increase transcription of several genes that are required for bioluminescence as well as other group behavioral factors, like virulence production (Figure 2). ${ }^{15}$ 


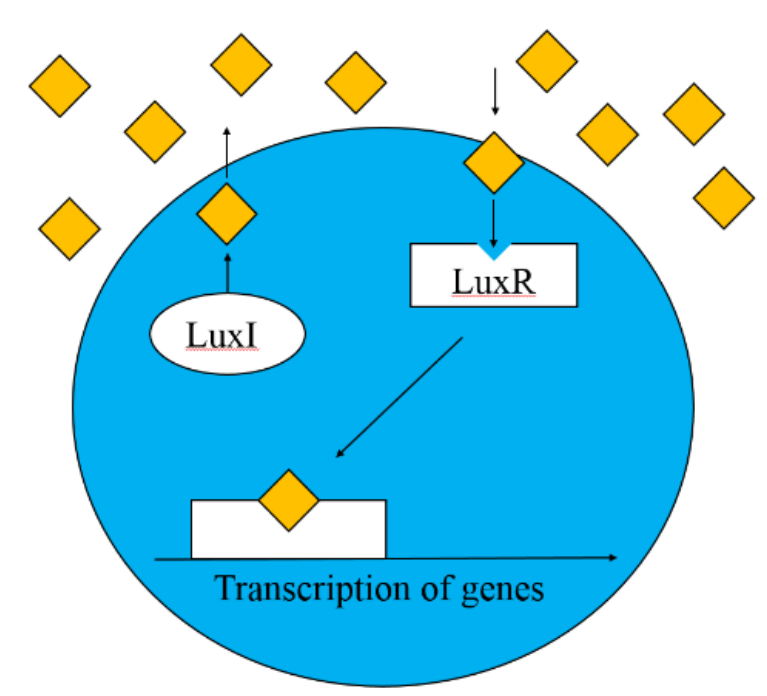

Figure 2 Autoinducer system for Gram-negative bacteria. An initiator enzyme (belonging to the LuxI family) synthesizes autoinducers that can diffuse in and out of the cell. Once bound to the receptor protein, either the release or binding of this protein to the DNA regulate virulence gene expression.

There are different types of QS systems depending on the type of bacteria. ${ }^{3}$ As described above, Gram-negative bacteria have initiator and receptor proteins that induce QS. More specifically, Gram-negative bacteria use acyl-homoserine lactone (AHL) synthases as their initiator enzymes, which are responsible for making their specific AHL autoinducer. ${ }^{16}$ The difference in the signaling molecule lies within the acyl-chain, as shown in Figure 3, in the acyl-ACP or acyl-CoA substrate. Most AHL synthases have narrow substrate specificity, and therefore signal production specificity, so bacteria can communicate within its own species without having other bacteria interfere. Some bacteria have other methods to ensure signal fidelity. For example, the plant pathogen Agrobacterium tumefaciens, have low half-lives of the receptor protein, TraR, unless it is bound with the signaling molecule. ${ }^{17}$ This allows for the QS cascade to only occur when there is a high enough concentration of the signaling molecule. ${ }^{3}$ 

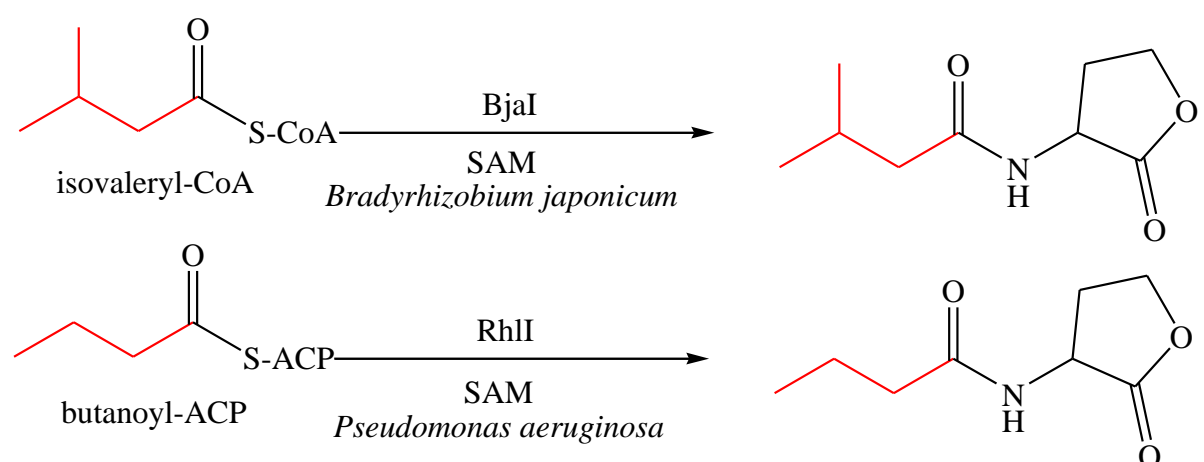<smiles>CCCC(=O)NC1CCOC1=O</smiles>
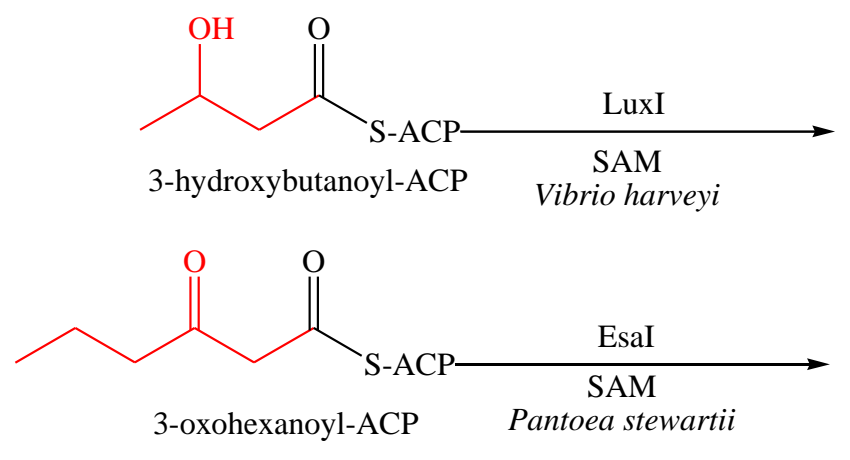<smiles>CC(O)CC(=O)NC1CCOC1=O</smiles>

Figure 3 Specific acyl-substrate for certain acyl-homoserine lactone synthases. This allows them to have intraspecies communication without interference from other nonspecific autoinducers. The acyl-ACP substrate is derived from fatty acid biosynthesis and acyl-CoAs are derived from CoA biosynthesis.

Autoinducers in Gram-positive bacteria are short cyclic or linear peptides that are exported out of the cell and bind to cell membrane proteins. ${ }^{3,18,19}$ Unlike Gram-negative bacteria, Gram-positive have a two component response system, usually with a membranebound histidine kinase and a response regulator. ${ }^{16,20,21}$ More specifically, the histidine kinase will detect and interact with the autoinducer peptide (AIP), which causes a phosphorylation cascade. During this process, the response regulator protein will become activated, allowing it to bind to DNA and increase quorum sensing gene expression (Figure 4). The variation in these signaling molecules comes in the modification of the peptide (Figure 5), which gives rise to specificity between bacteria. 


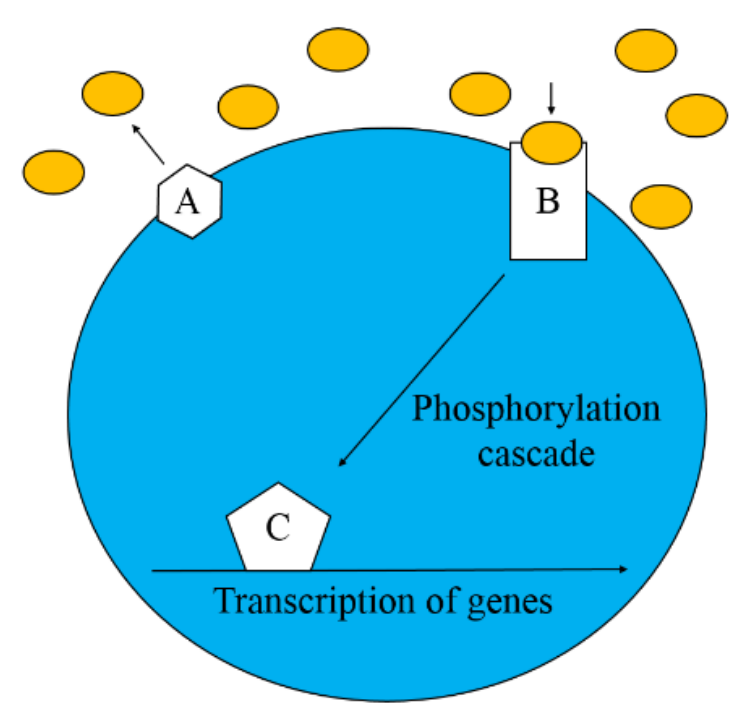

Figure 4 Autoinducer system in Gram-positive bacteria. Small peptides are synthesized and modified for each specific Gram-positive bacterial species. These peptides get transported out (A), bind to a histidine kinase (B), which then causes a phosphorylation cascade. The response regulator gets activated through phosphorylation, which then increases gene expression.

AHL's and AIP's are beneficial to bacteria because they allow the colony to be able to communicate between themselves with less interference from neighboring colonies. However, it can also be advantageous to work together with different bacteria. To facilitate communication in this case, there is another type of signaling molecule, called autoinducerII (AI-II), which works more like a universal language between the many types of bacteria. $^{22}$ Each species can carry out a certain function benefitting the entire bacterial population and they can do it in a controlled and organized fashion with AI-IIs (Figure 5). 
B. subtilis / CSF

Glu-Arg-Gly-Met-Thr

S. aureus /(AIP-I)

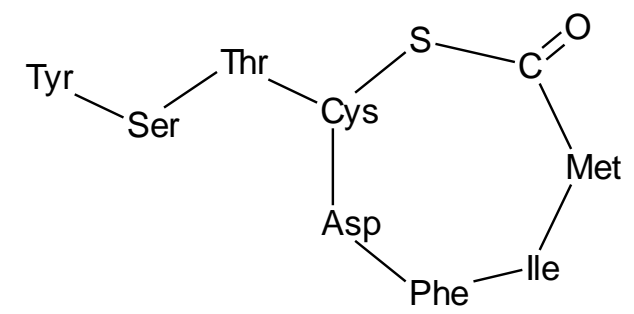

S. aureus / (AIP-II)

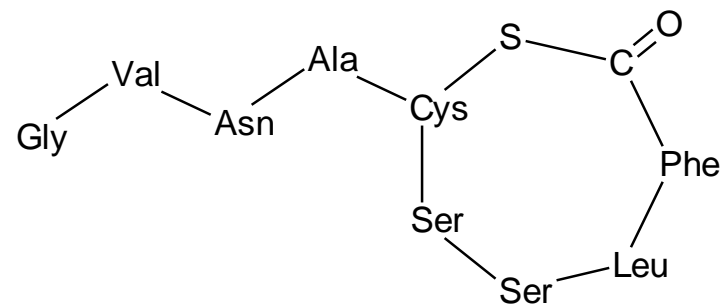

S. pneunomiae / CSP

Glu-Met-Arg-Leu-Ser-Lys-Phe-Arg-Asp-Phe-Ile-LeuGln-Arg-Lys-Lys

V. harveyi / AI-II

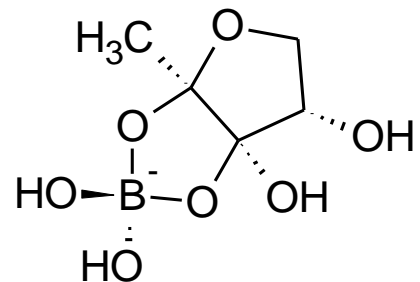

Figure 5 Examples of autoinducers in Gram-positive bacteria and structure of an autoinducer-II molecule.

\section{BjaI, an AHL Synthase found within the bacteria Bradyrhizobium japonicum}

Rhizobium are Gram-negative soil bacteria that form symbiotic relationships with plants. The bacteria will fix atmospheric nitrogen into ammonia and ammonium, which is in a form that the plants can use, and in return the plants let the bacteria uptake some of its carbohydrates. ${ }^{23}$ More specifically, Bradyrhizobium japonicum is commonly found within 
the root nodules of soybeans, where nitrogen fixation can occur. ${ }^{24}$ When the soil is low on fixed nitrogen (nitrate, ammomia, urea, etc.) legumes will release flavonoids that signal to rhizobia bacteria that they are needed. ${ }^{25}$ After the initial association of bacteria to the plant, the flavonoids then induce the gene expression of nod factors. ${ }^{26}$ Nod factors induce nodule formation and root hair curling, which can trap bacteria, giving them a home where replication can occur (Figure 6). ${ }^{27}$ Once the bacteria have reached an optimal population density, they penetrate the outer cell wall of the plant and form an infection thread inside the root. This thread then spreads to other plant cells, allowing further replication to occur. At this point, the bacteria morph into bacteroids and start synthesizing nitrogenase inside the plant cells. Nitrogenase converts nitrogen gas into ammonium, which is a nitrogen form that the plants can use. This whole process is thought to depend on quorum sensing, but the exact role of quorum sensing with this symbiotic relationship is still unknown. ${ }^{28}$ 


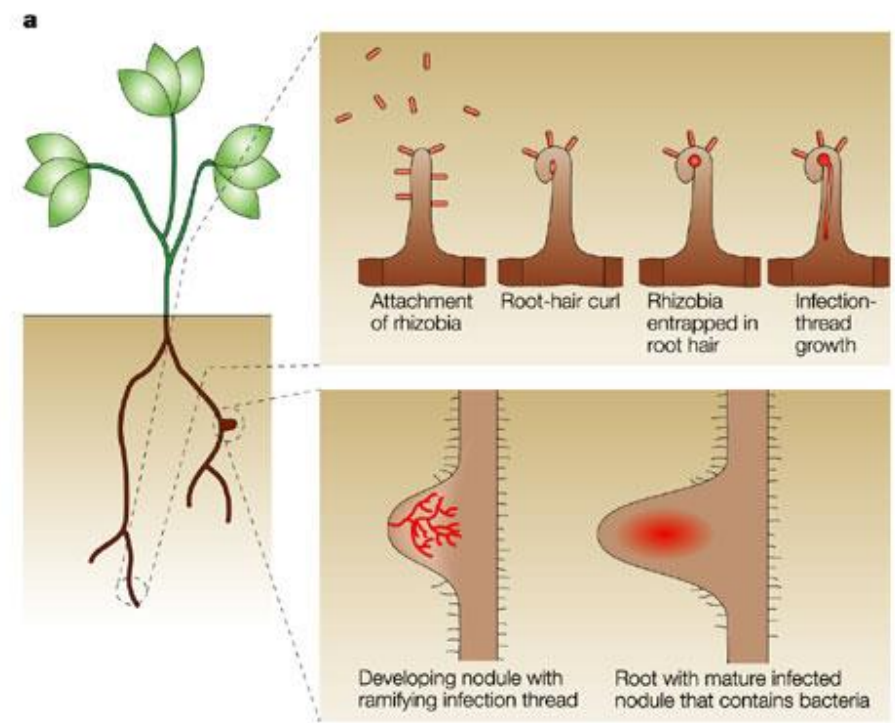

Figure 5 Root nodulation. Bacteria attach onto root-hair curls where the bacteria can easily replicate as it uses carbohydrates that the plant provides. Eventually, the bacteria will penetrate through the cell wall and form a thread inside the plant. Once inside, the bacteria will start synthesizing nitrogenase, which converts nitrogen gas into a nitrogen source the plants can use (ammonium). Reprinted by permission from Macmillan Publishers Ltd: [Nat. Rev. Mol. Cell Biol.] (27), copyright (2004).

B. japonicum uses an AHL synthase, BjaI, to produce its quorum sensing molecule, isovaleryl-homoserine lactone. Interestingly, unlike most other AHL synthases, BjaI uses an acyl-coenzyme A (acyl-CoA) as its acyl-substrate instead of acyl-acyl carrier protein (acyl-ACP). It is believed that an acyl-CoA utilizing synthase such as BjaI, has evolved from a common acyl-ACP utlilizing synthase ancestor. ${ }^{29}$

\section{AHL Synthases are Bisubstrate Enzymes}

AHL synthases are bisubstrate enzymes where one substrate is conserved, $\mathrm{S}$ adenosyl-L-methionine (SAM), and the other is an acyl-substrate specific for that AHL synthase. For most of these synthases, the second substrate is an acyl-acyl carrier protein (acyl-ACP), with the exception of a few synthases that use acyl-coenzyme A (acyl-CoA) 
as their acyl-substrate. The specificity in the substrate lies within the acyl-chain (Figure 3). Some variations include differing chain lengths, branch points, saturated vs unsaturated, and, as mentioned previously, acyl-ACP vs acyl-CoA. The AHL synthase transfers the acyl-chain from the acyl-substrate to homoserine lactone head group in autoinducer biosynthesis (Figures 3 and 7). Two other products formed during this reaction are Smethyl-5'-thioadenosine (MTA) and holo-ACP or CoA depending on if acyl-substrate used is an acyl-ACP or acyl-CoA.

Figure 7 shows a general representation of a proposed mechanism of how AHL synthases produce autoinducers, however, the order of which step occurs first is still unknown. A basic amino acid or an activated water molecule is proposed to act as a general base to deprotonate the amine group in SAM (step 1). This frees a lone pair on the amine group, which can do a nucleophilic attack on the carbonyl carbon in the acyl-substrate (either acyl-ACP or acyl-CoA). This is called the acylation step (step 2). Interestingly, SAM is not used as a methyl donor, but instead forms the lactone ring. Lactonization (step 3) occurs when the carboxylate attacks the carbon next to the sulfur, closing the ring that transforms the unstable, positively charged sulfonium ion to a stable, neutral species (MTA). The combination of the lactonization and acylation step is what forms the autoinducer in Gram-negative bacteria. 


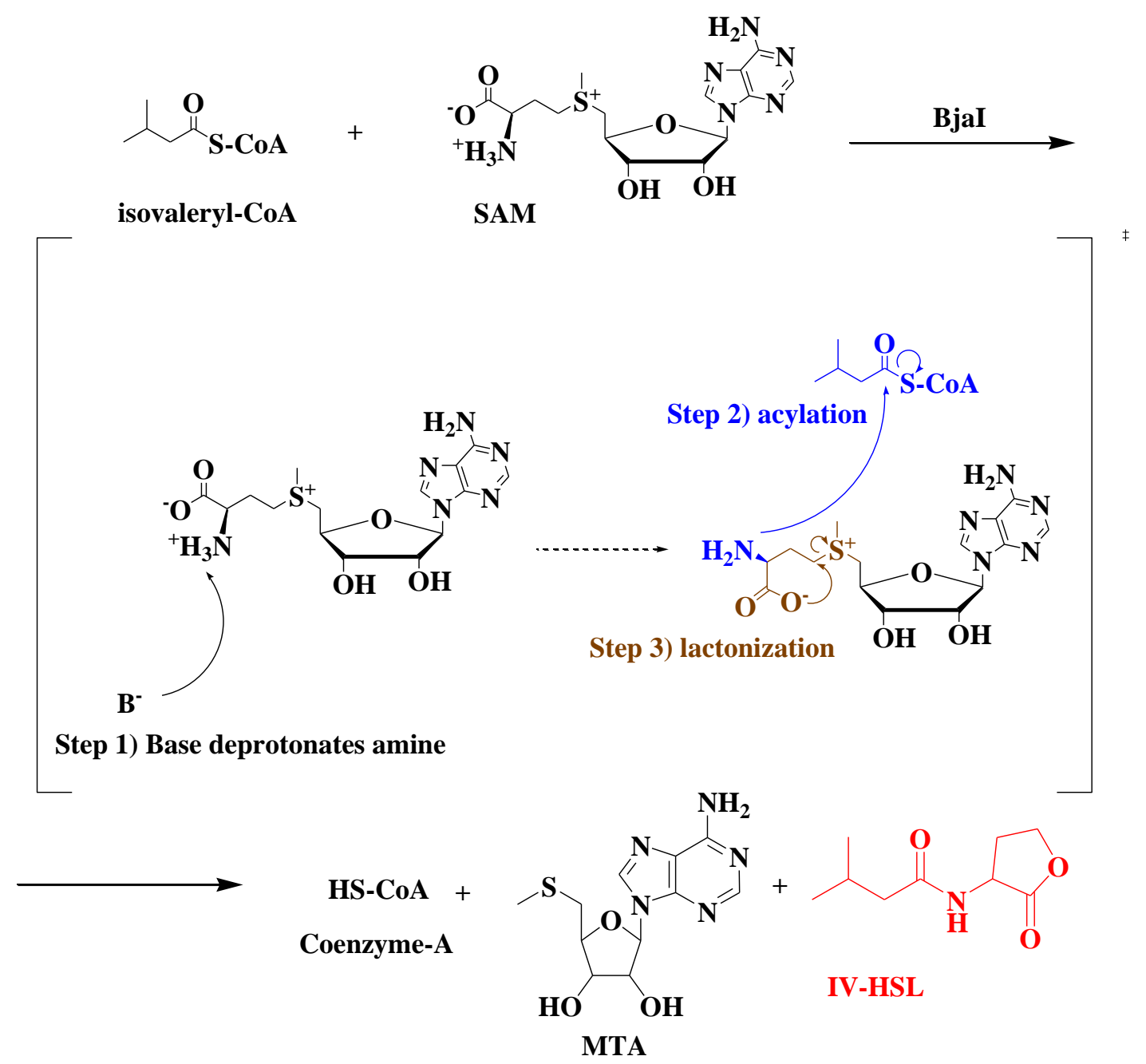

Figure 7 Proposed chemical mechanism for AHL synthases. AHL synthases are bisubstrate enzymes, where a basic amino acid or activated water molecule will deprotonate the amine group in SAM. The nitrogen can now do a nucleophilic attack on the thioester carbonyl carbon to complete the acylation step. Lactonization occurs when the carboxylate within SAM does an intrinsic attack, closing the ring, and the sugar moiety leaves. The order of which chemical steps occur first is still unknown.

\section{Crystal Structures of LasI, EsaI, and TofI}

To date, only three crystal structures of AHL synthases have previously been studied - LasI, EsaI, and TofI. ${ }^{30,31}$ The most conserved portion of the AHL synthases are found within the N-terminal region. It is predicted that this highly conserved region is used to bind with the common substrate, SAM. The C-terminal region, however, fluctuates between the AHL synthases and is most likely the region that binds to the varying acyl- 
chain substrate. LasI binds to the longest acyl-chain (3-oxo-dodeconoyl-ACP), followed by TofI (octanoyl-ACP), and finally EsaI (3-oxo-hexanoyl-ACP). ${ }^{32-33}$ A hydrophobic Vcleft pocket is found within all three structures where the depth of this pocket changes to accommodate different acyl-chain lengths (Figure 8). Mutational analysis of EsaI and LasI showed that hydrogen bonding between a threonine within the V-cleft and the 3-oxo in the acyl-chain plays a critical role to help the enzyme differentiate between substituted and unsubstituted acyl-chains. Towards the top of the V-cleft, there are multiple positively charged amino acids that can electrostatically interact with the negatively charged ACP. ${ }^{33}$ Single and double mutations within the predicted ACP binding site decreased the activity of LasI supporting the idea that electrostatic interaction is occurring between the enzyme and ACP. ${ }^{30,33}$ Just recently, the crystal structure of BjaI has been obtained (see chapter 3), where one goal of this thesis is to predict some possible roles certain amino acids play in specific recognition of isovaleryl-CoA substrate by the BjaI AHL sythase.

A.

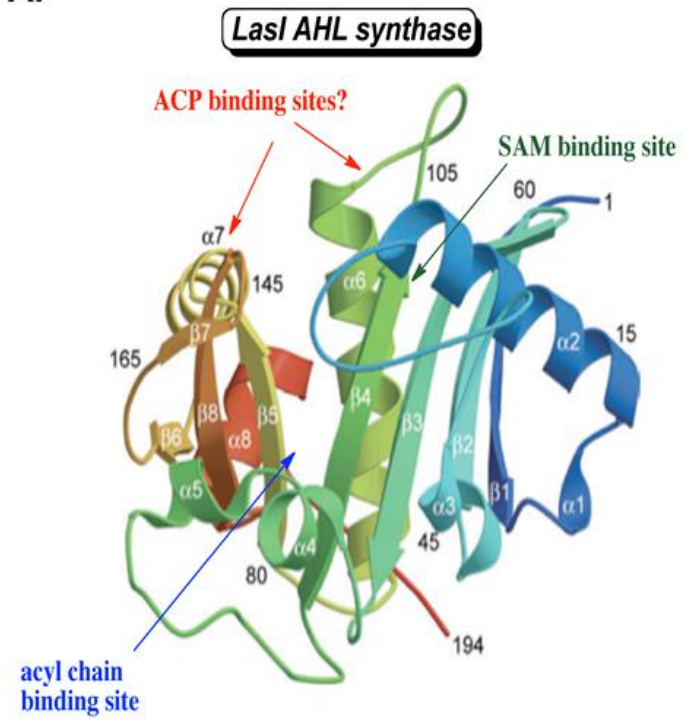

B.

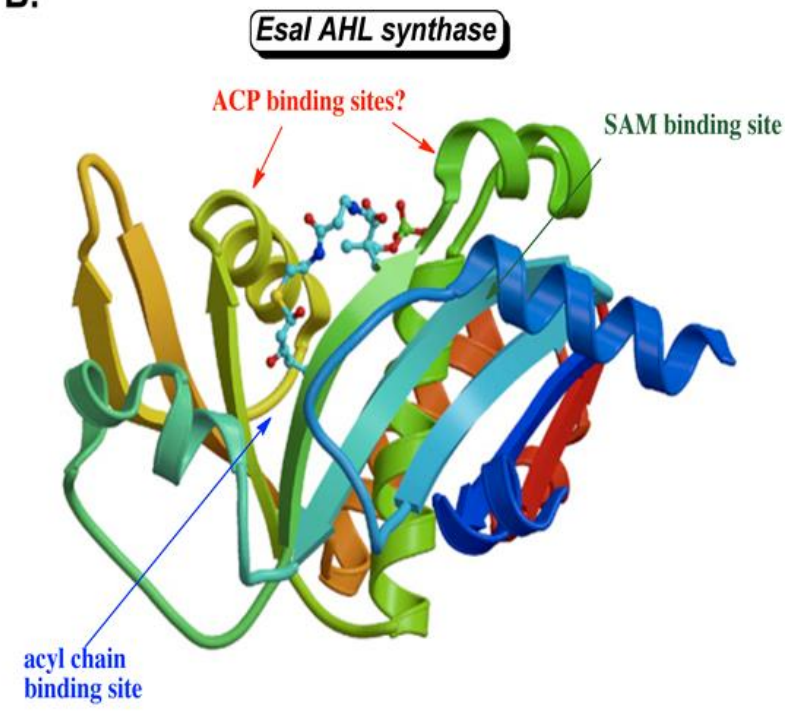

Figure 8 Crystal structures of two acyl-homoserine lactone synthases - LasI and EsaI. 


\section{Michaelis-Menten Enzyme Kinetics}

A common tool used to analyze enzymes, especially when it comes to substrate specificity, is the Michaelis-Menten equation. Under certain assumptions, the reaction between an enzyme, E, and a substrate, $\mathrm{S}$, can be represented as:

$$
E+S \rightleftharpoons E S \rightarrow E+P
$$

where $E S$ is an enzyme-substrate complex, and $P$ is the product released after catalysis. Furthermore, the rate of the reaction $(v)$ is related to $K_{m}$ and $V_{\max }$ as follows:

$$
v=\frac{V_{\max }[S]}{[S]+K_{m}}
$$

where $V_{\max }$ is the maximal velocity the enzyme can catalysize the reaction, $[S]$ is the substrate concentration, and $K_{m}$ is the amount of substrate required to reach a rate that is half of $V_{\max }$. By plotting the rate of the reaction vs substrate concentration, $V_{\max }$ and $K_{m}$ can be determined, as shown in Figure 9. With bisubstrate enzymes, the intital velocity equation includes both substrates, $\mathrm{A}$ and $\mathrm{B}$. When the substrates $\mathrm{A}$ and $\mathrm{B}$ bind to the enzyme in a specific order, then the initial velocity equation is:

$$
v=\frac{V_{\max }[A][B]}{K_{i a} K_{b}+K_{b}[A]+K_{a}[B]+[A][B]}
$$

where $\mathrm{K}_{\mathrm{ia}}$ is the dissociation constant for substrate $\mathrm{A}$ in the absence of $\mathrm{B}$, and $\mathrm{K}_{\mathrm{b}}$ and $\mathrm{K}_{\mathrm{a}}$ are the Michaelis-Menten constants for substrate B and A, respectively, at saturating conditions of the other fixed substrate. To simplify this equation, if one substrate is held under saturating conditions (for example, substrate B) then it reduces down to:

$$
v=\frac{V_{\max }[A][B]}{K_{a}[B]+[A][B]}
$$


which can be further reduced back to the original Michaelis-Menten equation:

$$
v=\frac{V_{\max }[A]}{[A]+K_{a}}
$$

This allows bisubstrate enzymes to be studied like single substrate enzymes as long as one is at saturating conditions.

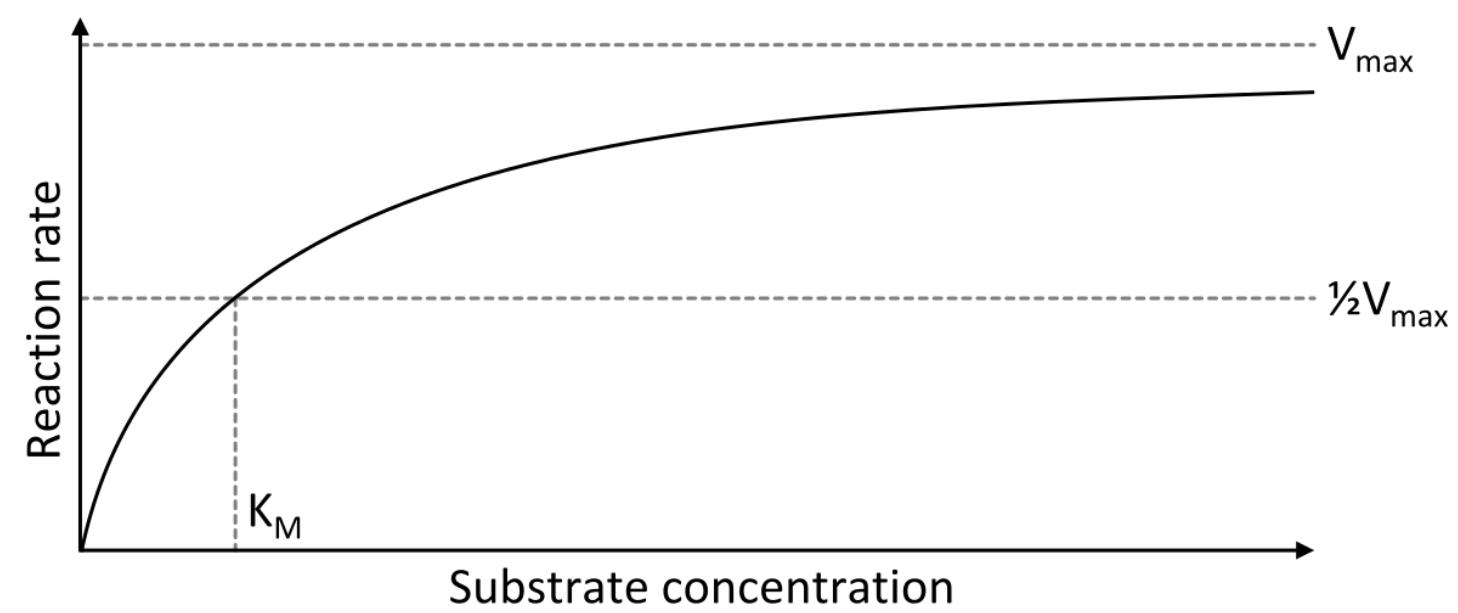

Figure 9 Substrate-velocity curve. $K_{m}$ represents the amount of substrate concentration to reach $1 / 2$ maximal velocity $\left(V_{\max }\right)$ that an enzyme can function. As the substrate concentration increases, so does the rate of the enzyme until it reaches a point where the enzyme is saturated and cannot increase the rate any longer (plateaus).

\section{Thesis Objectives}

The goal of this thesis is to gain a better understanding on how substrate recognition is accomplished in BjaI, an AHL synthase found in Bradyrhizobium japonicum. Part of understanding how AHL synthases selectively bind to specific substrates is by studying varying types of AHL synthases and BjaI is one of the few that binds to acyl-CoAs instead of acyl-ACPs. This thesis is subdivided in to three main sections, which are covered in three separate chapters - SAM synthesis, measuring $k_{\text {cat }}$ and $K_{\mathrm{m}}$ for single-point mutations 
in BjaI, and measuring $k_{\text {cat }}$ and $K_{\mathrm{m}}$ for various acyl-CoAs and $K_{\mathrm{i}}$ for their respective substrate analogs.

\section{Chapter 2: SAM Synthesis}

Commercially available SAM is expensive and is impure due to SAM degradation. This has caused research labs to start synthesizing SAM in their own lab. Chapter 2 addresses some issues with synthesizing SAM and determines if this SAM can be used in the DCPIP assay to study AHL synthase mechanisms with less background rates than the commercially available SAM. A clean sample of SAM substrate is especially important in assaying slow enzymes with low turnover rates, such as BjaI.

\section{Chapter 3: BjaI Mutants}

In a collaborative project with Dr. Satish Nair, specific amino acids found within the acyl-binding pocket of BjaI (Bradyrhizobium japonicum) were mutated one at a time and the rate of the mutated enzyme was compared to the wildtype. The roles of specific amino acids in the recognition of isovaleryl-CoA and SAM substrates by the BjaI AHL synthase were investigated in this chapter.

\section{Chapter 4: BjaI Substrate Specificity}

Susbtrate specificity in BjaI, as well as other AHL synthases, are poorly understood. To understand more about substrate specificity in BjaI, the $k_{\text {cat }}$ and $K_{\mathrm{m}}$ of similar, nonnative substrates were compared to the native substrate, isovaleryl-CoA. Since the $K_{\mathrm{m}}$ cannot be used to determine true substrate binding affinites, substrate analogs of the acylCoAs were synthesized and inhibition studies were performed to measure $K_{\mathrm{i}}$ values. In this chapter, the most important enzymatic step (binding step $\left(K_{\mathrm{i}}\right)$, after binding $\left(k_{\mathrm{cat}}\right)$, or a 
combination of both) in acyl-substrate recognition was determined by comparing the effects on $k_{\text {cat }}$ and $K_{\mathrm{i}}$ between native and non-native substrates.

\section{Conclusion}

AHL synthases are potential antibacterial therapeutic targets, but designing synthase inhibitors have been complicated with the lack of detailed mechanistic characterization of these enzymes. To design effective inhibitors, it is critical to target only a specific AHL synthase. BjaI is one of the few AHL synthases that binds to acyl-CoAs instead of acyl-ACPs and can provide a more complete picture on substrate recognition. Not only that, BjaI so far is the only AHL synthase known that binds to a branched acylchain. The purpose of this thesis is to provide more insight on how an AHL synthase, BjaI, selectively recognizes its specific acyl-substrate. 


\section{CHAPTER TWO: SAM SYNTHESIS}

\section{Introduction}

In Gram-negative bacteria, the signaling molecules are produced from enzymes called acyl-homoserine lactone (AHL) synthases. These are bisubstrate enzymes where one substrate S-adenosyl-L-methionine (SAM) is conserved between all AHL synthases. SAM is commercially available, albeit with low purity (Figure 10). Methylthioadenosine (MTA) is one impurity commonly formed from SAM degradation, which can be an issue when trying to perform kinetic studies on AHL synthases - MTA is also a product of these enzymes and, therefore, can act as a product inhibitor resulting in reduced enzyme rates. Because SAM has stereocenters, it is possible that enantiomers are present. More specifically, the sulfur in SAM that is biologically active is the S-enantiomer, whereas the R-enantiomer is biologically inactive. ${ }^{34}$ It is difficult to distinguish between the enantiomers unless a chiral HPLC column is available to use. Otherwise, the actual amount of active SAM cannot be determined.

Purity is an important factor to consider when determining what to use to perform kinetic studies, but the activity of the enzyme with certain SAM salts must also be considered. There are different SAM salts that are commercially available, such as SAM$\mathrm{Cl}$ and SAM-tosylate. From previous studies, SAM-tosylate showed inhibition at high concentrations with BmaI1 (Burkholderia mallei), whereas SAM-Cl did not have this effect. ${ }^{35}$ However HPLC analysis revealed that SAM-tosylate is more pure than SAM-Cl. 
When choosing the appropriate commercially available substrate, these issues (inhibition and purity) must be taken into consideration.

A)

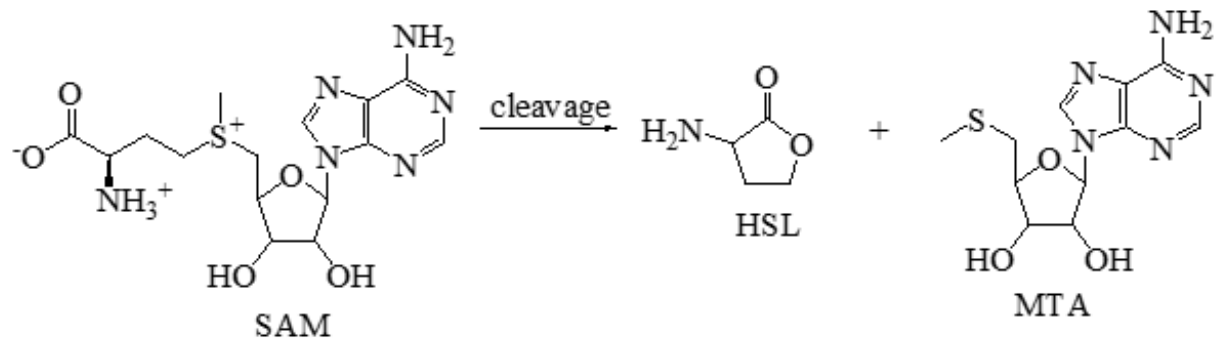

B)

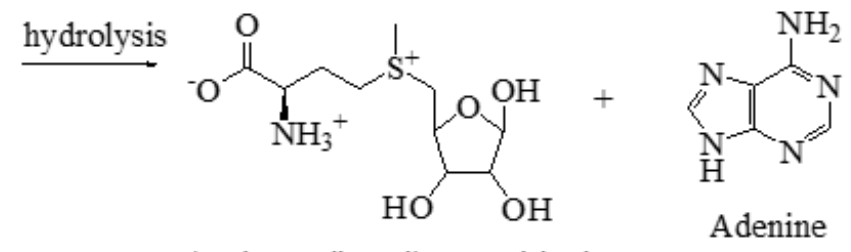
S-(5'-deoxyribosyl)-L-methionine

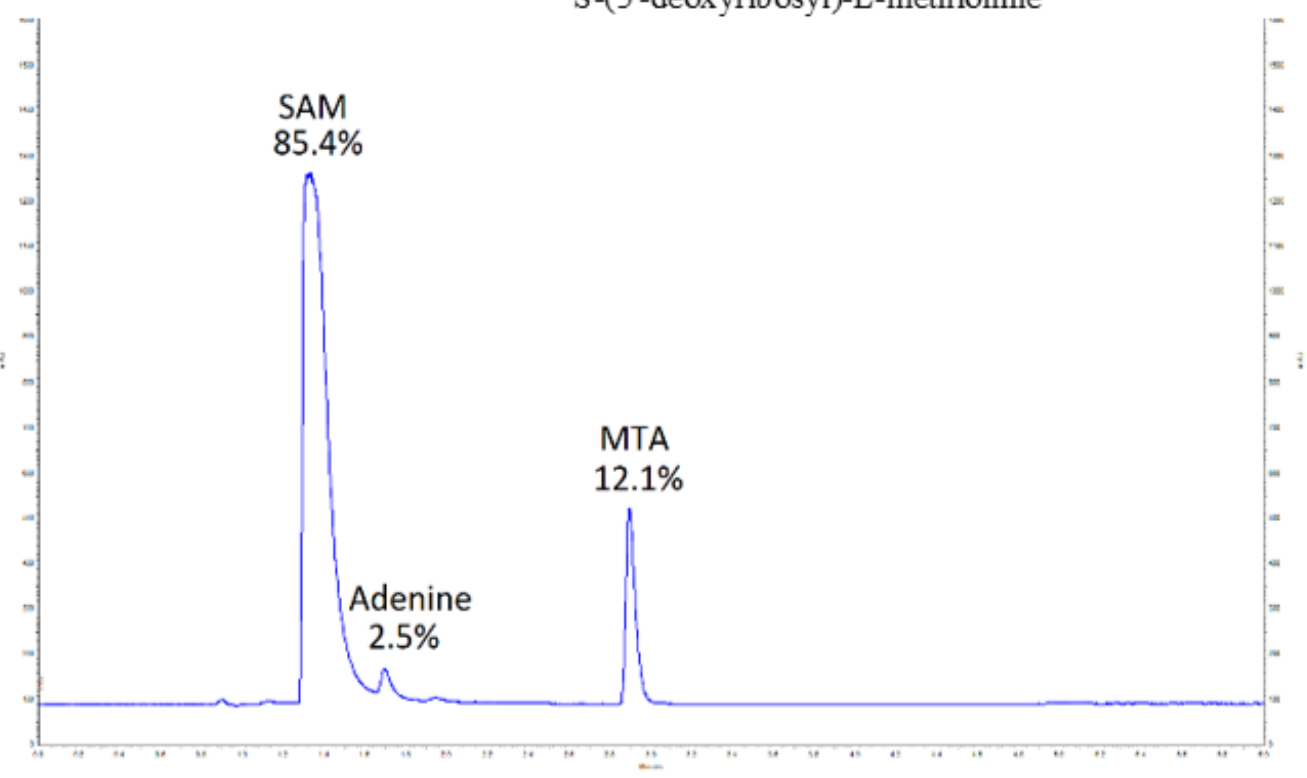

Figure 10 Problems with SAM degradation. A) SAM can undergo an internal cleavage to form homoserine lactone and methylthioadenosine and undergo hydrolysis to produce $S$-(5'-deoxyribosyl)-L-methionine and adenine. This is an issue when performing kinetic studies on AHL synthases since MTA and acyl-HSL are products of these enzymes, which can then act as product inhibitors. B) An HPLC chromatogram was obtained from commercially available SAM showing that SAM has degraded and therefore is not pure. 
When buying commercially available SAM, the type of SAM salt and SAM purity has to be considered because this can effect enzyme activity. There is, however, a way to reduce these concerns by synthesizing pure SAM using an enzyme called Sadenosylmethionine synthetase (MetK). MetK combines methionine and ATP to synthesize SAM as shown in Figure 11. The sulfur in L-methionine will do a nucleophilic attack on the 5' carbon of ATP, forcing $\mathrm{PPP}_{\mathrm{i}}$ as a leaving group. Before the products are released, MetK will hydrolyze $\mathrm{PPP}_{\mathrm{i}}$ to $\mathrm{PP}_{\mathrm{i}}$ and $\mathrm{P}_{\mathrm{i}}{ }^{36,37}$ MetK will only form the $\mathrm{S}$ enantiomer, so S-adenosyl-L-methionine will be the main product. A few advantages of synthesizing SAM within the lab are as follows: 1) it eliminates the possibility of SAM degradation during shipment, 2) only the S-enantiomer is made so the buyer does not have to be concerned if SAM is a racemic mixture, and 3) the ability to replace the methyl group of SAM with other alkyl chains (Figure 11). In this chapter, we discuss the efforts we took and the challenges we encountered during the enzymatic synthesis of SAM.<smiles>CSCCC([NH3+])C(=O)[O-]</smiles>

Figure 11 Enzymatic reaction to form S-adenosyl-L-methionine (SAM) using MetK. A few advantages of synthesizing SAM are only the S-enantiomer (on sulfur) is made and the alkyl-chain (methyl) can be varied.

\section{Materials}

All materials were supplied by Sigma Aldrich unless otherwise specified. The MetK plasmids were generously supplied by Dr. Satish Nair from University of Illinois at 
Urbana-Champaign. Evolution 260 Bio UV-Visible Spectrophotometer, coupled with Peltier Water Cooled Cell Changer SPE 8 W, and Sorvall Legend X1R Centrifuge, FreeZone 2.5 Lyophilizer, Labconco, and Accela600, HPLC were from Thermo Scientific. Two reverse phase C-18 columns were used: one was used for checking and fractioning out large quantities of MetK (Thermo Scientific 25005-109070) on the HPLC and the other was used to check the purity (Thermo Scientific 25002-054630) on the UHPLC.

\section{Methods}

\section{$\underline{\text { MetK Transformation }}$}

Transformation was performed under a sterilized hood with sterile gloves and pipette tips. After thawing on ice, $2.5 \mu \mathrm{L}$ of plasmid was mixed with $50 \mu \mathrm{L}$ E. coli BL21 competent cells. The mixture sat on ice for 30 mins before heat shocking it for 30 seconds in a $42{ }^{\circ} \mathrm{C}$ water bath and then put back on ice for 2 mins. The competent cells, which now have the plasmid in it, were diluted with $1000 \mu \mathrm{L}$ of LB. This mini growth was incubated with shaking at $37^{\circ} \mathrm{C}$ for $1-1.5$ hours. LB-agar plates containing kanamycin were then streaked with varying amounts of the mini growth $(10,40$, and $75 \mu \mathrm{L})$. The plates were incubated at $37^{\circ} \mathrm{C}$ overnight.

MetK Growth, Lysis, and Purification

In a sterilized environment, MetK cell stocks were streaked on an LB-agar plate containing kanamycin resistance $(50 \mu \mathrm{g} / \mathrm{mL})$. After growing for $12-24$ hours at $30{ }^{\circ} \mathrm{C}$, one colony was picked and added to LB $(5 \mathrm{~mL})$ containing the same final concentrations of kanamycin. This mini growth was incubated with gentle shaking $(225 \mathrm{rpm})$ at $30{ }^{\circ} \mathrm{C}$ for 12 hours. The now turbid mini growths were added to $300 \mathrm{~mL}$ of LB-M9 media containing kanamycin resistance $(50 \mu \mathrm{g} / \mathrm{mL})$, which incubated at $37^{\circ} \mathrm{C}$ with shaking $(225 \mathrm{rpm})$ until 
$\mathrm{OD}_{600}$ reached $0.5-0.8$. Once isopropyl $\beta$-D-1-thiogalactopyranoside (IPTG, $0.5 \mathrm{mM}$ ) was added to induce expression, the LB with bacterial growth was incubated for another 2 hours at $37{ }^{\circ} \mathrm{C}$ with shaking. The cells were pelleted by centrifugation at $5,000 \mathrm{x}$ g for $10-15$ mins and stored in $-20{ }^{\circ} \mathrm{C}$ overnight. The cell pellets were first incubated with BugBuster Master Mix (5 mL / 1L growth) for 40 mins at room temperature. Then $5-10 \mathrm{~mL}$ of loading buffer ( $25 \mathrm{mM}$ HEPES, $\mathrm{pH}=7.5,0.5 \mathrm{M} \mathrm{NaCl}, 20 \%$ glycerol, $5 \mathrm{mM}$ TCEP, 20 $\mathrm{mM}$ imidazole) were added to the lysate and incubated at RT for another 5 mins. The lysate was centrifuged at $14,000 \mathrm{x}$ g for 20 mins. The supernatant was decanted into $1.5 \mathrm{~mL}$ NiNTA resin (Qiagen) equilibriated with loading buffer. To allow for maximum binding, the resin and supernatant was incubated at $4{ }^{\circ} \mathrm{C}$ for 30 mins. The column was washed with 20X bed volume of loading buffer followed by another 20X bed volume of loading buffer with $60 \mathrm{mM}$ imidazole. The protein was eluted using $5 \mathrm{X}$ bed volumes of loading buffer with $500 \mathrm{mM}$ imidazole. The enzyme was further dialyzed using $25 \mathrm{mM}$ HEPES, $\mathrm{pH}=$ 7.0, $0.2 \mathrm{mM} \mathrm{KCl}, 10 \%$ glycerol, and $1 \mathrm{mM}$ TCEP at $4{ }^{\circ} \mathrm{C}$. These fractions were then combined, filtered and concentrated with $10 \mathrm{kD}$ Amicon spin column at 5,000 x g. Concentration of MetK was determined using UV-Vis $\left(\varepsilon_{280}=40,000 \mathrm{M}^{-1} \mathrm{~cm}^{-1}\right)$. The purified protein was stored at $-80{ }^{\circ} \mathrm{C}$ in $50 \mathrm{mM}$ lithium 4-morpholine-ethanesulfonate (MES) at a $\mathrm{pH}=6$ containing $20 \%$ glycerol.

\section{Enzymatic SAM Synthesis using MetK}

An enzyme reaction mixture containing $100 \mathrm{mM}$ Tris/ $\mathrm{HCl}(\mathrm{pH}=8.0), 200 \mathrm{mM}$ $\mathrm{KCl}, 100 \mathrm{mM} \mathrm{MgCl}$, $30 \mathrm{mM}$ L-methionine, $20 \mathrm{mM}$ ATP, and $20-40 \mu \mathrm{M}$ MetK was incubated at $37^{\circ} \mathrm{C}$ for $2-3$ hours. Completion of the reaction was monitored on the HPLC, where ATP eluted out at 3.3 mins and SAM eluted at 4.1 mins (method - $0.2 \mathrm{M}$ sodium 
acetate with a $5 \%$ methanol gradient over 30 mins and a $200 \mu \mathrm{L} / \mathrm{min}$ flow rate). Once reaction was completed, $4 \mathrm{M}$ sodium acetate buffer $(\mathrm{pH}=4.0)$ was added $(\sim 1 / 4$ of original volume) to precipitate out MetK enzyme. The enzyme was pelleted by centrifugation at $15,000 \mathrm{x} \mathrm{g}$ for 2 mins and the supernatant was diluted with $0.2 \mathrm{M}$ sodium acetate buffer, $\mathrm{pH}=4.0(\sim 2 \mathrm{X}$ original volume $)$. To purify the protein, an Amberlite dry resin was first soaked in equilibration buffer $(0.2 \mathrm{M}$ sodium acetate buffer, $\mathrm{pH}=4.0)$ until it swelled to approximately $1.5 \mathrm{X}$ the original volume. The resin was then transferred to a column, which was equilibrated with $10 \mathrm{X}$ bed volumes of $0.2 \mathrm{M}$ sodium acetate buffer $(\mathrm{pH}=4.0)$. The supernatant was poured onto the column and the run through was collected. The column was washed with $10 \mathrm{X}$ bed volumes of $0.2 \mathrm{M}$ sodium acetate buffer $(\mathrm{pH}=4.0)$ before SAM was eluted out with $0.1 \mathrm{M} \mathrm{H}_{2} \mathrm{SO}_{4}+10 \% \mathrm{EtOH}(\mathrm{pH}<1)$ in $1 \mathrm{~mL}$ fractions. The fractions were checked on the HPLC using the same method as described before and the fractions that contained pure SAM were combined and lyophilized. SAM was dissolved in $0.1 \mathrm{M}$ $\mathrm{H}_{2} \mathrm{SO}_{4}+10 \% \mathrm{EtOH}$ at high concentrations and stored in $-80{ }^{\circ} \mathrm{C}$. The $\mathrm{pH}$ was neutralized with Tris / $\mathrm{HCl}(\mathrm{pH}=8.0)$ buffer before being used in the DCPIP assay.

\section{DCPIP Assay}

The enzymatic reaction catalyzed by $\mathrm{BjaI}$ was monitored by measuring the reduction of the blue dye 2,6-dichlorophenolindophenol (DCPIP) into DCPIPH $\mathrm{D}_{2}$ at $600 \mathrm{~nm}$ $\left(\varepsilon_{600}=21,000 \mathrm{M}^{-1} \mathrm{~cm}^{-1}\right)$. The reaction contained final concentrations of $100 \mathrm{mM}$ HEPES (pH 7.3), $30 \mu \mathrm{M}$ DCPIP, $0.6 \mu \mathrm{M}$ BjaI, isovaleryl-CoA at 31 or $60 \mu \mathrm{M}$, and $300 \mu \mathrm{M}$ of either synthesized or commercially available S-adenosyl-L-methionine (SAM from Sigma Aldrich Co.). The reactions were initiated with enzyme after a 10 min incubation period to reduce interference of non-specific reduction of DCPIP. 


\section{Results and Discussion}

SAM is a conserved substrate between all AHL synthases, so the purity and activity of this compound is important in order to study these enzymes. Instead of buying commercially available SAM salts, which are impure, it is becoming a new standard to sythesize pure SAM in the lab. For example, S-adenosylmethionine synthetase (MetK) can enzymatically react with methionine and ATP to form SAM. However, the conditions for this reaction can be very sensitive. The major problem was the precipitation of MetK in the reaction buffer before SAM synthesis reaction went to completion (see methods Enzymatic SAM Synthesis using MetK). Since an active, soluble MetK enzyme is absolutely necessary for SAM synthesis to proceed, we undertook multiple strategies to determine the cause for MetK precipitation in this reaction.

$\underline{\text { Issues with MetK Precipitation }}$

First, we tried changing the $\mathrm{pH}$ to see if our enzyme was precipitating due to too low of a $\mathrm{pH}$, causing disulfide bond formation, or too high of a $\mathrm{pH}$. The $\mathrm{pH}$ was varied from $6.5-9.0$ and it was found that a $\mathrm{pH}$ between $7.0-8.0$ worked the best. Another reason for MetK precipitation can be attributed to high concentrations of glycerol. This might have been due to unfavorable interactions between the glycerol, ACN, and MetK. To reduce the amount of glycerol (MetK was stored in $20 \%$ glycerol), the MetK solution was filtered before adding to the reaction mixture. This did not seem to have any effect, so the next step was to see if the enzyme can be added in aliquots. This did not work eitherpreciptation still occured.

Another possibility of MetK precipitation is if disulfide bonds were forming between the enzymes even if the $\mathrm{pH}$ was between $7.0-8.0$. One way to check for this is 
by adding tris(2-carboxyethyl)phosphine (TCEP) to break apart some of these disulfide bonds - TCEP was chosen because the originally protocol used TCEP instead of other reducing agents such as DTT. ${ }^{36}$ Again, the results showed that it did not matter if TCEP was present or not. Next, varying the percentage of acetonitrile (ACN) was attempted. There were varying results, but a $0-10 \% \mathrm{ACN}$ in the reaction buffer worked slightly better than the $20 \%$ ACN originally reported by Lin et al. ${ }^{37}$ Another varied aspect of the reaction buffer was the concentrations of MetK, ATP, and methionine to see if higher or lower concentrations could help push the reaction further, or help decrease the amount of enzyme precipitation.

What worked the best was keeping the $\mathrm{pH}$ between $7.0-8.0$, MetK concentration between $10-40 \mu \mathrm{M}, \mathrm{ACN}$ between $0-10 \%$, and having methionine in excess instead of ATP. Unfortunately, excess methionine cannot be detected using the HPLC (the HPLC was used to detect when the SAM reaction went to completion and to determine what purified fractions of SAM to combine). Therefore, some methionine might be left in the purified SAM. Although the precipation issue was never fully fixed, the reaction did proceed. Separating two charged compounds (SAM and ATP) that were important for determining when the reaction was complete on the HPLC was difficult. After repeated trials, we determined the following HPLC method was effective in resolving SAM and ATP: 0.2 M sodium acetate with a $5 \%$ methanol gradient over $30 \mathrm{mins}$ and a $200 \mu \mathrm{L} / \mathrm{min}$ flow rate. ATP eluted as two peaks, one at 3.3 minutes and another at 3.8 minutes, whereas SAM eluted only as one peak at 4.1 minutes (Figure S1). Decreasing the flow rate helped the most with the separation of these two charged compounds. 


\section{$\underline{\text { Issues with SAM neutralization for use in DCPIP Assay }}$}

Once SAM was successfully synthesized and purified, it was lyophilized and then stored under acidic conditions $(\mathrm{pH}<1)$ at $-80^{\circ} \mathrm{C}$ to reduce degradation. As a result, SAM had to be neutralized before performing any kinetic analysis with the DCPIP assay. Not only is the enzymatic reaction $\mathrm{pH}$ sensitive, but the colorimetric DCPIP dye is also $\mathrm{pH}$ sensitive $-\Delta \varepsilon_{600}$ decreases from 21000 to 14000,4000 , and $2000 \mathrm{M}^{-1} \mathrm{~cm}^{-1}$ from $\mathrm{pH} 7.3$ to 6,5 , and 4, respectively. ${ }^{38}$ Even if SAM was less than $10 \%$ of the total volume, it resulted in high background rates that used up most, if not all, of the DCPIP due to these acidic conditions. ${ }^{38}$

Multiple attempts were made to neutralize the SAM solution, such as: dissolving $\mathrm{NaHCO}_{3}$ or $\mathrm{CaCO}_{3}$ directly into the solution, diluting the concentrated SAM with saturated solutions of $\mathrm{NaHCO}_{3}$ or $\mathrm{CaCO}_{3}$, or with various buffers, such as HEPES (pH = 7.3) and Tris- $\mathrm{HCl}\left(\mathrm{pH}=7.5\right.$ and 8.0). Dissolving $\mathrm{NaHCO}_{3}$ or $\mathrm{CaCO}_{3}$ directly into the SAM solution was not successful because it became supersaturated before the $\mathrm{pH}$ was increased to 7 . The buffers worked with increasing the $\mathrm{pH}$, but when the synthesized SAM was compared to the commercially available SAM within an assay, the rate of the synthesized SAM was still lower than Sigma SAM. If SAM was lyophilized and stored in its solid form, and then dissolved in water, the synthesized SAM would have the same rates as the commercial SAM (Table 1). However, this was not checked for degradation over time. 
Table 1 Comparing enzymes rates of Sigma SAM with synthesized SAM in Tris-HCl $(\mathbf{p H}=\mathbf{8 . 0})^{1}$ and water ${ }^{2}$

\begin{tabular}{|c|c|c|c|c|}
\hline Type of SAM & $\begin{array}{l}\text { Average rate } \\
(\mu \mathrm{M} / \mathrm{min})^{1}\end{array}$ & $\begin{array}{l}\text { Relative } \\
\text { Percent }^{1}\end{array}$ & $\begin{array}{c}\text { Average rate } \\
(\mu \mathrm{M} / \mathrm{min})^{2}\end{array}$ & $\begin{array}{l}\text { Relative } \\
\text { Percent }^{2}\end{array}$ \\
\hline Synthesized & 0.380 & $27.3 \%$ & 1.670 & $95.8 \%$ \\
\hline Sigma & 1.394 & $100 \%$ & 1.743 & $100 \%$ \\
\hline
\end{tabular}

\section{Conclusion}

Synthesizing SAM within the lab is becoming the new standard, but the conditions for synthesis must be optimized to obtain pure SAM. Various reaction conditions were changed to see if the precipation of the enzyme would be reduced $-\mathrm{pH}$, removal of glycerol, decreasing amount of ACN, adding TCEP, and others. Eventually the synthesis did work, but the precipitation issues were never resolved. It is critical to address the issue of degradation of SAM into MTA, especially in regards to enzymes that use MTA as either a substrate or product; AHL synthases fall into this catergory. It is possible to couple the DCPIP assay with nucleosidase, but most likely there are other impurities as well that could effect enzymatic reaction rates. However, since the synthesized SAM had the same rates as Sigma SAM, and due to time constraints, the experiments performed in this thesis study were continued with Sigma SAM. 


\section{CHAPTER THREE: BJAI MUTANTS}

\section{Introduction}

Four crystal structures of AHL synthases have been obtained to date, namely LasI (apo-enzyme), EsaI (apo-enzyme), BjaI (enzyme-substrate and enzyme-inhibitor cocrystal structures) and TofI (enzyme-inhibitor complex). The crystal structures show a dedicated acyl-binding pocket to accommodate the acyl-chain of acyl-substrate (Figure 8). This pocket is believed to be optimized for selective recognition of acyl-chain of the native acylsubstrate for the AHL synthase. For example, two beta-sheets combine to form a deeper, V-shaped acyl-chain binding pocket in the 3-oxododecanoyl-ACP utlilizing LasI enzyme, whereas this pocket is narrow in the shorter acyl-chain (3-oxohexanoyl-ACP) utilizing EsaI. The x-ray structures for AHL synthases provide some clues for understanding the structural basis of acyl-substrate specificity. The acyl-ACP utilizing synthases contain a basic patch of residues that specifically recognize negatively charged acidic residues in helix II of ACP, a phosphopantetheine recognition site and an acyl-chain binding pocket that include a combination of the following features: a) hydrophobic amino acid residues to stabilize the nonpolar acyl-chain of the acyl-substrate, b) amino acid residue(s) whose side chains can donate or accept hydrogen bonds to or from the 3-oxo or a 3-hydroxy moiety in a beta-substituted acyl-substrate, and c) amino acid residues that cap the size of an acyl-chain fitting in this pocket (Figure 8). The acyl-CoA utilizing synthase, however, do not contain the cluster of basic amino acid residues, but instead carry one or more aromatic residues that may stabilize the nucleotide portion of acyl-CoA substrate. 


\section{Mutagenesis Experiments with EsaI and LasI}

Mutagenesis studies in the acyl-chain binding pocket for EsaI revealed that a threonine amino acid (T140) in the acyl-chain pocket functions as a gate-keeper to selectively recognize a 3-oxohexanoyl-ACP substrate instead of the unsubstituted hexanoyl-ACP substrate. When T140 was mutated to alanine, EsaI produced twice as much hexanoyl-HSL relative to its native signal, 3-oxo-hexanoyl-HSL. However, it was not known if the change was due to a shift in specificity of hexanoyl-ACP over 3-oxohexanoyl-ACP or a loss of specificity. ${ }^{39}$ Further studies were done with mass spectroscopy analysis to see if other AHL signals were being produced at lower quantities. The results showed the T140A mutation in EsaI lead to the production of many acyl-chains, with a huge preference of hexanoyl-HSL and some 3-oxo-hexanoyl-HSL, most likely due to having the same chain length. ${ }^{40}$ This means the mutation lead to a loss of specificity indicating that T140 restricts the enzyme to preferentially recognize the 3-oxo-hexanoylACP instead of the unsubstituted hexanoyl-ACP.

LasI binds to a similar, but longer 3-oxo-dodecanoyl-ACP substrate. Unlike EsaI, the LasI active site contains two threonine residues namely T142 and T144 that could potentially aid the recognition of a beta-keto oxygen moiety. Churchill and coworkers transformed E. coli bacteria with several LasI mutant plasmids and the types and amounts of acyl-homoserine lactones (AHL) synthesized by each recombinant bacteria were measured using mass spectrometry. ${ }^{40}$ When T142 was mutated to alanine or serine, there was a slight loss of specificity for the native substrate, but not as much of a shift when T140 was mutated in EsaI. The T142G mutation resulted in lower production of all acylHSL, including the native signal, 3-oxo-dodecanoyl-HSL. Further studies were done to see 
if T144 was the amino acid that helped the enzyme differentiate between the native and non-native substrates, but when T144 was mutated to valine it did not affect the ratio of native to non-native signal production. Unfortunately, the roles of T142 and T144 in the specific recognition of 3-oxo-dodecanoyl-ACP substrate still remains unresolved.

\section{$\underline{\text { BjaI Crystal Structure }}$}

A few crystal structures of BjaI have now been obtained with various ligands bound: SAH with isopentyl-CoA and MTA with isovaleryl-CoA. ${ }^{41}$ These crystal structures helped define the SAM, pantothenic acid, and acyl-CoA binding sites, which are discussed in further detail below. In comparison to the AHL synthase crystal structures, the Cterminal region is vey similar, but the N-terminal region has more variation. This is most likely because LasI, EsaI, and TofI all bind to acyl-ACPs, whereas BjaI binds to an acylCoA. The crystal structure of BjaI also has similarities with a sub-clade of GNAT proteins. Both have seven beta-sheets flanked by alpha-helices and a similar phosphopantetheinebinding domain (Figure 12). 


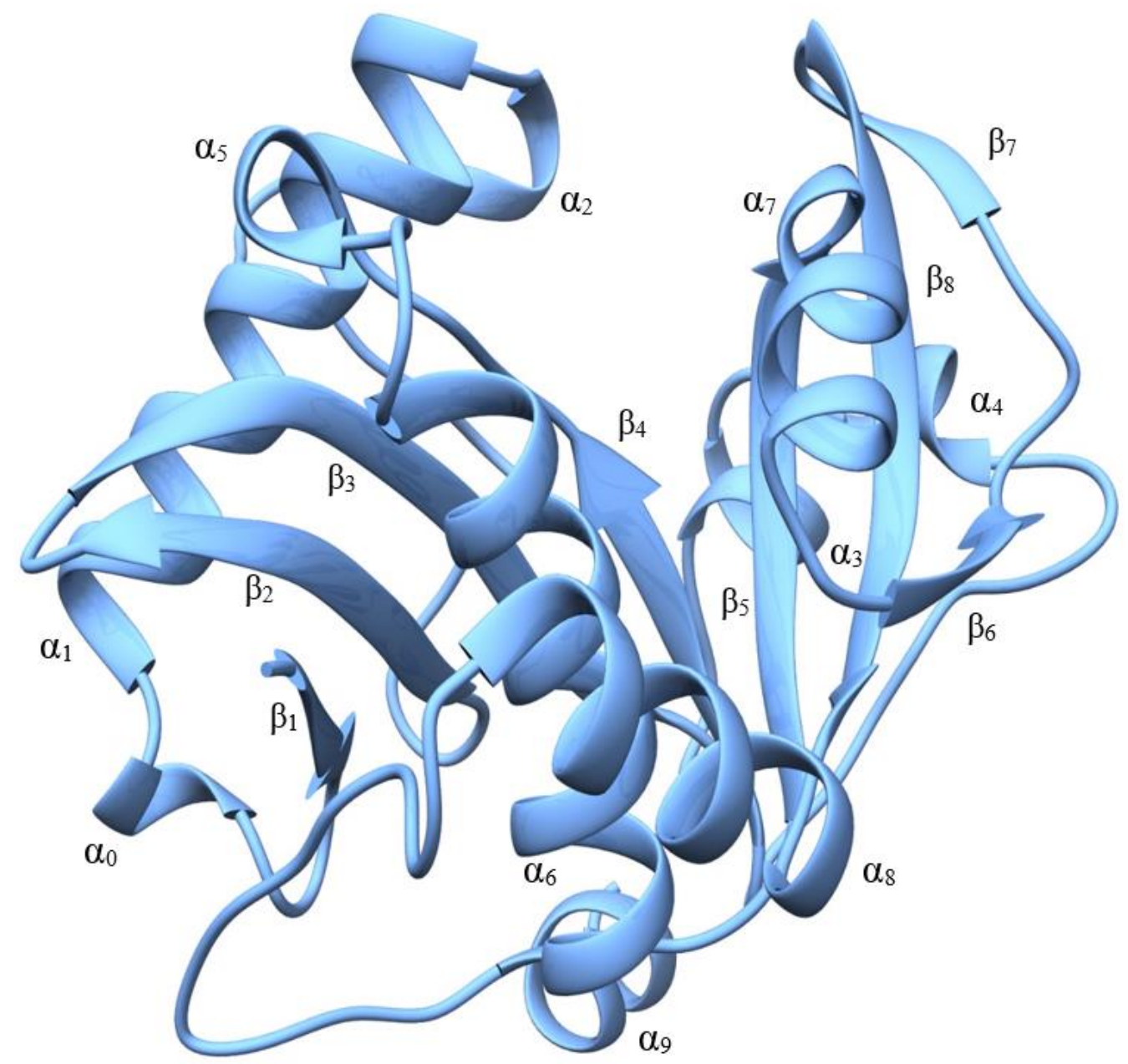

Figure 12 Crystal structure of BjaI. BjaI has similar phosphopantetheine-binding domain as a sub-clade of the GNAT proteins, where it is flanked by seven beta sheets and alpha helices. 


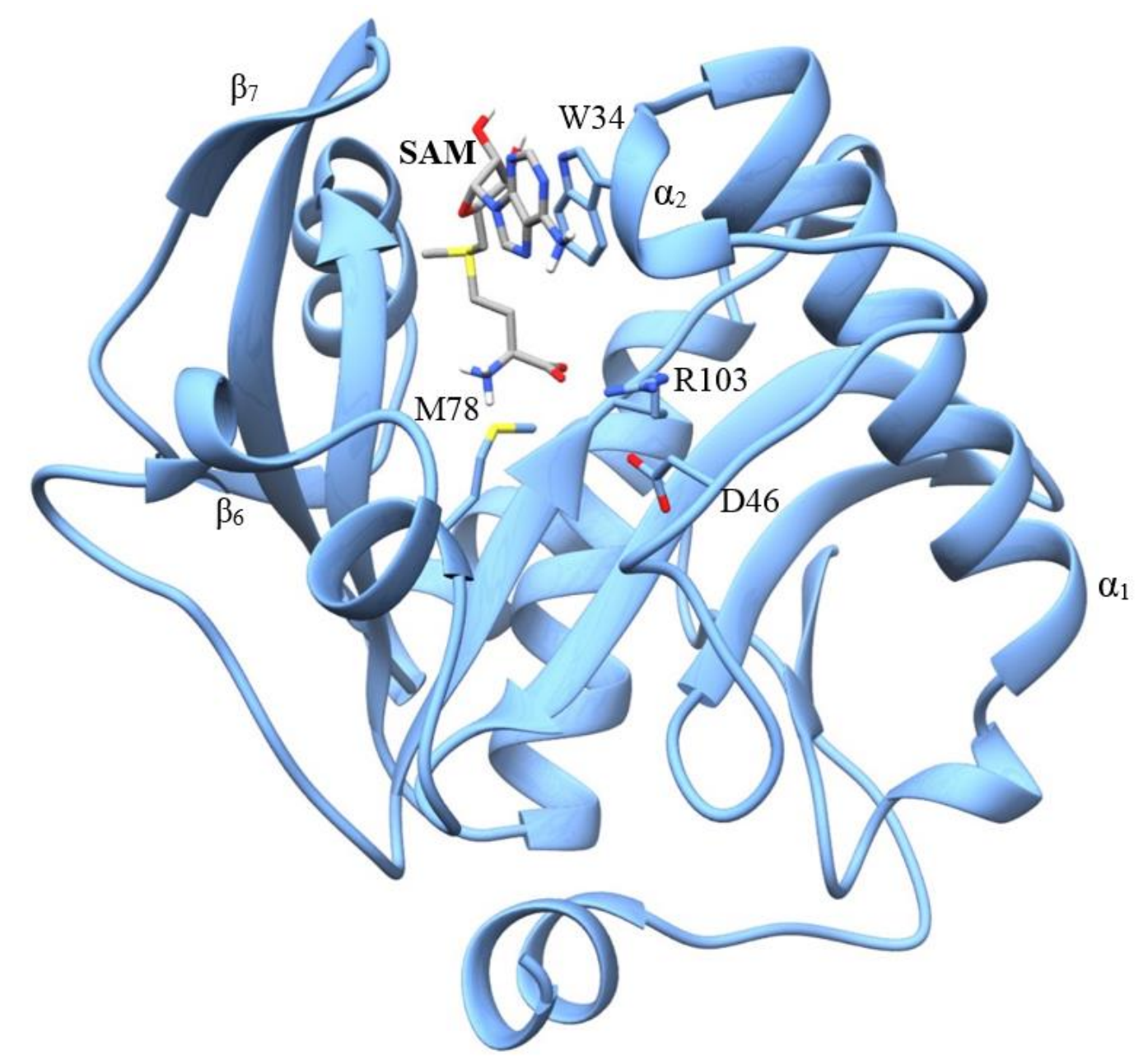

Figure 13 SAM binding pocket in BjaI. The SAM binding is located between $\alpha_{1}$ and $\alpha_{2}$ as well as $\beta_{6}$ and $\beta_{7}$. Specific amino acids that were mutated are shown and labeled.

\section{$\underline{\text { SAM Binding Pocket }}$}

The SAM binding pocket is located between $\alpha_{1}$ and $\alpha_{2}$ as well as $\beta_{6}$ and $\beta_{7}$ (Figure 13). To gain a better understanding of the SAM binding pocket, single point mutations of specific amino acids were done on BjaI. The amino acids within the SAM pocket that were mutated are W34, D46, M78, and R103. The nitrogen in the indole ring of W34 may be hydrogen bonded to the oxygen within the sugar ring in SAM. The x-ray structure reveals that W34 could also help stabilize the nucleotide portion of SAM through pi-stacking during substrate binding. In addition, R103 and M78 is close to the amine group in SAM, 
so these may play a role orientating the amine to do the nucleophilic attack on the thioester bond in isovaleryl-CoA.

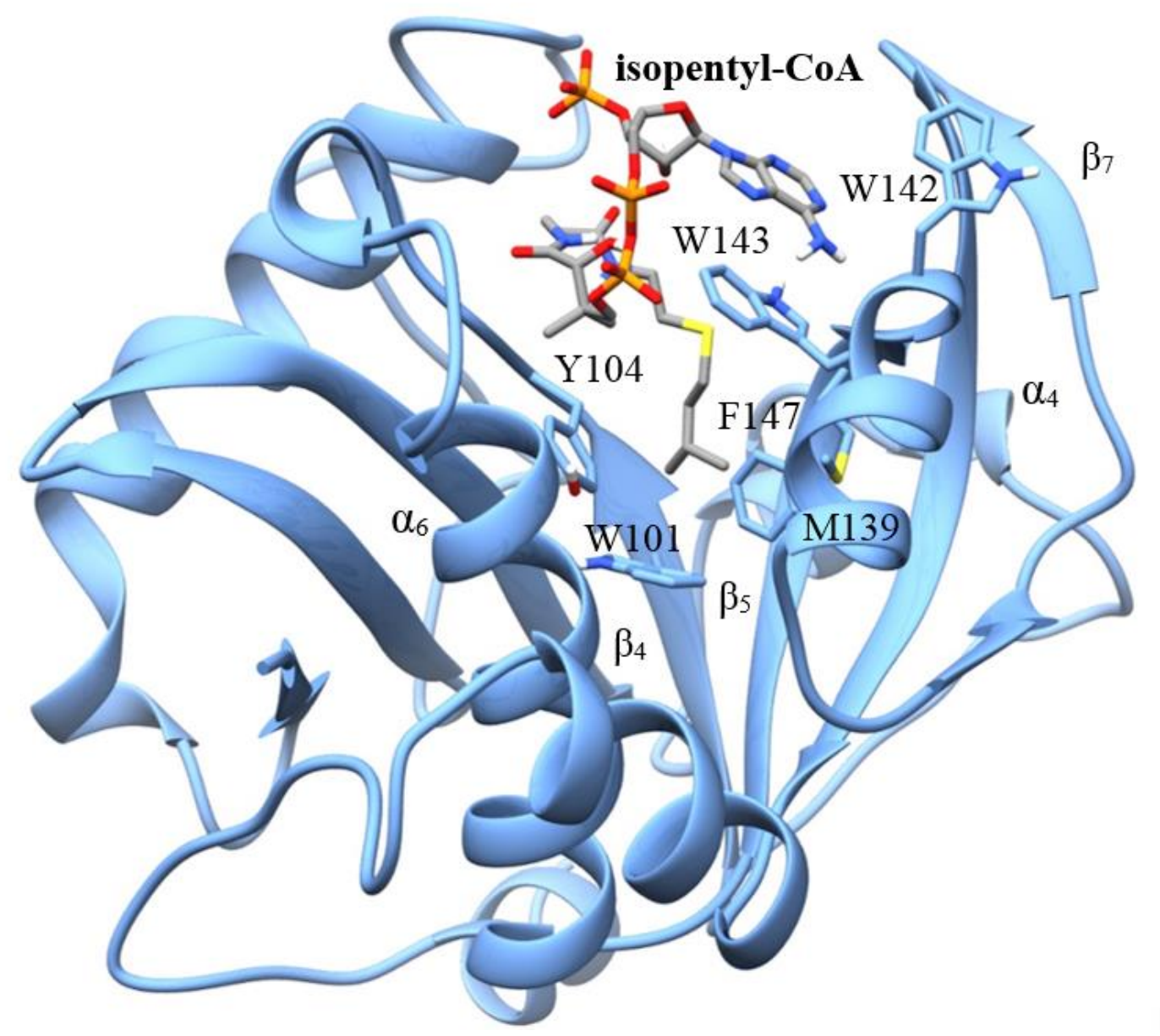

Figure 14 Isovaleryl-CoA binding pocket in BjaI. The isovaleryl-CoA binding site is located between $\alpha_{4}$ and $\alpha_{6}$ as well as $\beta_{4}, \beta_{5}, \beta_{7}$. Specific amino acids that were mutated are shown and labeled.

\section{$\underline{\text { Isovaleryl-CoA Binding Pocket }}$}

The isovaleryl-CoA binding pocket is enclosed by $\beta_{4}, \beta_{5}, \beta_{7}$, $\alpha_{4}$ and $\alpha_{6}$. Within this binding pocket, W101, Y104, M139, W142, W143, and F147 were mutated to see if these play a critical role in substrate specificity. F147 and W101 is at the bottom of the pocket so it could restrict longer acyl-chains from binding. Just like in SAM, isovaleryl-CoA has a nucleotide portion and it may be crucial to stabilize this ring. We hypothesize that W142 
and W143 could stack with the acyl-CoA nucleotide to facilitate acyl-substrate binding. Y104 and M139 are closer to the top of the acyl-chain pocket and could help to orient the sulfur in the thioester bond in order for acylation to occur (Figure 14 is the cocrystal structure with BjaI and isopentyl-CoA, meaning the carbonyl carbon in the thioester group is not shown).

\section{$\underline{\text { Objectives }}$}

The purpose of this chapter is to understand how the amino acids that outline the acyl-CoA binding pocket in BjaI aid in specific recognition of isovaleryl-CoA substrate. Single point BjaI active site mutants were evaluated for detrimental effects in the enzyme's ability to recognize isovaleryl-CoA substrate to produce isovaleryl-homoserine lactone, the quorum sensing molecule in BjaI. These studies should help us understand the molecular basis of native substrate recognition by the BjaI enzyme.

\section{Materials}

All materials were supplied by Sigma Aldrich unless otherwise specified. The mutant BjaI enzymes were generously supplied by Dr. Satish Nair from University of Illinois at Urbana-Champaign. The Thermo Scientific instruments that were used are Evolution 260 Bio UV-Visible Spectrophotometer, coupled with Peltier Water Cooled Cell Changer SPE $8 \mathrm{~W}$.

\section{Methods}

\section{DCPIP Assay}

The enzymatic reaction catalyzed by $\mathrm{BjaI}$ was monitored by measuring the reduction of the blue dye 2,6-dichlorophenolindophenol (DCPIP) into DCPIPH$_{2}$ at $600 \mathrm{~nm}$ $\left(\varepsilon_{600}=21,000 \mathrm{M}^{-1} \mathrm{~cm}^{-1}\right)$. The reaction contained final concentrations of $100 \mathrm{mM}$ HEPES 
(pH 7.3), $30 \mu \mathrm{M}$ DCPIP, 300-400 $\mu$ M S-adenosyl-L-methionine (SAM), and 0.5 - $1.5 \mu \mathrm{M}$ BjaI (both wild-type and mutants), with varying concentrations of isovaleryl-CoA (ranging from $2-300 \mu \mathrm{M})$. The reactions were initiated with enzyme after a 10 min incubation period to reduce interference of non-specific reduction of DCPIP.

In the DCPIP assays, each data point was repeated in triplicate, and the average initial rate obtained from the slope of the progress curves was fit to substrate inhibition equation (4) or to the Michaelis-Menten equation (1) in Prism 6.0 to obtain kinetic constants:

$$
v_{0}=\frac{k_{c a t}\left[E_{t}\right][S]}{K_{m}+[S]\left(1+\frac{[S]}{K_{i}}\right)}
$$

where $k_{\mathrm{cat}}, K_{\mathrm{m}}$, and $K_{\mathrm{i}}$ refer, respectively, to the catalytic, Michaelis-Menten, and substrate inhibition constants, and $\left[E_{t}\right]$ and $[S]$ are the total enzyme concentration and substrate concentration, respectively.

\section{$\underline{\text { Molecular Dynamic Simulations }}$}

Molecular dynamics (MD) simulations were performed using the GROMACS 5.0.5 software package utilizing the Amber03 force-field parameter set. ${ }^{42-47}$ The crystal structure of BjaI bound with S-adenosyl-L-homocysteine and isopentyl-CoA was used as a template for generating initial geometries used in the MD simulations. All simulations were performed using periodic boundary conditions with explicit solvation using a transferable intermolecular potential 3-point (TIP-3P) potential model. ${ }^{48}$ To prepare the solvated systems for simulation, a conjugate gradient energy minimization followed by NVT and NPT equilibrations were performed. A 100-ps equilibration was conducted under a NVT ensemble using a v-rescale thermostat at $300 \mathrm{~K}$ with coupling time constant of $0.1 \mathrm{ps} .{ }^{49,50}$ A subsequent 100-ps NPT equilibration was performed using the isotropic Parrinello- 
Rahman barostat with a time constant of 1.0 ps. ${ }^{51}$ The integration time steps for both equilibration steps and the MD simulation were set at $1 \mathrm{fs}$. All bonds were constrained to equilibrium values using the LINCS algorithm. ${ }^{52}$ The Verlet cut-off scheme was used in calculation of short-range coulomb and van der Waals forces, and particle-mesh Ewald for long-range electrostatics. ${ }^{53,54}$ The topologies for SAM and acyl-CoA inhibitors were initially generated using Antechamber with the general AMBER force field. ${ }^{55,56}$ Topology and coordinate files produced by Antechamber were converted to Gromacs format using ACPYPE (Antechamber python parser interface).${ }^{57}$ Optimized molecular geometries and atomic charges for the ligands were accurately determined using quantum mechanical methods at the MP2/6-31G(d,p) level of theory.

Production MD simulations initiating from the crystal structure were performed at $50 \mathrm{~ns}$ durations. As the starting structure for subsequent calculations, the atomic positions in the BjaI: isopentyl-CoA:SAM complex were averaged over the final one ns of a representative simulation, followed by a conjugate gradient energy minimization. All simulations involving BjaI mutants or acyl-CoA variants used this initial geometry. Point mutations to the BjaI pdb structure were carried out using UCSF Chimera. ${ }^{58}$ Acyl-CoA variants were generated by GaussView, and placed within the binding complex such that the common atoms with isopentyl-CoA ligand shared initial coordinates, and with the acyl chain extending into the BjaI acyl binding pocket. Each newly generated system was progressed through the solvation, energy minimization, and NVT and NPT equilibration steps proceeding $50 \mathrm{~ns}$ production MD simulations as described above.

An alchemical perturbative MD free energy method was used to calculate the relative binding free energies of the acyl-CoA variants, for which unphysical intermediate 
states were used in determining the Coulomb and Lennard-Jones (LJ) contributions to the binding energy. Ligands over a series of linear acyl-chain lengths from ethyl- to octyl-, and two branched acyl-chains, isobutyl- and isopentyl-, were evaluated. Simulating the transitions from real to virtual states was implemented in two steps constituting of A, B, and C states. State A corresponds to the ligand atoms with full Coulomb and van der Waals $(\mathrm{vdW})$ interactions turned on, state B corresponds to an intermediate state for which the partial charges on the acyl chain atoms are set to zero, and state $\mathrm{C}$ represents a virtual state with the partial charges and vdW radii set to zero. Values for the relative binding free energy, $\Delta \Delta G_{\text {bind }}$, were determined for ligand transitions from states A to $\mathrm{C}$ (decoupling) and $\mathrm{C}$ to $\mathrm{A}$ (coupling) using the thermodynamic relationship $\Delta \Delta G_{\text {bind }}=\left(\Delta A_{\text {bound }}^{\text {Coul }}+\right.$ $\left.\Delta A_{\text {bound }}^{L J}\right)-\left(\Delta A_{\text {solv }}^{\text {Coul }}+\Delta A_{\text {solv }}^{L J}\right)$, where $\Delta A_{\text {bound }}$ is the change in free energy of the state transition while the ligand is bound with $\mathrm{BjaI}$, and $\Delta A_{\text {solv }}$ is the free energy change for the ligand in an unbound, or solvated, environment.

Calculations of intermediate $\lambda$ states were performed at non-equidistant nodes. The partial charges of modified atoms were decreased from $\lambda=0$ to $\lambda=1$ through 9 steps, and the vdW parameters were decreased from $\lambda=0 \rightarrow 1$ through 22 steps. During decoupling of $\mathrm{LJ}$ interactions, soft-core potential functions were applied with $\alpha_{\mathrm{LJ}}=0.5$ and $\lambda$ power dependency set to $1.59,60 \mathrm{~A}$ harmonic restraint with force constant of $100 \mathrm{~kJ} \mathrm{~mol}^{-1} \mathrm{~nm}^{-2}$ was placed between the receptor and ligand centers of mass to prevent unreasonable repositioning of the ligand during intermediate decoupling steps. Simulations were performed at each $\lambda$ value for $1000 \mathrm{ps}$ at $0.5 \mathrm{fs}$ time steps. $\partial H / \partial \lambda$ was saved every $10 \mathrm{fs}$ for post-processing and free-energy calculations using Bennett's acceptance ratio (BAR) 
perturbation method. ${ }^{61}$ The first 250 ps of each $\lambda$ state simulation were considered as additional system equilibration and not used in the energy calculations.

\section{Results and Discussion}

\section{$\underline{\text { SAM Binding Pocket }}$}

The binding pocket for SAM is located between two alpha helices and two beta strands. The amino acids that were mutated in this binding pocket are: W34, D46, M78, R103, and Y104. When W34 was mutated to alanine, the $K_{m}$ was hardly effected, but the $k_{\text {cat }}$ and $k_{\text {cat }} / K_{\mathrm{m}}$ decreased by 25 and 20 -fold, respectively (Table 2 ). When D46 was mutated to alanine, this resulted in one of the most damaging mutations studied with 100fold decrease in $k_{\text {cat }} / K_{\mathrm{m}}$. Looking closer at the X-ray crystal, D46 is within hydrogen bond distance $(2.88 \AA$ ) from the adenine N6 in MTA (Figure 15). Interestingly, this hydrogen bond interaction is not shown in the docking simulation with SAM binding.

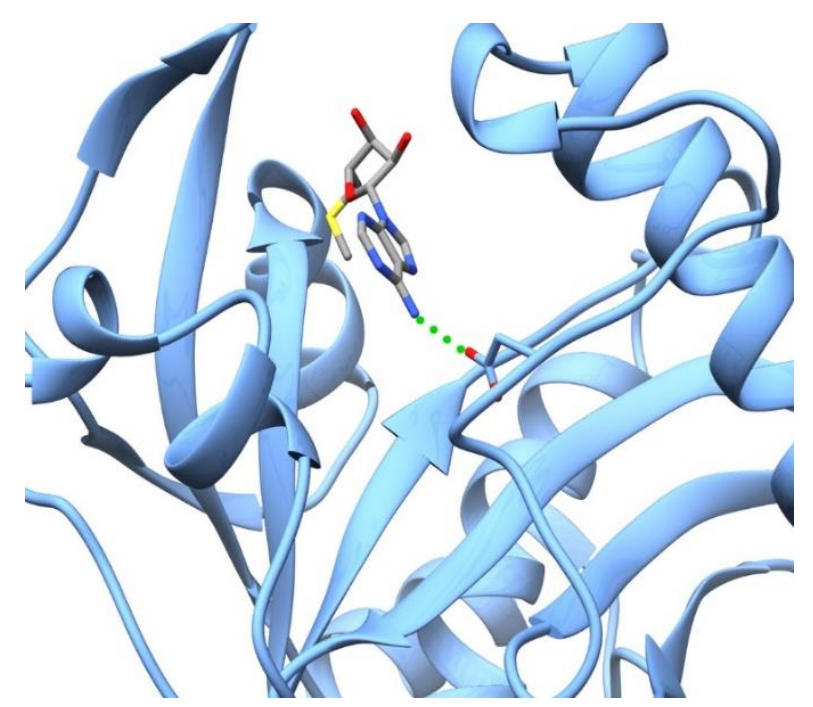

Figure 15 X-ray crystal of D46 possibly stabilizing MTA. D46 is within hydrogen bond distance away from the adenine N6 in MTA $(2.88 \AA)$.

M78 is found within the SAM / MTA pocket where it does not seem to have any significant interactions with either. This is supported by M78A mutation having one of the 
least effects on $k_{\text {cat }} / K_{\mathrm{m}}$ out of the mutations studied (only a 16-fold decrease). M78 may help SAM / MTA to fit better within the pocket spacially, without interacting with either.

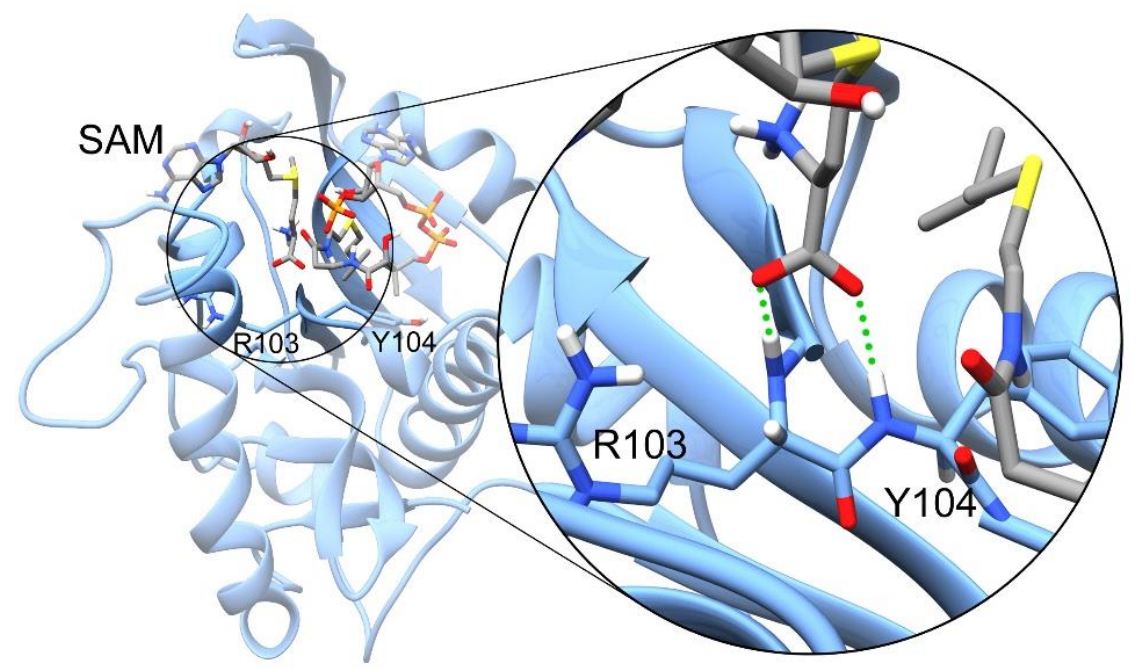

Figure 16 Interactions with polypeptide backbone of R103 and Y104. When these two amino acids were mutated to alanine, it caused a 33 -fold decrease in $k$ cat. It is possible that the mutations caused the backbone to not be in the correct position to help orient the amine group in SAM to do the nucleophilic attack on isovaleryl-CoA.

The R103A mutation had one of the greatest impacts in $k_{\mathrm{cat}}$ in this set of mutations (33-fold decrease) and did not the effect $K_{\mathrm{m}}$. We predict that the backbone amide in R103 hydrogen bonds with the alpha-carboxylate in the 3-amino-3-carboxylpropyl group in SAM (Figure 16). This helps to stabilize the negative charge on the carboxylate anion. R103 also helps to position the 3-amino group of SAM in the correct orientation to do a nucleophilic attack on the thioester carbon in IV-CoA (acylation) as well as help stabilize the oxyanion formation that occurs during that process. Y104A also resulted in a 33-fold decrease in $k_{\text {cat. }}$ The amide found in the backbone of Y104 stabilizes the carboxylate anion, which could be the reason why these mutations had a similar effect on $k_{\text {cat }}$ and $K_{\mathrm{m}}$. Overall, the mutations located within the SAM binding pocket mostly decreased the $k_{\text {cat }}$ and hardly changed the $K_{\mathrm{m}}$, if at all. This could mean that these amino acids are playing a critical role 
in orientating SAM in the correct position to perform catalysis rather than specifically binding to SAM. The substrate-velocity curves for all mutations are shown in Figure 17.

Table 2 Kinetic Constants for BjaI Single-Point Mutants

\begin{tabular}{|c|c|c|c|c|c|c|}
\hline & $\begin{array}{c}k_{\text {cat }} \\
\left(\mathrm{min}^{-1}\right)\end{array}$ & $\begin{array}{c}\text { fold } \\
\text { decrease }\end{array}$ & $\begin{array}{c}K_{\mathrm{m}} \\
\left(\mu \mathrm{M}^{-1}\right)\end{array}$ & $\begin{array}{c}\text { fold } \\
\text { increase }\end{array}$ & $\begin{array}{c}k_{\text {cat }} / K_{\mathrm{m}} \\
\left(\mu \mathrm{M}^{-1} \mathrm{~min}^{-1}\right)\end{array}$ & $\begin{array}{c}\text { fold } \\
\text { decrease }\end{array}$ \\
\hline Wildtype & $2.70 \pm 0.16$ & - & $2.11 \pm 0.4$ & - & $1.28 \pm 0.26$ & - \\
\hline \multicolumn{7}{|c|}{ Mutations in SAM Binding Pocket } \\
\hline W34A & $0.11 \pm 0.006$ & 25 & $1.8 \pm 0.3$ & 1 & $0.061 \pm 0.011$ & 20 \\
\hline D46A & $0.13 \pm 0.02$ & 20 & $11 \pm 2.2$ & 5 & $0.011 \pm 0.003$ & 100 \\
\hline M78A & $0.13 \pm 0.002$ & 20 & $1.8 \pm 0.3$ & 1 & $0.072 \pm 0.12$ & 16 \\
\hline R103A & $0.08 \pm 0.001$ & 33 & $2.0 \pm 0.3$ & 1 & $0.038 \pm 0.005$ & 33 \\
\hline Y104A & $0.08 \pm 0.005$ & 33 & $2.1 \pm 0.5$ & 1 & $0.037 \pm 0.009$ & 33 \\
\hline & Mutations in Isovaleryl-CoA Binding Pocket & \\
\hline W101A & $0.10 \pm 0.001$ & 25 & $1.9 \pm 0.1$ & 1 & $0.054 \pm 0.003$ & 25 \\
\hline W101F & $0.07 \pm 0.01$ & 36 & $6.0 \pm 2.8$ & 3 & $0.012 \pm 0.006$ & 100 \\
\hline M139A & $0.25 \pm 0.02$ & 10 & $3.4 \pm 1.3$ & 2 & $0.074 \pm 0.16$ & 16 \\
\hline W142A & $0.14 \pm 0.01$ & 20 & $10.1 \pm 1.6$ & 5 & $0.014 \pm 0.003$ & 100 \\
\hline W142F & $0.69 \pm 0.34$ & 4 & $26 \pm 17$ & 12 & $0.026 \pm 0.022$ & 50 \\
\hline W143A & $0.19 \pm 0.02$ & 14 & $5.4 \pm 0.7$ & 3 & $0.036 \pm 0.006$ & 36 \\
\hline W143F & $0.09 \pm 0.01$ & 30 & $8 \pm 1.2$ & 4 & $0.011 \pm 0.002$ & 100 \\
\hline F147A & $0.40 \pm 0.02$ & 7 & $3.9 \pm 0.6$ & 2 & $0.104 \pm 0.017$ & 13 \\
\hline
\end{tabular}



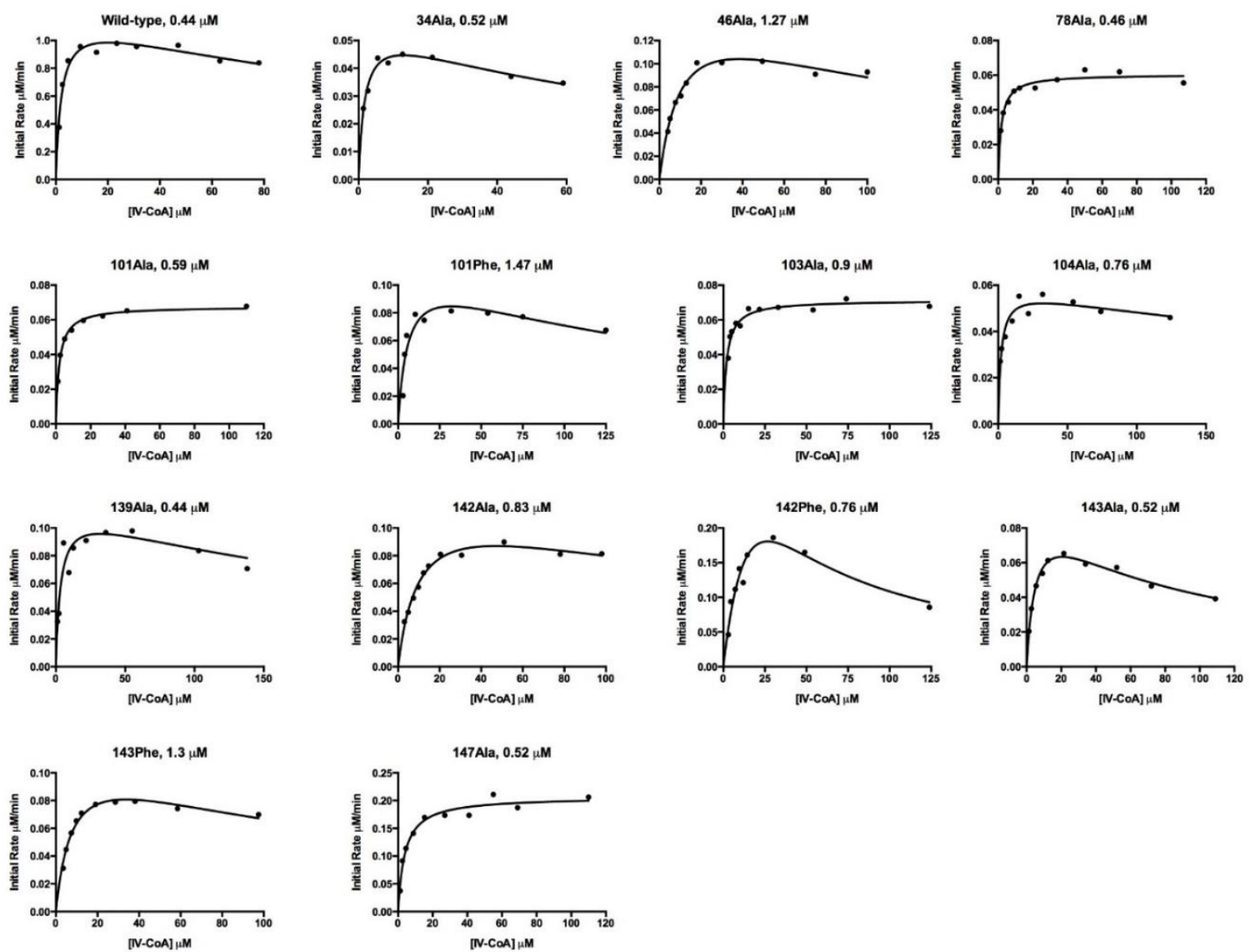

Figure 17 Substrate-velocity curves for BjaI mutants. The title of each graph reveals the mutation and concentration of enzyme used in each assay.

$\underline{\text { Isovaleryl-CoA Binding Pocket }}$

From the crystal structure of BjaI, the binding pocket of the acyl-chain and the pantetheine-linker can be seen located between a $\beta$-bulge on the $\beta 4$ strand as well as between two other beta strands and alpa helices (Figure 14). ${ }^{41} \mathrm{~W} 101$ is found at the bottom of the acyl-chain pocket and does not have any direct interactions with IV-CoA; it most likely serves as a way to discriminate from longer chained acyl-CoAs. W101A mutation resulted in a 25 -fold decrease in $k_{\text {cat }}$ and no change in $K_{\mathrm{m}}$ (Table 2). One prediction for why it affected the $k_{\text {cat }}$ is because without the snug fit, the carbonyl carbon is not placed in the correct position for the 3-amino group in SAM to do a nucleophilic attack during acylation. W101F mutation lead to a 36-decrease in $k_{\text {cat, }}$ 3-fold increase in $K_{\mathrm{m}}$, and an overall 100 - 
fold decrease in $k_{\text {cat }} / K_{\mathrm{m}}$. This was a surprising result as it was originally predicted to keep the acyl-chain pocket approximately the same depth since tryptophan and phenylalanine are similar in size. Therefore, computational analysis was performed to identify a possible reason for why the $\mathrm{W} 101 \mathrm{~F}$ mutation was more detrimental than the W101A mutation. When W101 was mutated to phenylalanine, the amino acid stabilized in a different orientation causing it to slightly close off the acyl-binding pocket (Figure 18). This resulted in possible steric hinderance with isopentyl-CoA and caused the acyl-chain to move slightly out of the pocket. Overall, W101 plays a role in closing the acyl-chain binding pocket and mutations could have lead to either an increase (W101A) or decrease (W101F) in size.

W142 and W143 have pi-stacking intereactions with the CoA nucleotide in IVCoA; Dong et al. calls this the indole platform (Figure 19A). ${ }^{41}$ Mutations in W142 effected the catalytic efficiency slightly more than W143 mutations - W142A and W142F resulted in 100- and 50-fold decrease, respectively, and W143A and W143F resulted in 36- and 100-fold decrease, respectively (Table 2). This could be because W142 is the initial amino acid that pi stacks with the isopentyl-CoA adenine ring and may help to pull it into the isovaleryl-CoA pocket. This prediction is supported by the observation of the adenine ring being pulled closer to W143 within 10-20 ns, which ends up getting stabilized in between W143 and W142 (Figure 19B).

M139 is found on the side of the acyl-chain pocket and is too far away to interact with the acyl-chain directly. This is supported by the smaller effect the M139A mutation had on $k_{\text {cat }} / K_{\mathrm{m}}$ (16-fold decrease). F147A mutation had the least effect on catalytic efficiency with only a 13 -fold decrease. There were not any direct intereactions with the 
acyl-chain with this amino acid either, which could be the reason why it did not affect the catalytic efficiency as much.

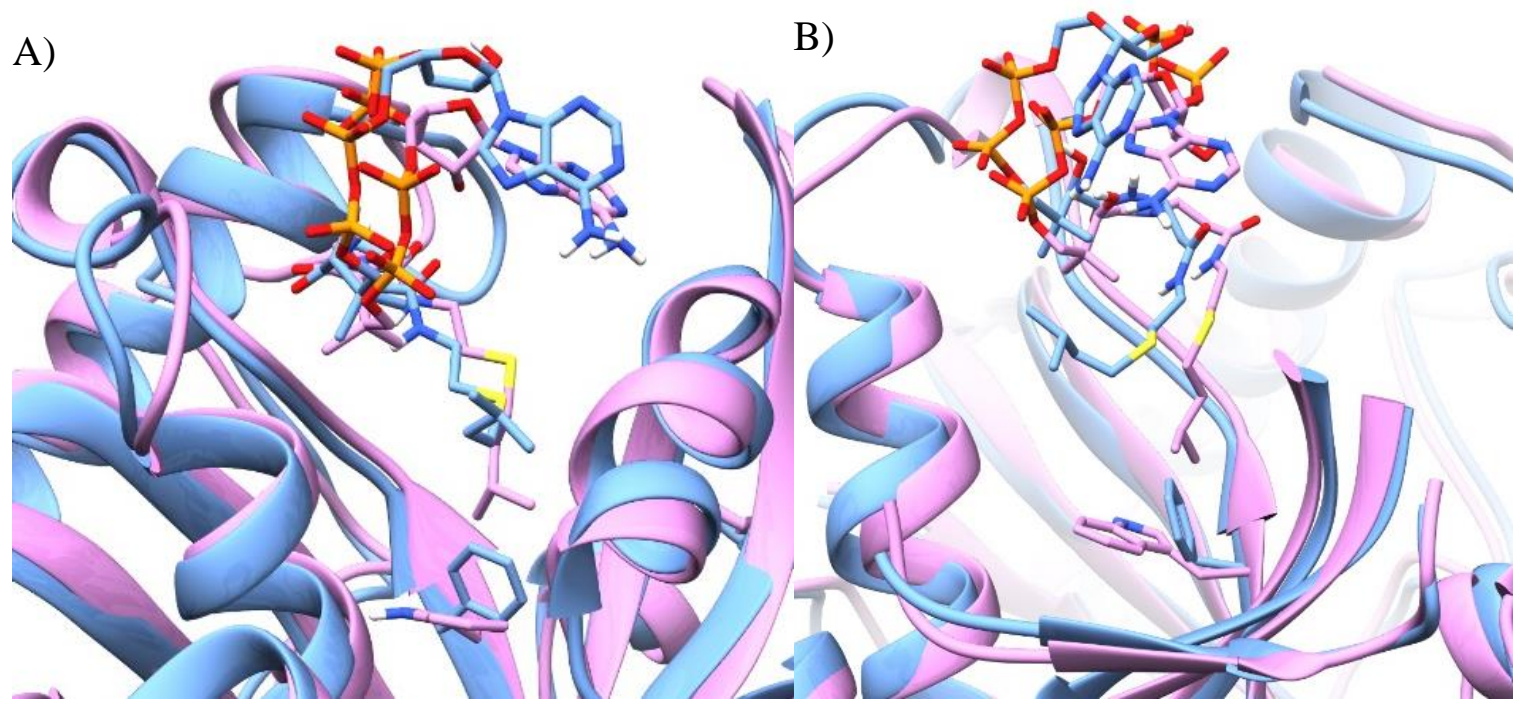

Figure 18 Overlay of wildtype BjaI with W101F mutant. When W101 was mutated to phenylalanine, the ring turned and closed a portion of the pocket. This caused isopentyl-CoA to be pushed out of the acyl-binding pocket. A) is a front view whereas $B$ ) is a side view where part of the enzyme is spliced. BjaI wildtype is shown in blue and the W101F mutated BjaI is shown in light purple. 


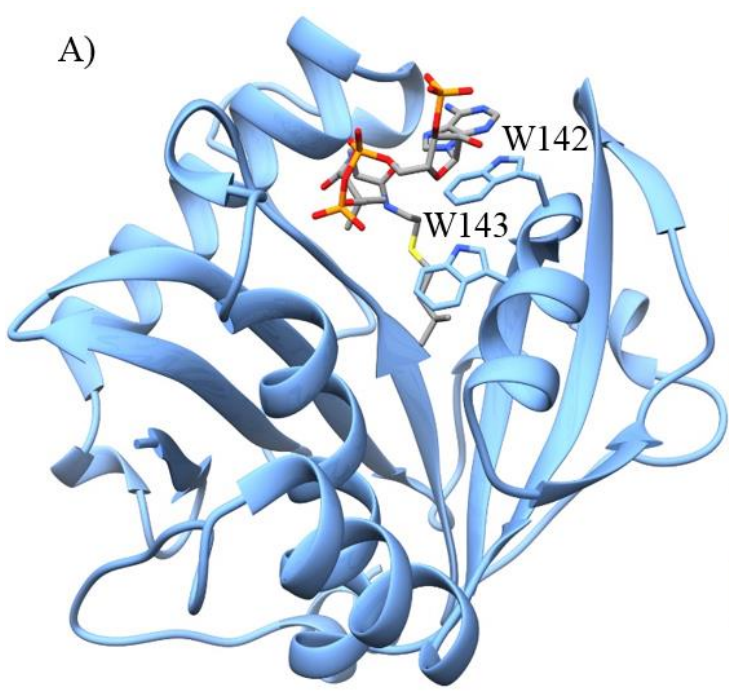

B)

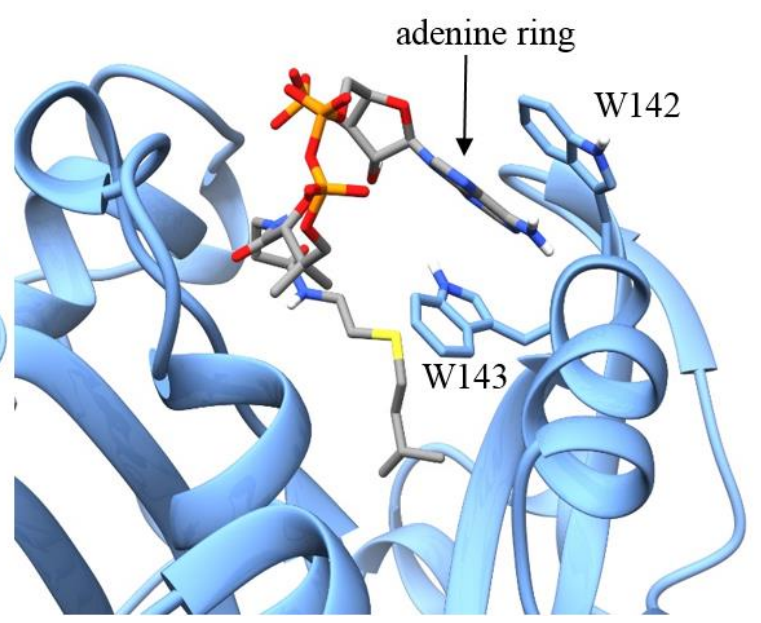

Figure 19 W142 and W143 indole platform with isopentyl-CoA. A) The CoA nucleotide in isopentyl-CoA has pi-stacking interactions with W142 (top) which could be pi-stacking with W143 (bottom). B) After running the MD simulation for $50 \mathrm{ns,}$ the adenine ring actually inserted itself between the W142 and W143.

\section{Possible Future Single Point Mutations:}

After analyzing the crystal structure of BjaI, a few other amino acids that may play a critical role in substrate recognition are S102, R32, and V106. S102 is another amino acid that may be hydrogen binding with the carboxylate in SAM like R103 and Y104 (Figure 20). It is possible that there are multiple amino acids needed to align the carboxylate group in SAM in order to position the amine group for catalysis. R32 and V106 could be stabilizing the pantetheine linker. R32 is within hydrogen bond distance with one of the negatively charged phosphate groups and the amide backbone of V106 is within hydrogen bonding distance to the amide oxygen atom in the pantetheine linker (Figure 20). When the pantetheine linker is destabilized, it could effect how the rest of IV-CoA binds as discussed with inhibition studies in Chapter 4. 


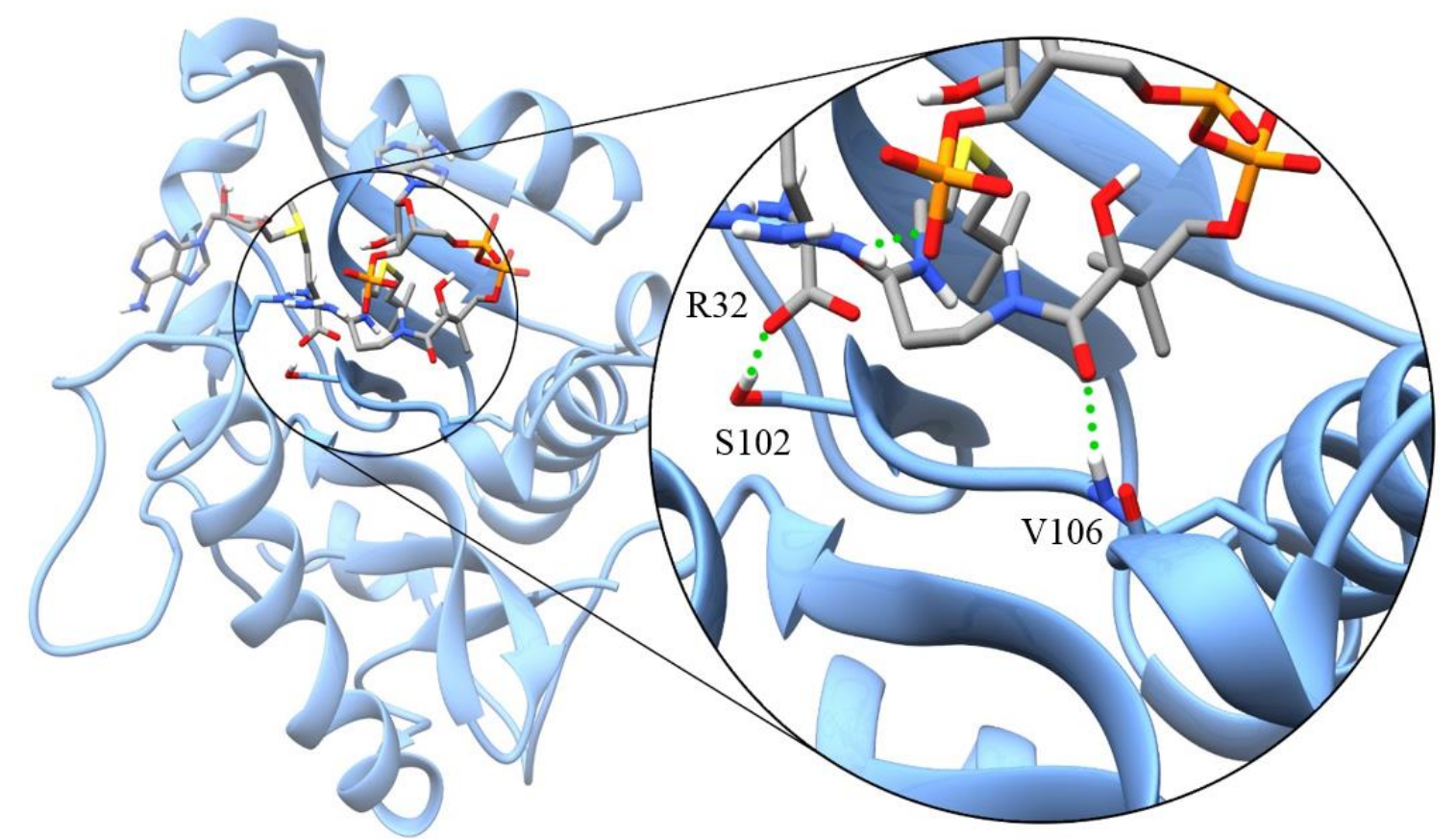

Figure 20 Possible future amino acid mutations. S102, R32, and the backbone of V106 are hydrogen bonding with a portion of SAM.

\section{Conclusion}

Single point BjaI active site mutants were evaluated for detrimental effects in the enzyme's ability to recognize isovaleryl-CoA substrate to produce isovaleryl-homoserine lactone. In general, the single-point mutations within the SAM binding pocket decreased the $k_{\text {cat }}$ without affecting the $K_{\mathrm{m}}$. One possible reason for R103 and Y104 mutants to affect the turnover rate is these amino acids are stabilizing the carboxylate in SAM and may even help orient the amine group for acylation. Within the isovaleryl-CoA binding pocket, W101, W142, and W143 had the greatest impact on the catalytic efficiency. W101, along with F147, close off the bottom of the acyl-chain pocket. Since alanine mutation of these two residues expands the acyl-chain pocket, the isovaleryl side chain has more space to occupy. The increased flexibility of isovaleryl-chain presumably interferes with the formation of tight, productive [Enzyme-acyl-CoA.SAM] ternary complex necessary for optimum positioning of SAM-amine and thioester carbonyl towards acylation step in 
catalysis. W142 and W143 are important in stabilizing the adenine ring in isopentyl-CoA and without this, the rest of the substrate was also destabilized. Overall, the mutations within the isovaleryl-CoA binding pocket and within the SAM binding pocket were detrimental to the enzyme's capability to recognize its specific acyl-substrate. 


\section{CHAPTER FOUR: SUBRATE SPECIFICITY IN BJAI}

\section{Introduction}

AHL synthases in Gram-negative bacteria produce signaling molecules to detect when the local bacterial population reach a quorum. Most AHL synthases use a specific acyl-ACP and SAM to synthesize these signaling molecules, while a few use a specific acyl-CoA and SAM. While the homoserine lactone moiety is conserved, the acyl-chains in AHLs vary depending on the type of QS signal used by a bacterium. Although it is not clear how bacteria makes specific signal molecules for interbacterial communication, the following scenarios could potentially explain how a bacterium might achieve this outcome:

1) The AHL synthases could differentiate between similar acyl-chain substrates and therefore only produce one signal, 2) AHL synthases could produce multiple AHL signals, but then nonspecific signals are selectively degraded, and 3) Fatty acid biosynthesis could be optimized to accummulate a specific acyl-ACP in vivo to aid in specific AHL synthesis. There is not any evidence supporting the selective degradation of signals or the optimization of fatty acid biosynthesis pathway, but there has been some evidence supporting the idea that AHL synthases can differentiate between native and non-native substrates. $^{35,62}$

In order for AHL synthases to have high fidelity in signaling production, the enzyme must be able to recognize its specific acyl-CoA / ACP. There are three possible steps where the enzyme can differentiate between native and non-native substrates: 1) at the binding step, 2) during catalysis, and / or 3) during product release (Figure 21). The 
acyl-ACP binding sites for EsaI, LasI, and TofI accommodate different acyl-chain lengths due to these enzymes catalyzing different acyl-homoerine lactones with shorter or longer acyl-chain lengths. This may be one way AHL synthases could selectively bind to its specific acyl-substrate. It is also possible that the acyl-binding pocket can accommodate similar substrates, but the thioester bond is not orientated correctly for catalysis to occur (Figure 7). Lastly, the non-native substrates could be binding, and even turned over, but the enzyme-product complex inhibits the enzyme, which slows down the rate of catalysis. To determine if substrate specificity is occuring at the binding step or sometime after binding, $K_{\mathrm{i}}$ and $k_{\text {cat }}$ values were measured and compared.

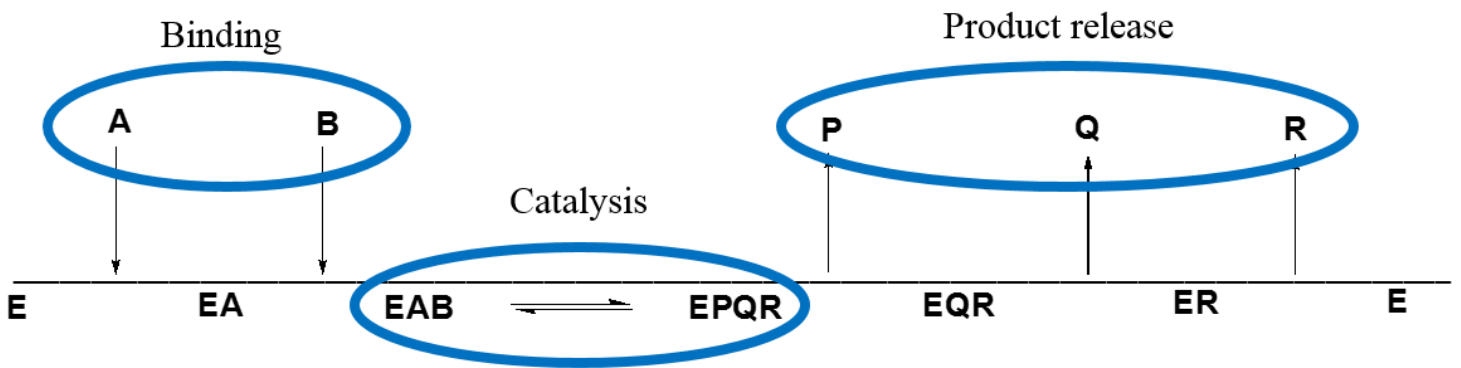

Figure 21 Three possible enzymatic steps where BjaI can differentiate between native and non-native substrates. BjaI could be differentiating 1) at the binding step 2) during catalysis and/or 3) during product release, where $A$ and $B$ can represent either IV-CoA or SAM and P, Q, and R can either be MTA, CoA, or IV-HSL. Comparing $K_{\mathrm{i}}$ and $k_{\text {cat }}$ values will help determine if substrate specificity is occurring at the binding step $\left(K_{\mathrm{i}}\right)$ and / or after binding $\left(k_{\mathrm{cat}}\right)$. This figure is not meant to represent the mechanism of substrate addition or product release; that is still unknown.

To determine if BjaI can catalyze similar, non-native substrates, $k_{\text {cat }}$ was measured for various acyl-CoAs shown in Figure 22. Additionally, substrate analogs were synthesized to determine the approximate binding affinity of these various acyl-CoAs; the analogs mimic the substrate except for one oxygen atom in the carbonyl. Without the carbonyl, the amine group in SAM is less likely, if at all, to do a nucleophilic attack on that 
carbon. Since these analogs mimic the substrate, it is expected that these will bind to the same binding site and therefore act as competitive inhibitors to the acyl-substrate. The acylCoA substrates, and consequently the substrate analogs, were selectively chosen to help us understand substrate specificity mechanism in BjaI. Valeryl-CoA, an isomer of isovalerylCoA, can be used to determine if BjaI will differentiate between substrates that have similar hydrophobic interactions within the acyl-binding pocket. Acetyl-, propionyl-, and isobutyryl-CoA are a few carbons shorter than the native substrate and therefore may not be positioned correctly for catalysis $\left(k_{\text {cat }}\right)$, but the V-cleft has enough room for these to bind, so $K_{\mathrm{i}}$ might not be affected. Butyryl-CoA is the same carbon length as isovalerylCoA and will give insight on if the loss of a methyl-group in the acyl-chain impairs catalysis $\left(k_{\text {cat }}\right)$ and / or the initial binding $\left(K_{\mathrm{i}}\right)$ step in AHL synthesis. Hexanoyl- and octanoyl-CoA are a few carbons too long and is expected to not even bind within the acylCoA binding pocket due to insufficient room. Therefore, both $k_{\text {cat }}$ and $K_{\mathrm{i}}$ should be dramatically affected. 

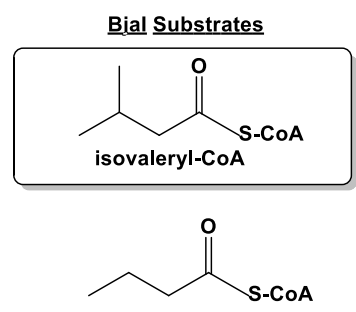

butyryl-CoA
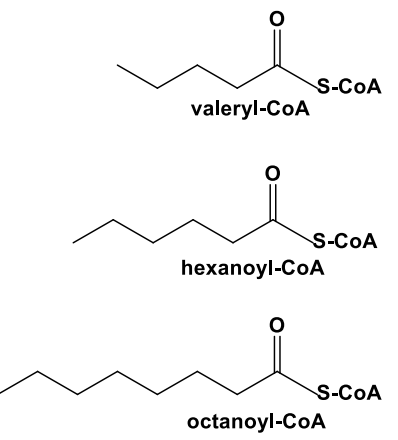

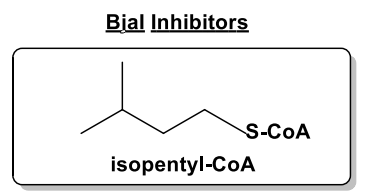

isopentyl-CoA
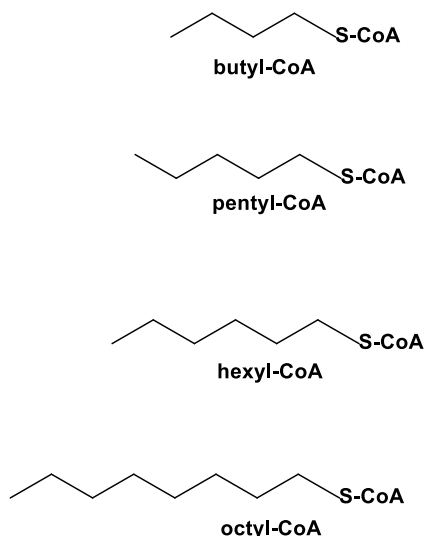

Bial Substrates (cont'd)
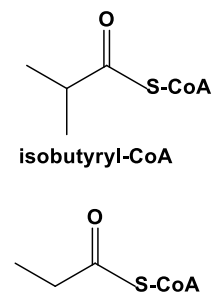

propionyl-CoA

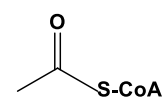

acetyl-CoA
Bial Inhibitors (cont'd)
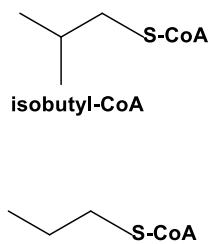

propyl-CoA

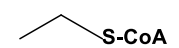

ethyl-CoA

Figure 22 Structures of various acyl-CoAs and alkyl-CoAs. The native (boxed) and non-native acyl-CoAs were used to determine $k_{\text {cat }}$ values (left) and the corresponding alkyl-CoA inhibitors used to measure $K_{\mathbf{i}}$ values (right). Without the carbonyl group, acylation cannot occur (Figure 7).

\section{Michaelis-Menten Enzyme Kinetics and Inhibition}

As discussed in chapter one, the Michaelis-Menten equation works well for one substrate enzymes or bisubstrate enzymes where one substrate is held at saturating conditions. When performing inhibition studies, the Michaelis-Menten equation (1):

$$
v_{0}=\frac{V_{\max }[S]}{[S]+K_{m}}
$$

can be rearranged into equation (5):

$$
\frac{1}{V}=\frac{K_{m}}{V_{\max }} \times \frac{1}{[S]}+\frac{1}{V_{\max }}
$$

where $V$ is the rate of the reaction, $V_{\max }$ is the maximal velocity the enzyme can catalyze the reaction, $[S]$ is the substrate concentration, and $K_{m}$ is the amount of substrate required to reach half of $V_{\max }$. By plotting inverse rate vs inverse substrate concentration, this can be used to determine the mode of inhibition. 
There are three main modes of inhibition - competitive, uncompetitive, and mixed. Competitive inhibitors bind to the same enzyme form as the substrate and therefore blocks the substrate from binding. Due to the substrate competing with the inhibitor, a decrease in the rate of the reaction is observed initially. However, $V_{\max }$ does not change because high concentrations of substrate will likely overturn the effects of the inhibitor. Since the inhibitor and substrate are competing for the same enzyme form, there will be an increase in $K_{\mathrm{m}}$. In the double reciprocal plot, an increase in $K_{\mathrm{m}}$ with no effect on $V_{\max }$ will result in a slope change while keeping the y-intercept the same (equation 5). Uncompetitive inhibitors, however, will bind to a different form of enzyme than the substrate and result in intercept effects. For example, by increasing the inhibitor concentration, the amount of $E S$ complex will decrease as it forms $E S I$. This will decrease $K_{\mathrm{m}}$ (it will appear the $E$ and $S$ have a higher binding affinity) and $V_{\max }$ will also decrease. $K_{\mathrm{m}}$ and $V_{\max }$ will be effected by the same ratio, thus canceling each other out and resulting in no slope effect. It is also possible for the inhibitor to act as both competitive and uncompetive, which is called mixed inhibition. A special type of mixed inhibition is noncompetitive inhibition, where the inhibitor functions as a competive and uncompetive inhibitor equally. In this scenerio, $K_{m}$ is not effected, but the $V_{\max }$ decreases. The Lineweaver-Burke plots of competitive, uncompetitive, and noncompetitive are shown in Figure 23. 


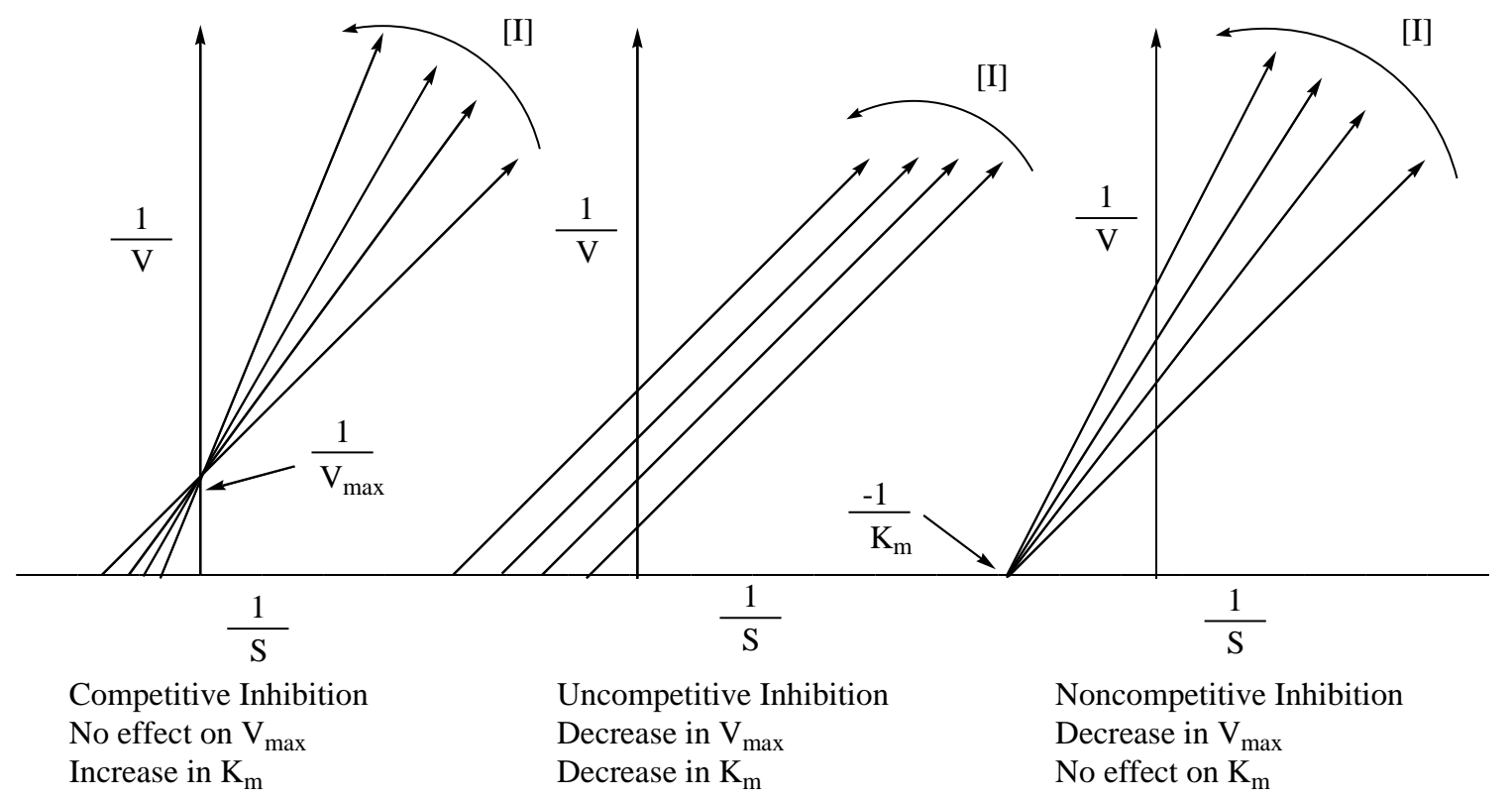

Figure 23 Lineweaver-Burke plots can be used to determine mode of inhibition. When the substrate and inhibitor bind to the same enzyme form, slope effects are observed due to an increase in $K_{\mathrm{m}}$. Uncompetitive inhibition occurs when the substrate and inhibitor are binding to different enzymes forms that are reversibly connected. This effects both the $k_{\text {cat }}$ and $K_{\mathrm{m}}$, resulting in no slope effect, but a varied $y$-intercept. Noncompetitive occurs when there are equal parts of competitive and uncompetitive inhibition, resulting in both slope and y-intercept effects, but merges on the same $x$-intercept. Retrieved on August 18, 2016 and adopted from http://guweb2.gonzaga.edu/faculty/cronk /CHEM440/images/inhibition_Lineweaver Burk.gif

\section{Objective}

In vivo, only specific quorum sensing molecules are observed. To determine if BjaI acyl-CoA substrate selectivity, $k_{\text {cat }}$ and $K_{\mathrm{i}}$ values were measured with various acyl-CoAs and alkyl-CoAs. The variation in the $k_{\mathrm{cat}}$ and $K_{\mathrm{i}}$ values were used to predict where substrate specificity is occuring - at the binding step $\left(K_{\mathrm{i}}\right)$, after binding ( $k_{\text {cat }}$ ), or a combination of both - depending on which step was affected the most.

\section{Materials}

All materials were supplied by Sigma Aldrich unless otherwise specified. The instruments used were: Excella E24 Incubator Shaker, New Brunswick Scientfic; Evolution 260 Bio UV-Visible Spectrophotometer, Thermo Scientific coupled with Peltier 
Water Cooled Cell Changer SPE 8 W, Thermo Scientific; Sorvall Legend X1R Centrifuge, Thermo Scientific; and FreeZone 2.5 Lyophilizer, Labconco. Two reverse phase C-18 columns were used: one was used for checking and fractioning out large quantities of MetK (preparatory column, Thermo Scientific 25005-109070) on the HPLC and the other was used to check the purity (analytical column, Thermo Scientific 25002-054630) on the UHPLC.

\section{Methods}

Wildtype BjaI Growth, Expression, and Purification

In a sterilized environment, BjaI cell stocks were streaked on an LB-agar plate containing chloramphenicol and ampicillin (50 $\mu \mathrm{g} / \mathrm{mL}$ each). After growing for 12 - 24 hours at $37^{\circ} \mathrm{C}$, one colony was picked and added to LB ( $15 \mathrm{~mL}$, Fisher) containing the same final concentrations of chloramphenicol and ampicillin. This mini growth was incubated with gentle shaking $(225 \mathrm{rpm})$ at $37{ }^{\circ} \mathrm{C}$ for 12 hours. The now turbid mini growths were added to $1 \mathrm{~L}$ of LB containing chloramphenicol and ampicillin resistance (50 $\mu \mathrm{g} / \mathrm{mL}$ each), which incubated at $37^{\circ} \mathrm{C}$ with shaking $(225 \mathrm{rpm})$ until $\mathrm{OD}_{600}$ reached 0.5 - 0.8. Once isopropyl $\beta$-D-1-thiogalactopyranoside (IPTG, $1.0 \mathrm{mM}$ ) was added to induce expression, the incubation temperature was reduced to $16{ }^{\circ} \mathrm{C}$ and grown overnight. The following day, the cells were pelleted by centrifugation at 5,000 $\mathrm{x} g$ for $10-15$ mins. Lysing the cells required the addition of B-PER ( $2 \mathrm{~mL} / 1 \mathrm{~L}$ growth, Thermo Scientific), DNase (40 $\mu \mathrm{g} / \mathrm{mL}$ ), RNase (40 $\mu \mathrm{g} / \mathrm{mL})$, and phenylmethylsulfonyl fluoride (PMSF, 1 $\mathrm{mg} / \mathrm{mL}$ ) to the cell pellets, which incubated with these for 15 mins at $37^{\circ} \mathrm{C}$ at $225 \mathrm{rpm}$. The lysate was centrifuged at 20,000 x g for 30 mins. The supernatant was collected and stored in the fridge until the Ni-NTA agarose resin (Qiagen) was prepared. This column 
was equilibrated with $10 \mathrm{X}$ bed volumes of Buffer A (50 mM Tris- $\mathrm{HCl}, \mathrm{pH} 7.5,0.5 \mathrm{M}$ $\mathrm{NaCl})$. To bind the protein, the supernatant was added to the column and eluted out through gravitation. The column was washed with $10 \mathrm{X}$ bed volume of Buffer A with $50 \mathrm{mM}$ imidazole to help purify the protein. To elute the protein of interest, $5 \mathrm{X}$ bed volumes of Buffer A with $300 \mathrm{mM}$ imidazole was added to the column, which was collected in $1 \mathrm{~mL}$ fractions. SDS-PAGE was used to determine which fractions contained clean BjaI. These fractions were then combined, filtered and concentrated with $10 \mathrm{kD}$ Amicon spin column at $5,000 \mathrm{x}$. The concentration of BjaI was determined using $\mathrm{UV}$-Vis $\left(\varepsilon_{280}=48,500 \mathrm{M}^{-1}\right.$ $\left.\mathrm{cm}^{-1}\right)$. The purified protein was stored at $-80{ }^{\circ} \mathrm{C}$ in $50 \mathrm{mM}$ lithium 4-morpholineethanesulfonate (MES) at a $\mathrm{pH}=6$ containing $20 \%$ glycerol.

\section{DCPIP Assay}

The enzymatic reaction catalyzed by BjaI was monitored by measuring the reduction of the blue dye 2, 6-dichlorophenolindophenol (DCPIP) into $\mathrm{DCPIPH}_{2}$ at 600 $\mathrm{nm}\left(\varepsilon_{600}=21,000 \mathrm{M}^{-1} \mathrm{~cm}^{-1}\right)$. The reaction contained final concentrations of $100 \mathrm{mM}$ HEPES (pH 7.3), $30 \mu \mathrm{M}$ DCPIP, 300 - $400 \mu \mathrm{M}$ S-adenosyl-L-methionine (SAM), and approximately $0.5 \mu \mathrm{M}$ BjaI, with varying concentrations of isovaleryl-CoA (ranging from $3-150 \mu \mathrm{M})$. The reactions were initiated with enzyme after a $10 \mathrm{~min}$ incubation period to reduce interference of non-specific reduction of DCPIP. Equations (1) and (4) were used to fit the data on Graphpad Prism 6.0.

\section{$\underline{\text { DCPIP Assay for Inhibition Studies }}$}

$\mathrm{IC}_{50} \mathrm{~s}$ were collected for each alkyl-CoA using the same set up as described in "DCPIP Assay," except the alkyl-CoA inhibitor was also included in the 10 min incubation period. The concentration range for each inhibitor varied depending on the strength of 
inhibition. Once the approximate $\mathrm{IC}_{50}$ values were determined, the inhibitor concentrations were chosen as follows: $0 \mu \mathrm{M}$, two below $\mathrm{IC}_{50}$, one at $\mathrm{IC}_{50}$, and two above $\mathrm{IC}_{50}$, for a total of six inhibitor concentrations. Varied concentrations of inhibitors were incubated with SAM $(\sim 350 \mu \mathrm{M}), 100 \mathrm{mM}$ HEPES (pH 7.3), $30 \mu \mathrm{M}$ DCPIP, and varying concentrations of isovaleryl-CoA (ranging from $1-24 \mu \mathrm{M}$ ), for 10 mins to reduce interference of nonspecific reduction of DCPIP. The reactions were initiated with approximately $0.5 \mu \mathrm{M} \mathrm{BjaI}$ and the reduction of DCPIP into DCPIPH 2 at $600 \mathrm{~nm}\left(\varepsilon_{600}=21,000 \mathrm{M}^{-1} \mathrm{~cm}^{-1}\right)$ was monitored. Each data point was repeated twice. Equation (6) was used to fit the data and calculate $K_{\mathrm{i}}$ and $K_{\mathrm{i}}^{\prime}$ on Graphpad Prism 6.0:

$$
v_{0}=\frac{V_{\max }^{a p p}[S]}{[S]+K_{m}^{a p p}}
$$

where $V_{\max }^{a p p}$ and $K_{m}^{a p p}$ change depending on the mode of inhibition:

Competitive inhibition:

$$
v_{0}=\frac{V_{\max }^{a p p}[S]}{[S]+\alpha K_{m}^{a p p}}
$$

Uncompetitive inhibitor:

$$
v_{0}=\frac{V_{\max }^{a p p} / \alpha^{\prime} \cdot[S]}{[S]+K_{m}^{a p p} / \alpha^{\prime}}
$$

Mixed inhibition:

$$
v_{0}=\frac{V_{\max }^{a p p} / \alpha^{\prime} \cdot[S]}{[S]+\alpha K_{m}^{a p p} / \alpha^{\prime}}
$$


where $\alpha$ and $\alpha^{\prime}$ can be expressed as $\alpha=1+\left(\frac{[I]}{K_{i}}\right)$ and $\alpha^{\prime}=1+\left(\frac{[I]}{K_{i}{ }^{\prime}}\right)$, and $[\mathrm{I}]$ is the inhibitor concentration. The inhibitors were fitted to each type of inhibition equation listed above to calculate $K_{\mathrm{i}}$ and / or $K_{\mathrm{i}}^{\prime}$.

$\underline{\text { Inhibitor Synthesis }}$

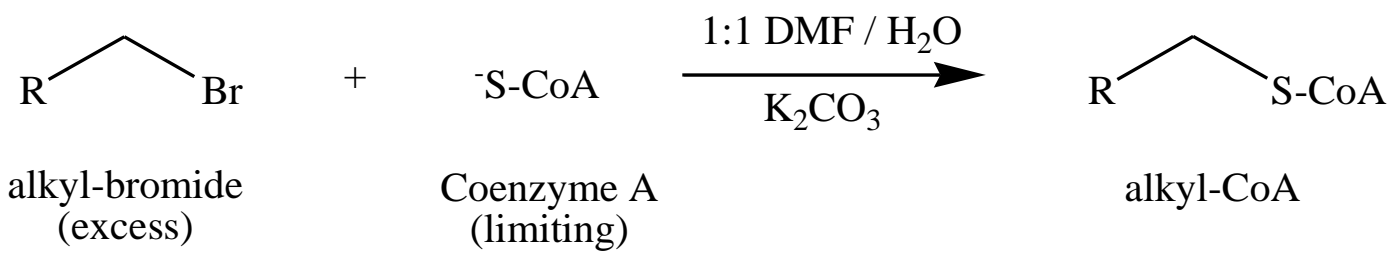

Figure 24 Synthesis of alkyl-CoA inhibitors. Alkyl-bromides were mixed with limiting $\mathrm{CoA}$ in a 1:1 DMF and water solution under basic conditions. Different alkylbromides were used to make the various alkyl-CoAs. These inhibitors were then checked for purity on a reverse-phase analytical column on the HPLC.

To synthesize alkyl-CoAs, the respective alkyl-bromides $(20 \mu \mathrm{L})$ was mixed into a 1:1 DMF and water solution with a $\mathrm{pH} \sim 8-10$ adjusted using $\mathrm{K}_{2} \mathrm{CO}_{3}$ (Figure 24). Free acid CoA (20 mg, $0.026 \mathrm{mmol}$ ) was added to the reaction under $\mathrm{N}_{2}$, which proceeded overnight. To check for completion, DCPIP was added to a filter paper, where a small amount of the reaction was also added. Solvent extraction with ether was used to remove any organic reactant or side products that was formed. The sample was then filtered with a $0.22 \mu \mathrm{m}$ syringe filter (Millex-GV) before being injected onto the HPLC (for acyl-chains with 4 carbons or more, the method started with $95 \%$ solvent A ( $25 \mathrm{mM}$ sodium acetate $\mathrm{pH}=5.0)$ and $5 \%$ solvent $\mathrm{B}(\mathrm{ACN}+0.1 \% \mathrm{TFA})$, and had a linear gradient for 20 mins until it reached $30 \%$ solvent $\mathrm{A}$ and $70 \%$ solvent $\mathrm{B}$ at a flow rate of $3000 \mu \mathrm{L} / \mathrm{min}$; for smaller acyl-chains, the method was exactly the same, but with a reduced flow rate of 700 $\mu \mathrm{L} / \mathrm{min})$. When the peak of interest started to elute out of the column, that peak was collected using a FoxyR1 Teledyne ISCO fraction collector. While on ice, the collected 
fractions were combined and then $\mathrm{N}_{2}$ gas was pushed through to evaporate any organic solvents left in solution. The solution was then stored in the $-80^{\circ} \mathrm{C}$ freezer for 1 or more hours, until ready to be lyophilized overnight. The alkyl-CoA powder was combined and stored in the $-80{ }^{\circ} \mathrm{C}$. To confirm that the powder was the expected alkyl-CoA, a mass spectrum was obtained. To check for purity, a small amount was dissolved in water and then injected into the UHPLC using the analytical column.

For the ethyl and propyl-CoA's, the method with a slower flow rate of $700 \mu \mathrm{L} /$ min was used. For the rest, the method with the faster flow rate of $3000 \mu \mathrm{L} /$ min was used. The eluted times for each compound on the preparatory column are: ethyl-CoA $6.3-9.4$ mins, propyl-CoA $7.9-11.0$ mins, butyl-CoA $6.3-9.1$ mins, isobutyl-CoA $6.0-7.5$ mins, pentyl-CoA $7.4-9.0$ mins, isopentyl-CoA $7.2-11.0$ mins, hexyl-CoA $9.3-11$ mins, and octyl-CoA 12.3 - 13.5 mins. The eluted times for each compound using the analytical column are: ethyl-CoA $2.3-2.8$ mins, propyl-CoA $3.2-4.2$ mins, isobutyl-CoA $4.2-5.0$ mins, butyl-CoA $4.4-5.2$ mins, isopentyl-CoA 5.5 - 6.0 mins, pentyl-CoA $5.7-6.4$ mins, hexyl-CoA 6.8 - 7.5 mins, and octyl-CoA $8.2-8.6$ mins.

\section{Results and Discussion}

\section{Confirming BjaI and Alkyl-CoAs}

Before any inhibition studies were performed, the purity and the identity of BjaI and alkyl-CoAs had to be confirmed. BjaI is a His-tagged protein, which was purified using Ni-NTA columns. To confirm that elutions containing only BjaI were collected, an SDSPAGE gel was ran and analyzed. The mass of the eluted protein is about $23 \mathrm{kDa}$, which was compared to the expected mass of $23 \mathrm{kDa}$ (Figure 25). The elutions with only one band (pure BjaI) were collected, combined, and stored in $20 \%$ glyercol. To confirm the identity 
and purity of the alkyl-CoAs, a small amount of a specific alkyl-CoA was dissolved in water and ran on a reverse-phase analytical UHPLC column. As the alkyl-chain length got longer, the alkyl-CoA eluted at a later time. This also showed that only one major peak was observed for each alkyl-CoA, indicating that the inhibitors were pure (Figure 26). To confirm that the alkyl-CoAs are indeed what was expected, mass spectrometry data was also obtained and analyzed (Figures S2-S9).

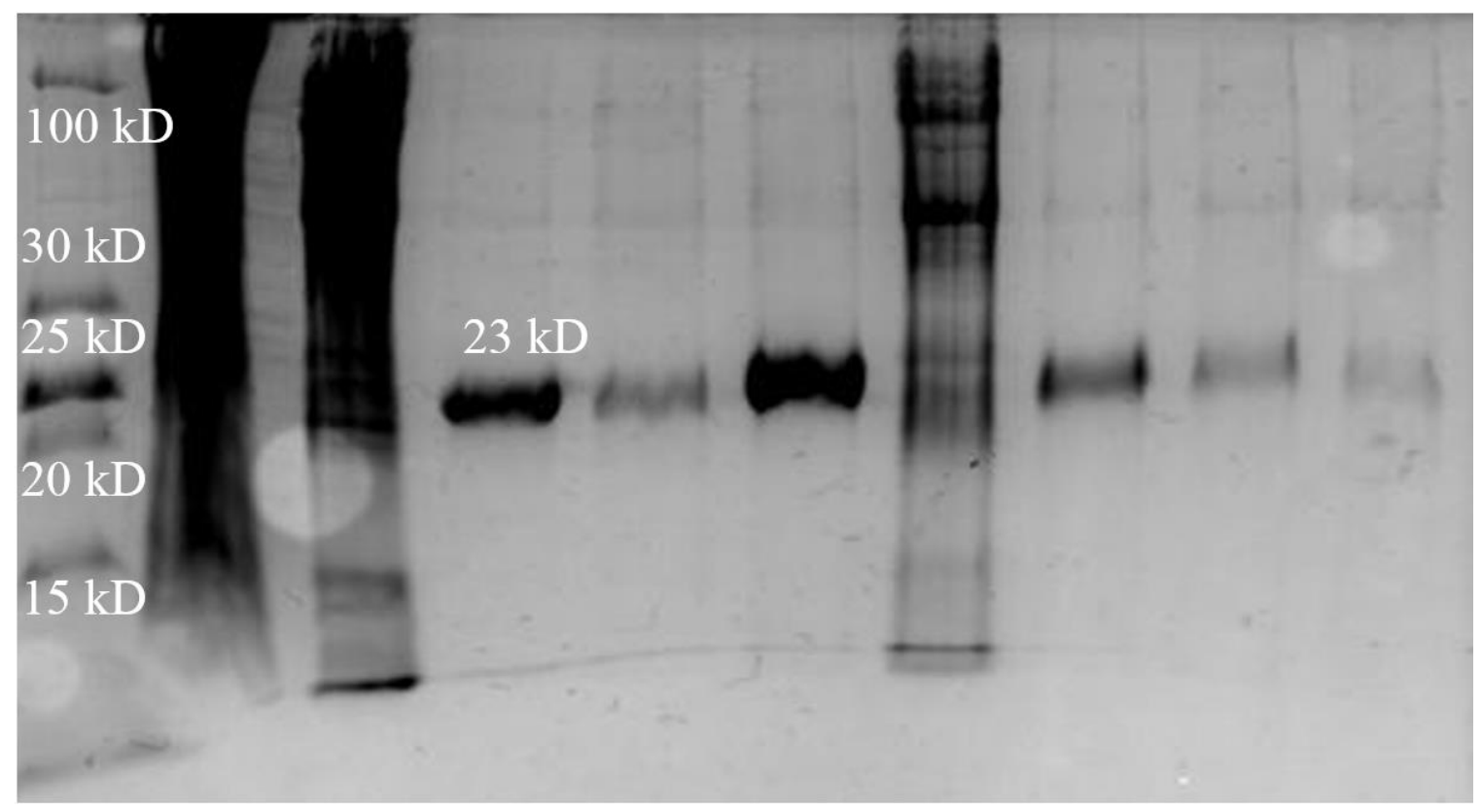

Figure 25 SDS-PAGE of BjaI. The expected weight of BjaI is $23 \mathrm{kDa}$ and the purified BjaI band was located around $23 \mathrm{kDa}$. The first, second, and third lane represents PageRuler low range ladder, crude load $(5 \mu \mathrm{L})$ of BjaI, and run-through lysate $(5 \mu \mathrm{L})$. Lanes four-six and eight-ten contains BjaI elutions $(10 \mu \mathrm{L})$. Lane seven contains the wash. 


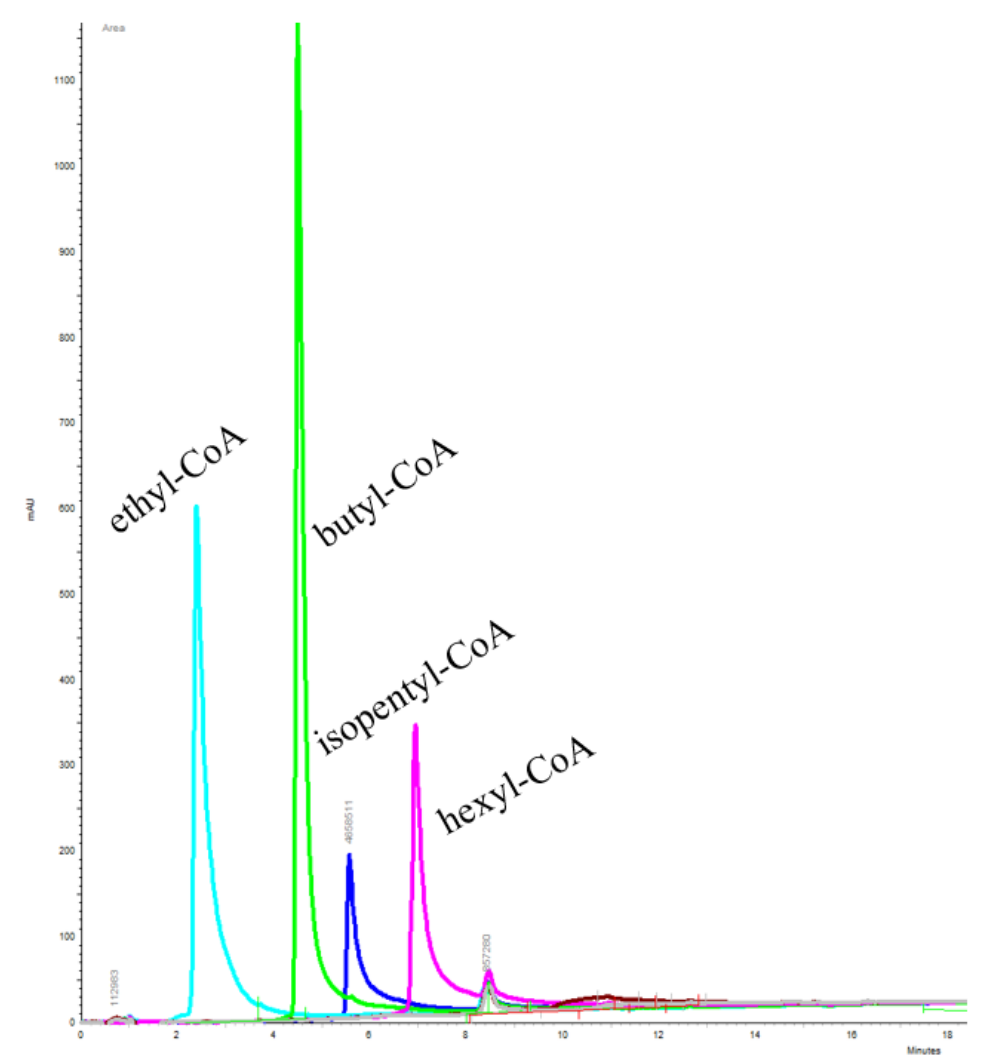

Figure 26 Overlapping HPLC chromatograms of various alkyl-CoAs. Each alkylCoA only had one major peak, indicating it was pure, and the elution time was later as the alkyl-chain got longer.

\section{$\underline{\text { Substrate Specificity in BjaI }}$}

In vivo, there are only specific acyl-homoserine lactone (acyl-HSL) signals detected. The substrate of interest is the acyl-CoA because this determines what type of acyl-chain is on the HSL signaling molecule. The purpose of this chapter is to gain insight on how substrate specificity is achieved in BjaI, one type of AHL synthase. $K_{\mathrm{i}}$ and $k_{\text {cat }}$ values were measured to see if BjaI is differentiating between native and non-native substrates at the binding step $\left(K_{\mathrm{i}}\right)$, after binding $\left(k_{\text {cat }}\right)$, or possibly a combination of the two. Isovaleryl-CoA, the native substrate, has a $k_{\text {cat }}$ of $2.7 \pm 0.2 \mathrm{~min}^{-1}$ and butyryl-CoA is $2.3 \pm$ $0.2 \mathrm{~min}^{-1}$, which is within error of each other (Table 3 and Figures $27-28$ ). This indicates that after butyryl-CoA binds to BjaI, it is being turned over just as quickly as the native 
substrate. The worst substrate, isobutyryl-CoA, has a turnover rate of $0.4 \pm 0.1 \mathrm{~min}^{-1}$, which is approximately a 7-fold decrease from the native substrate. The lack of major changes in the $k_{\text {cat }}$ for most analogs suggests that the substrate binding step could play a major role in BjaI catalysis. The $K_{m}^{a p p}$ values, determined using Prism 6.0, showed a lot more variance. To determine binding affinities, alkyl-CoA's were synthesized and used to measure and compare $K_{\mathrm{i}}$ values.

Table 3 Kinetics constants of various acyl-CoA substrates measured with fixed SAM

\begin{tabular}{|c|c|c|c|c|}
\hline Substrate & $\boldsymbol{K}_{\boldsymbol{m}}^{\boldsymbol{a p p}}(\boldsymbol{\mu M})$ & $\boldsymbol{k}_{\boldsymbol{c a t}}^{\boldsymbol{a p p}}\left(\mathbf{m i n}^{-\mathbf{1}}\right)$ & $\begin{array}{c}\boldsymbol{k}_{\boldsymbol{c a t}}^{\boldsymbol{a p p}} / \boldsymbol{K}_{\boldsymbol{m}}^{\boldsymbol{a p p}} \\
\left(\boldsymbol{\mu \mathbf { M } ^ { - 1 }} \mathbf{m i n}^{-\mathbf{1}}\right)\end{array}$ & $\begin{array}{c}\text { Fold decrease } \\
\left(\boldsymbol{k}_{\boldsymbol{c a t}}^{\boldsymbol{a p p}} / \boldsymbol{K}_{\boldsymbol{m}}^{\boldsymbol{a p p}}\right)\end{array}$ \\
\hline Isovaleryl-CoA & $2.1 \pm 0.4$ & $2.7 \pm 0.2$ & $1.286 \pm 0.263$ & - \\
\hline Valeryl-CoA & $3.1 \pm 0.2$ & $1.1 \pm 0.1$ & $0.355 \pm 0.039$ & 3.6 fold \\
\hline Butyryl-CoA & $8.7 \pm 1.2$ & $2.3 \pm 0.2$ & $0.264 \pm 0.043$ & 4.9 fold \\
\hline Isobutyryl-CoA & $5.3 \pm 0.8$ & $0.4 \pm 0.1$ & $0.075 \pm 0.022$ & 17.1 fold \\
\hline Hexanoyl-CoA & $9.1 \pm 3.0$ & $0.9 \pm 0.1$ & $0.098 \pm 0.034$ & 13.1 fold \\
\hline Octanoyl-CoA & $\mathrm{ND}^{\mathrm{a}}$ & $\mathrm{ND}$ & $\mathrm{ND}$ & - \\
\hline Propionyl-CoA & $86 \pm 17$ & $1.5 \pm 0.1$ & $0.017 \pm 0.003$ & 75.6 fold \\
\hline${ }^{\mathrm{a}} \mathrm{ND}=$ not determined & \multicolumn{4}{l}{}
\end{tabular}
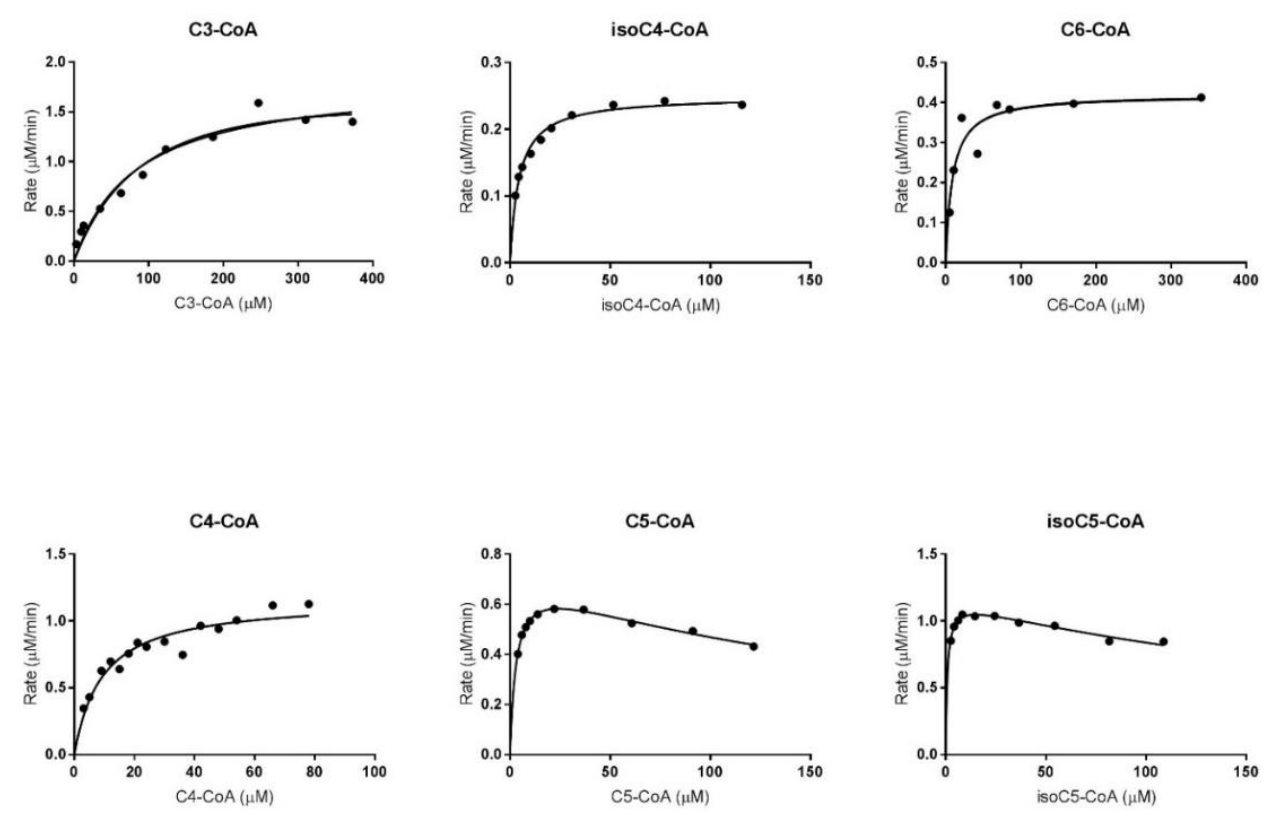

Figure 27 Substrate-velocity curves for various acyl-CoAs. Notice that substrate inhibition was observed for both valeryl(C5)- and isovaleryl(isoC5)-CoA. 


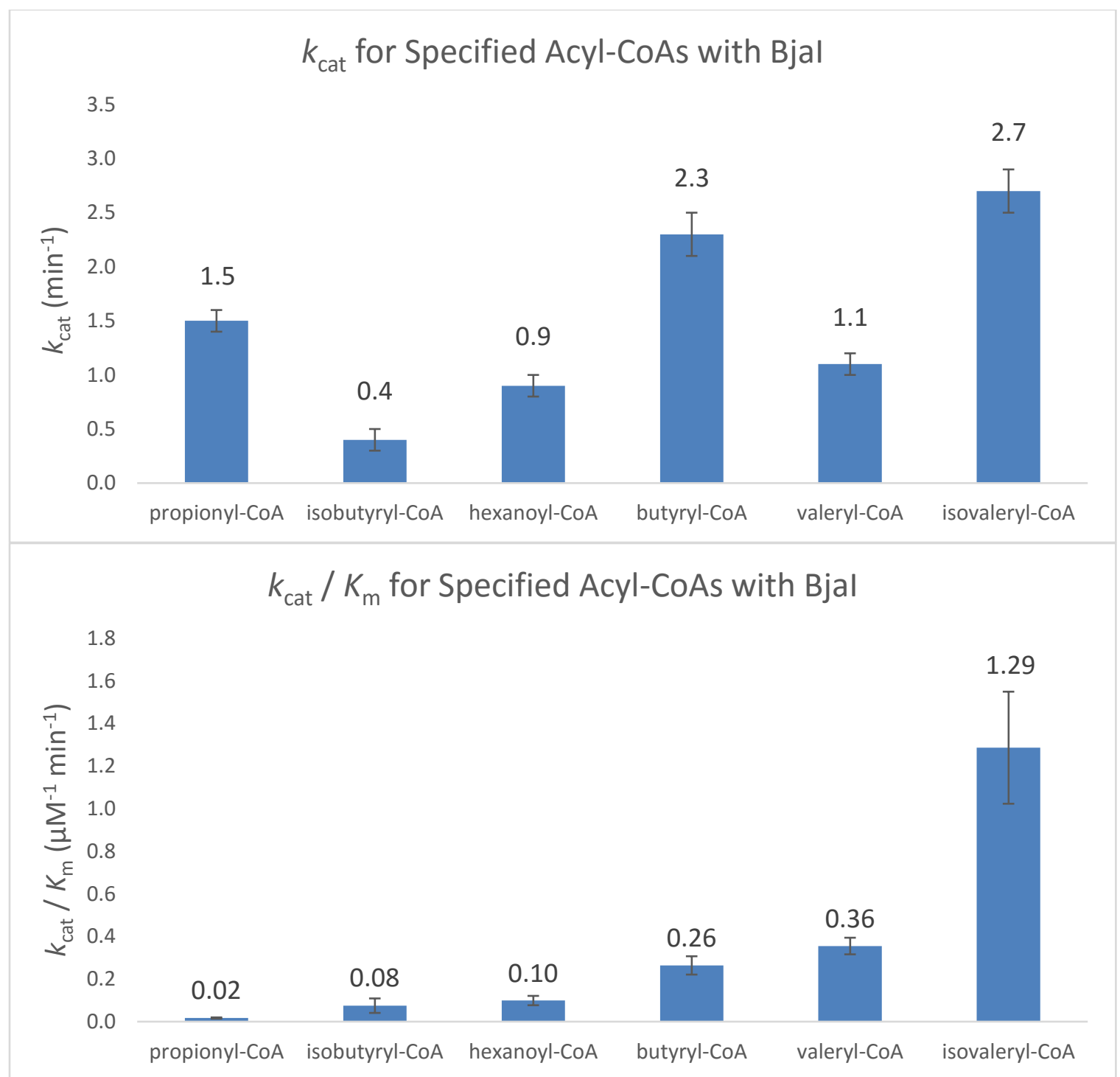

Figure 28 Bar graph of kinetic constants for various acyl-CoAs. The catalytic efficiency of the enzyme with non-native acyl-substrates decreased relative to the native substrate. However, it seems that the $k_{\text {cat }}$ is not the only cause for this variation.

Mixed Inhibition

Inhibition studies were performed and the data was fitted using Prism 6.0 (equations 6-9). It was hypothesized that the substrate analog inhibitors would be competitively binding for the isovaleryl-CoA binding pocket since the analog is only missing one oxygen atom, but instead the substrate analogs showed mixed inhibition (Figures 29-32), except for isobutyl-CoA. Further analysis (t-tests) were done to check if slope and y-intercept 
changed significantly with increase in concentration of inhibitor. With the exception of isobutyl-CoA, there was a significant change in slope and y-intercept, concluding that these are mixed inhibitors (Figures 31-32). Isobutyl-CoA only had a significant change in slope, which suggests that this is a competitive inhibitor. 

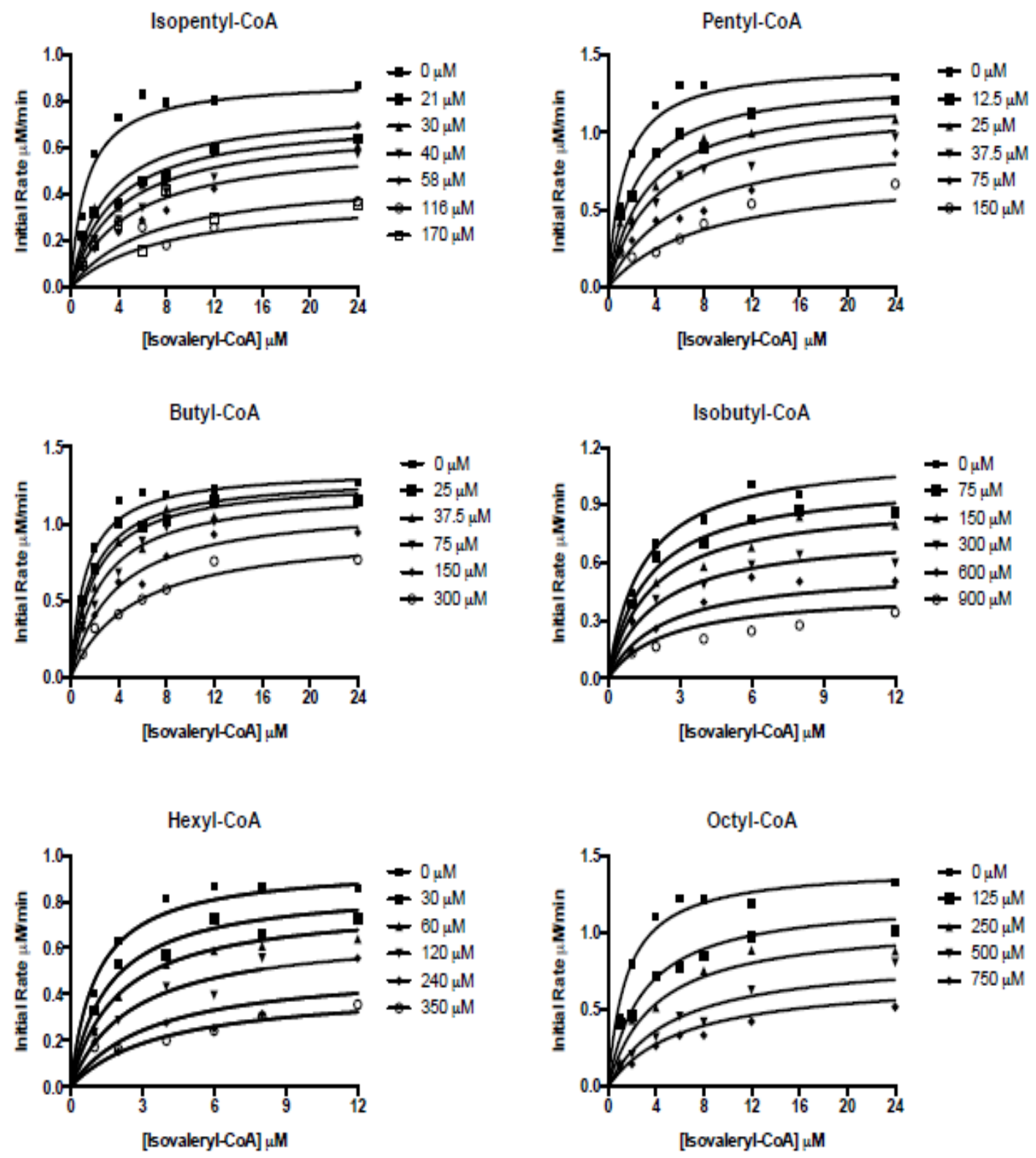

Figure 29 Inhibition curves for BjaI. Longer alkyl-chains, like octyl-CoA and hexyl-CoA, were able to inhibit better than shorter alkyl-chains, like isobutyl-CoA. Propyl- and ethyl-CoA were so weak that they did not show inhibition until $>3$ mM. $K_{i}$ and $K_{i}^{\prime}$ values are shown in Table 4. 

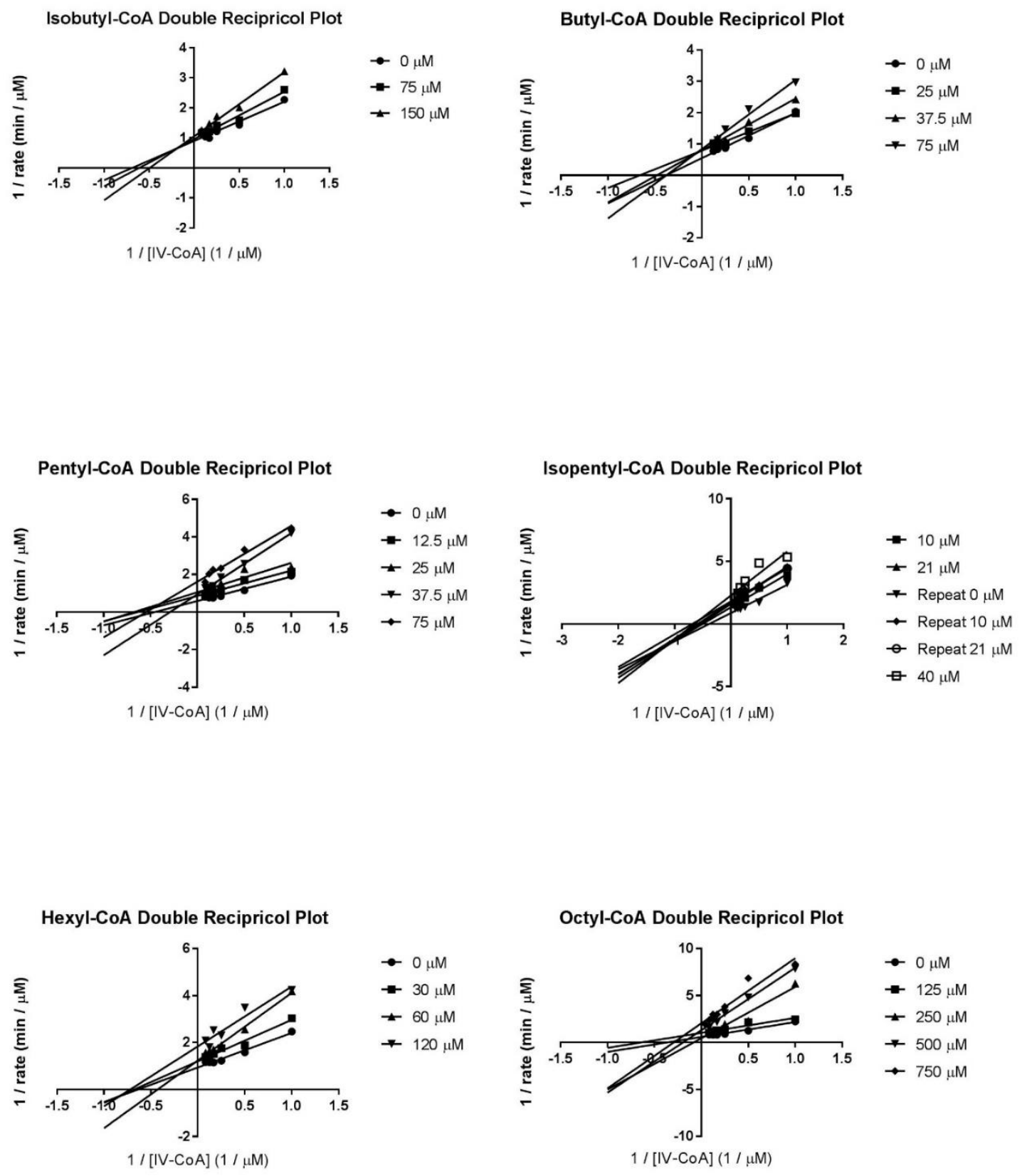

Figure $30 \quad$ Double-reciprocal plots of all six inhibitors studied with BjaI. IsobutylCoA was the only inhibitor to show competitive inhibition, whereas the rest showed mixed inhibition. 
Isobutyl-CoA Intercept Secondary Plot

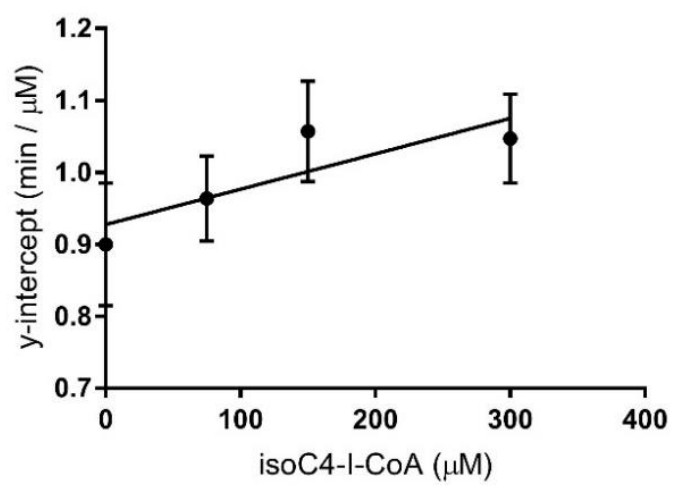

Pentyl-CoA Intercept Secondary Plot

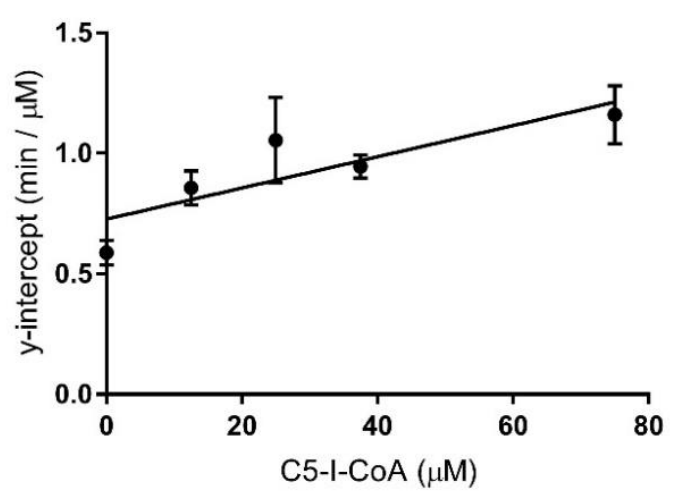

Hexyl-CoA Intercept Secondary Plot

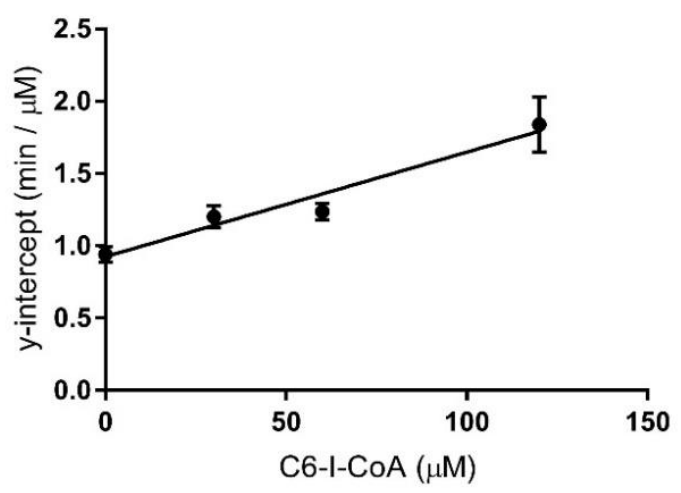

Butyl-CoA Intercept Secondary Plot

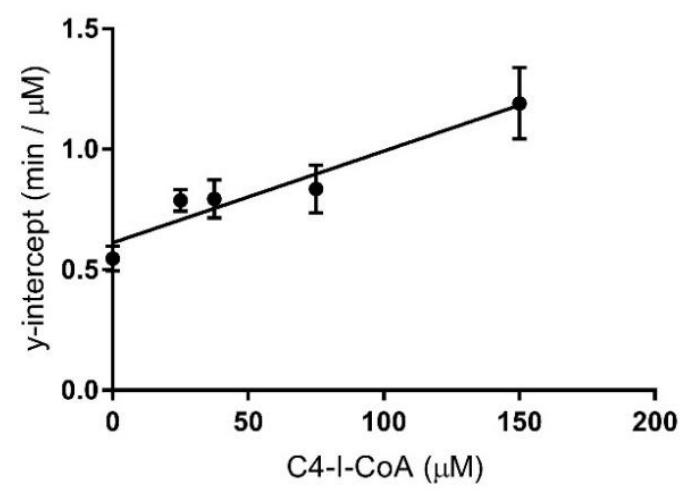

Isopentyl-CoA Intercept Secondary Plot

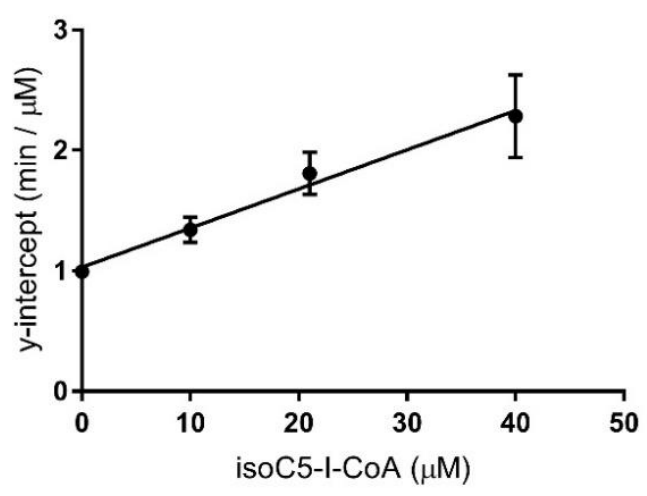

Octyl-CoA Intercept Secondary Plot

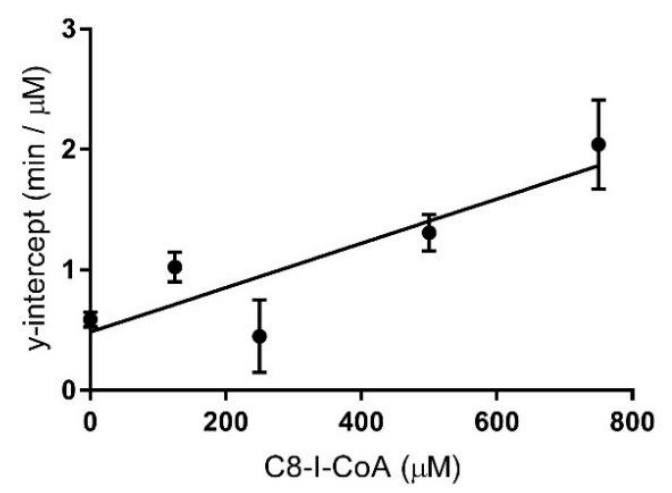

Figure 31 Secondary plot of intercept effects. By plotting the y-intercept against inhibitor concentrations, it was confirmed that there was or was not a significant intercept effect, validated by t-tests. The only secondary plot that did not show significant slope effect was isobutyl-CoA. 
Isobutyl-CoA Slope Secondary Plot

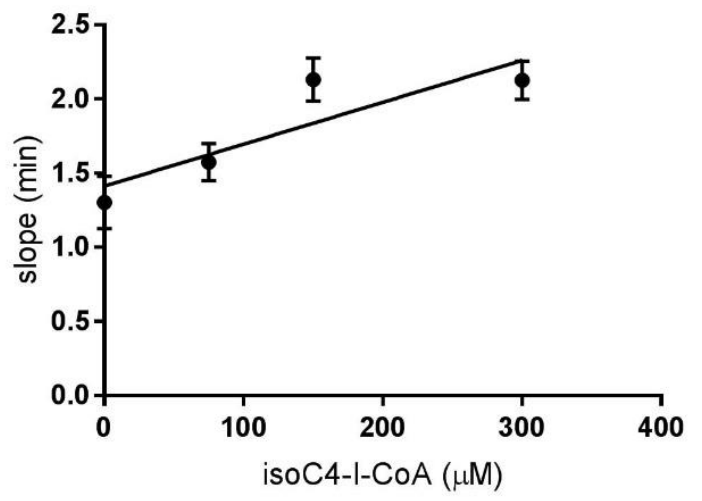

Pentyl-CoA Slope Secondary Plot

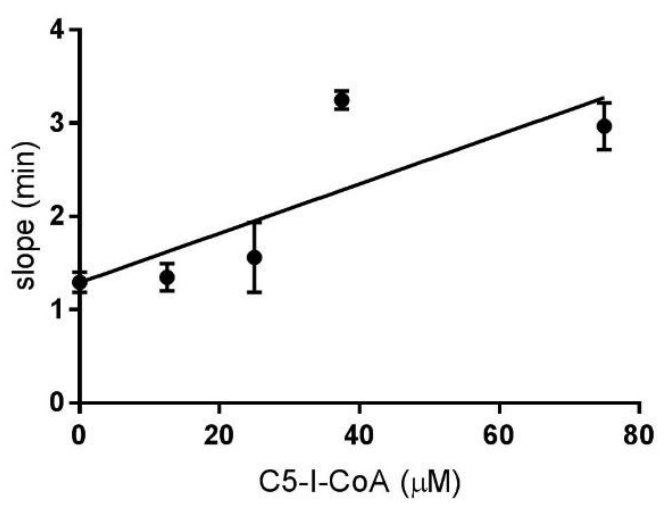

Hexyl-CoA Slope Secondary Plot

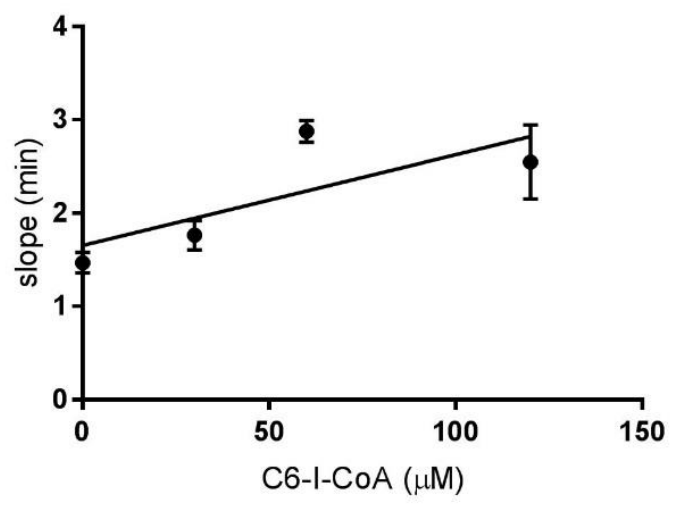

Butyl-CoA Slope Secondary Plot

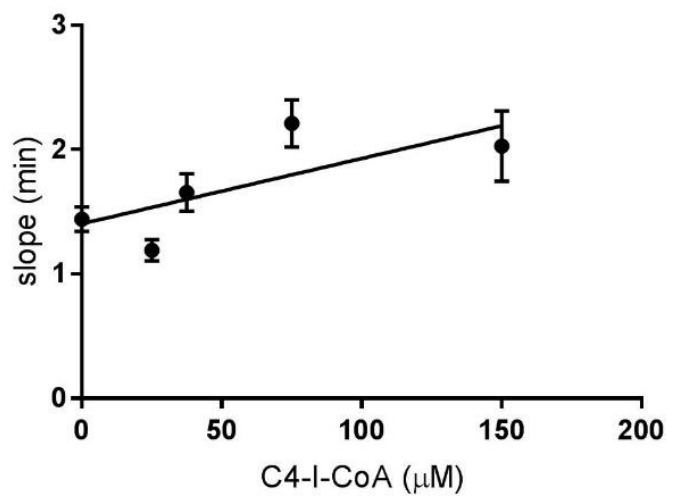

Isopentyl-CoA Slope Secondary Plot

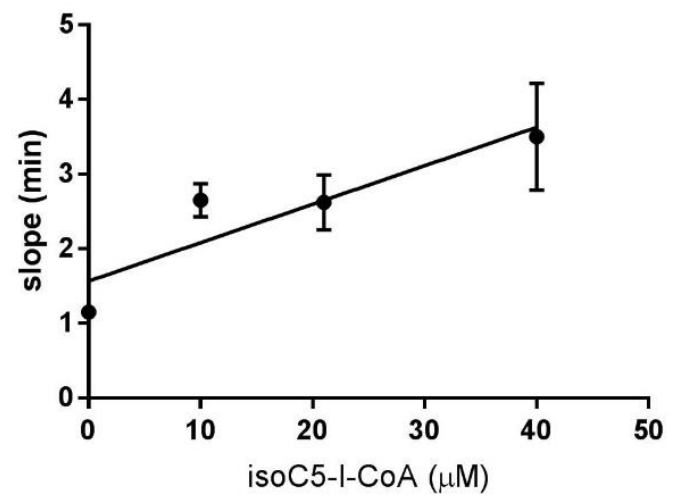

Octyl-CoA Slope Secondary Plot

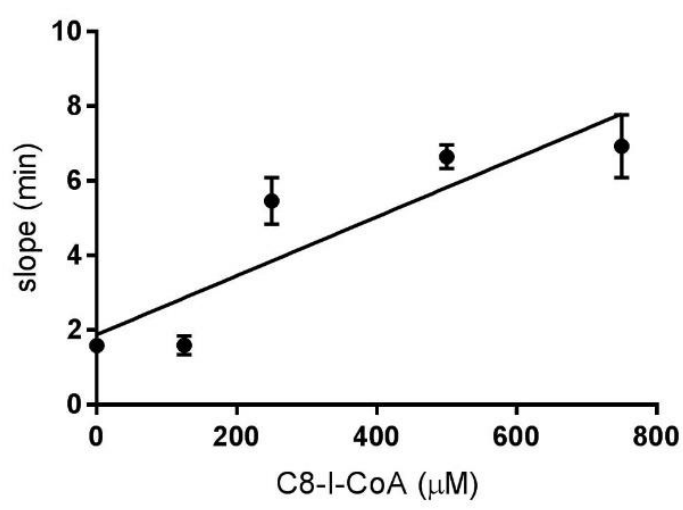

Figure 32 Secondary plots of slope effect. To confirm if there was a significant change in slope, slope was plotted against inhibitor concentration and analyzed using t-tests. 
Even though the alkyl-CoA's were synthesized as substrate analogs, mixed inhibition was observed for all inhibitors. The $K_{\mathrm{i}}$ values are due to isovaleryl-CoA and the alkyl-CoA competitively binding for the same enzyme form. Since the order of substrate addition is unknown, this could be occuring with the enzyme or [Enzyme-SAM] complex (Scheme 1). It is predicted that $K_{\mathrm{i}}$ ' can represent a few different or even a combination of different enzyme-inhibitor complexes: [Enzyme-Inhibitor] or [Enzyme-IsovalerylCoA.Inhibitor] complex where the inhibitor could be binding in the SAM binding pocket and [Enzyme-product.Inhibitor] complex where the inhibitor could be binding in either the MTA and / or CoA product pocket.

Scheme 1 is used to help explain which complexes are possible for the inhibitor to bind and does not necessarily portray the enzyme mechanism; the mechanism is still unknown. A possible explanation for why the alkyl-CoAs are binding to multiple enzyme forms is because the inhibitors have a common structure (adenosine) to SAM, CoA and MTA which may allow the alkyl-CoA to bind to any of these pockets (Figure 33). This is supported by the observation of substrate inhibition at high concentrations (Figure 27), where IV-CoA could be binding to the MTA and / or CoA product binding pocket. Further studies are necessary to determine which enzyme form the inhibitor is binding with respect to $K_{\mathrm{i}}$. One that is currently in progress is fluorescence quenching with SAM and isovalerylCoA where $K_{\mathrm{d}}$ can be determined. If $K_{\mathrm{d}}$ for isovaleryl-CoA is larger with SAM than it is without SAM, then this indicates that isovaleryl-CoA binds first. If isovaleryl-CoA binds first, then $K_{\mathrm{i}}$ is the dissociation constant for the inhibitor binding directly with BjaI. If the reverse is found, then $K_{\mathrm{i}}$ is the dissociation constant for the inhibitor binding with the 
[Enzyme-SAM] complex. In either scenario, $K_{\mathrm{i}}$ is the dissociation constant for inhibitor binding to the same enzyme form that binds the acyl-CoA substrate. 


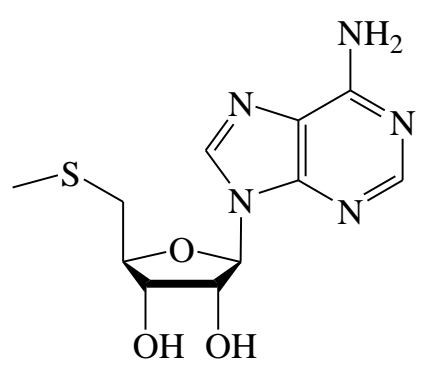

MTA<smiles>C[Si](CC[C@H]([NH3+])C(=O)O)CC1OC2C(O)C1OC(n1cnc3c(N)ncnc31)C2O</smiles>

SAM<smiles>CC(C)CCSCCNC(=O)CCNC(=O)C(O)C(C)(C)COP(=O)([O-])OP(=O)([O-])OCC1OC2OC1C(O)C2n1cnc2c(N)ncnc21</smiles>

Figure 33 Common structure between substrates and products for BjaI. MTA, SAM, and the alkyl-CoAs all have a nucleotide base structure present in the molecule. This could allow for the alkyl-CoA to bind not only to the acyl-CoA binding pocket, but also to the SAM and MTA binding pockets as well, resulting in mixed inhibition.

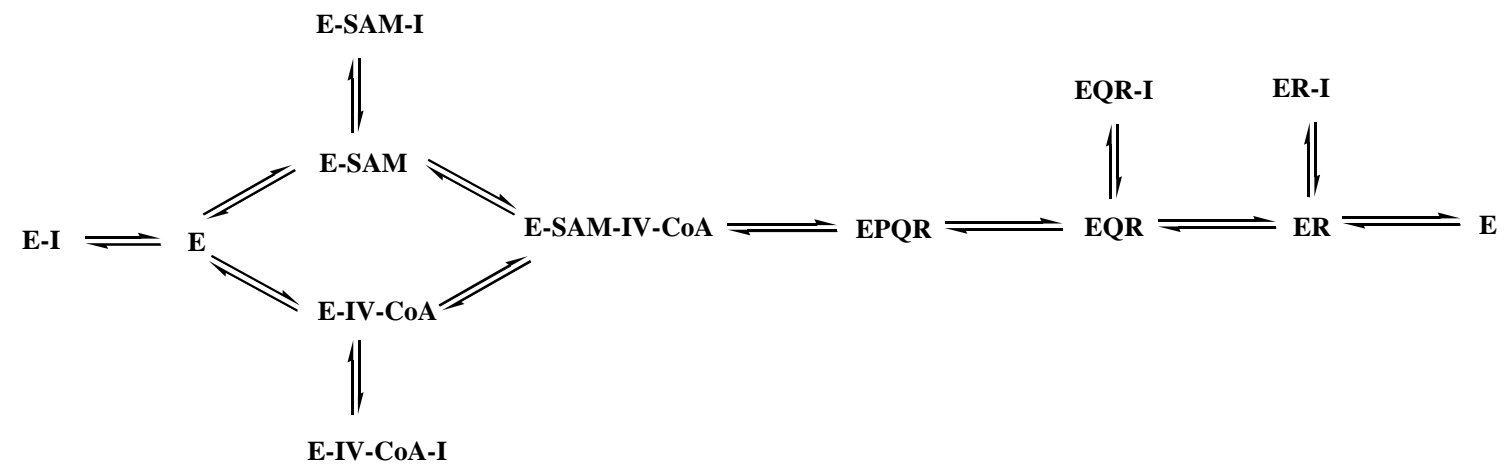

Scheme 1 Representative kinetic scheme showing possible enzyme forms for inhibitor binding. It is feasible for the alkyl-CoA inhibitors to bind to multiple enzyme forms, resulting in mixed inhibition. (This scheme is used solely to help explain which complexes are possible for the inhibitor to bind and does not necessarily portray the enzyme mechanism). $K_{\mathrm{i}}$ would result when the inhibitor and IV-CoA are binding to the same form of the enzyme, which could be $E$ or the E-SAM complex. The $K_{i}^{\prime}$ would mostly comprise of the inhibitor binding to the EQR or ER complex. (P, Q, and R can represent MTA, IV-HSL, or CoA) or it is possible that the inhibitor binds to the EIV-CoA complex. 
Prism 6.0 (equation 9) was used to determine the $K_{\mathrm{i}}$ values for various substrate analog inhibitors to measure the approximate binding affinities of their corresponding acylCoA to BjaI. Isopentyl-CoA, which is the substrate analog to the native substrate, has a $K_{\mathrm{i}}$ of $14 \pm 5 \mu \mathrm{M}$, whereas the worst detectable inhibitor, isobutyl-CoA, has a $K_{\mathrm{i}}$ of $259 \pm 87$ $\mu \mathrm{M}$ (Table 4 and Figure 34). The difference in binding affinity between isopentyl-CoA and isobutyl-CoA is approximately a 20-fold decrease, which is greater than the 7-fold decrease observed for the $k_{\text {cat }}$ values. Interestingly, pentyl-CoA has the same binding affinity to BjaI as its isomer, isopentyl-CoA. One possible explanation for why both alkyl-CoAs have the same approximate binding affinity is because these have the same number of carbons and therefore have similar hydrophobic interactions within the binding pocket. What separates valeryl-CoA as a worse substrate than isovaleryl-CoA is the decrease in $k_{\text {cat. }}$ Since valerylCoA has a longer straight chain length, the carbonyl group might not be positioned correctly for the amine group in SAM to do a nucleophilic attack, thus resulting in a decrease in catalysis (Figure 7). Another substrate analog that had similar binding affinity is butyl-CoA $\left(K_{\mathrm{i}}=62 \pm 14\right.$, a 4.4-fold increase $)$ and, on top of that, the $k_{\text {cat }}$ was within error of each other. This suggests that BjaI only has a modest preference for the branched substrate over the straight chain analog.

Table 4 Kinetic constants determined from Prism using the mixed inhibition model

\begin{tabular}{|c|c|c|c|c|c|}
\hline Inhibitor & $\boldsymbol{K}_{\mathbf{i}}(\boldsymbol{\mu M})$ & $\begin{array}{c}\text { Fold } \\
\text { increase }\end{array}$ & $\boldsymbol{K}_{\mathbf{i}}^{\prime}(\boldsymbol{\mu M})$ & $\begin{array}{c}\text { Fold } \\
\text { increase }\end{array}$ & $\begin{array}{c}\boldsymbol{K}_{\mathbf{i}}^{\prime} / \boldsymbol{K}_{\mathbf{i}} \\
\text { ratio }\end{array}$ \\
\hline Isopentyl-CoA & $14 \pm 5$ & - & $137 \pm 106$ & - & 9.8 \\
\hline Pentyl-CoA & $14 \pm 3$ & 1 & $162 \pm 85$ & 1.2 & 11.6 \\
\hline Butyl-CoA & $62 \pm 14$ & 4.4 & $746 \pm 397$ & 5.4 & 12.0 \\
\hline Isobutyl-CoA & $259 \pm 87$ & 18.5 & $561 \pm 337$ & 4.1 & 2.2 \\
\hline Hexyl-CoA & $51 \pm 18$ & 3.6 & $284 \pm 197$ & 2.1 & 5.6 \\
\hline Octyl-CoA & $105 \pm 24$ & 7.5 & $737 \pm 343$ & 5.4 & 7.0 \\
\hline
\end{tabular}




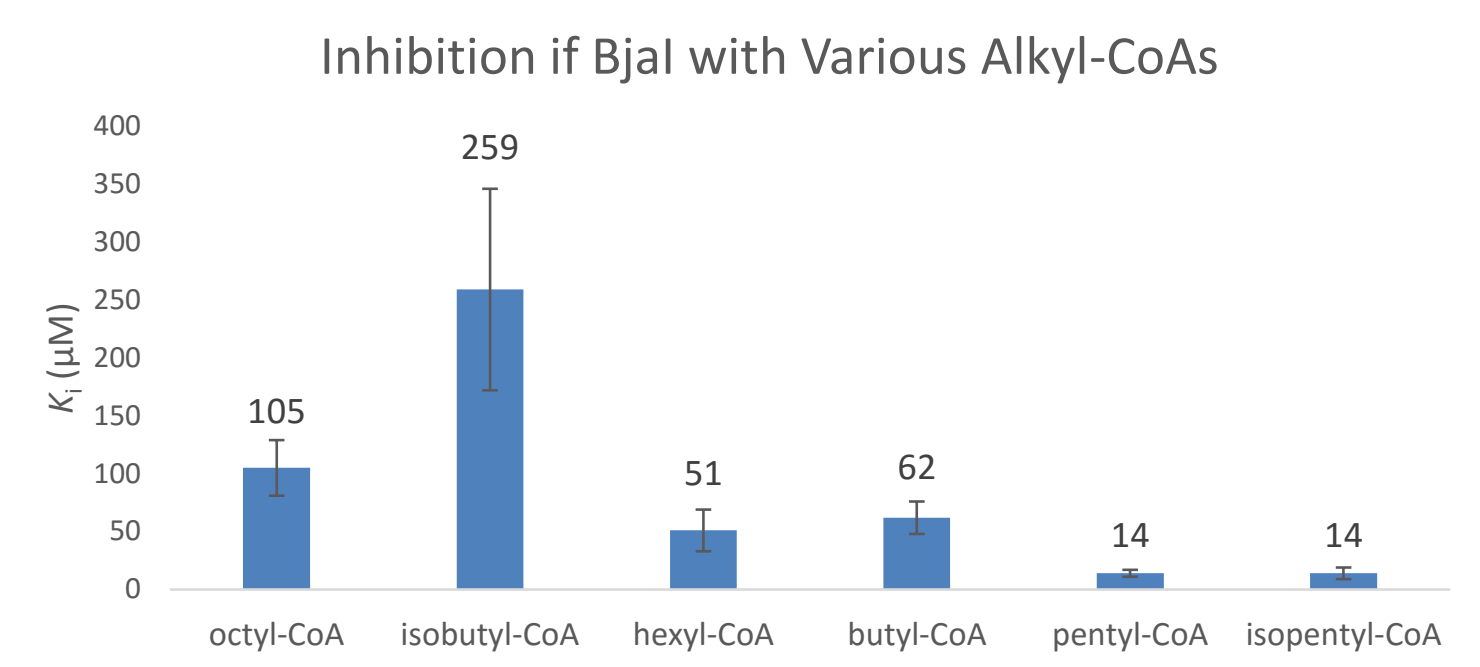

Figure 34 Bar graph of inhibition constants for various alkyl-CoAs. Ethyl- and propyl-CoA were also studied, but these were such poor inhibitors that the $K_{\mathrm{i}}$ values could not be determined. Variation in the $K_{\mathrm{i}}$ values are more prominent than in $\boldsymbol{k}_{\text {cat }}$, with the exception of pentyl-CoA.

The binding affinity of longer and shorter alkyl-chains show that BjaI does differentiate between too short and too long alkyl-CoAs. Hexyl-CoA and octyl-CoA have larger $K_{\mathrm{i}}$ values in comparison to isopentyl-CoA, indicating the binding affinities of these alkyl-CoAs have decreased. When comparing the longer alkyl-chains (hexyl and octyl) to the shorter chains (ethyl, propyl, isobutyl), the longer alkyl-chains bind better. For all alkylCoAs, $\mathrm{IC}_{50}$ s were measured to get an approximate $K_{\mathrm{i}}$ before moving into inhibition studies, but for ethyl-CoA and propyl-CoA it took millimolar concentrations to reduce the rate by even $50 \%$. Therefore, these were such poor inhibitors that inhibition studies were not performed on either of these. Originally, we hypothesized that shorter alkyl-CoAs would be able to bind because they have room in the acyl-binding pocket whereas the longer chains would not fit. Therefore, computational studies were done to gain a better understanding of why shorter alkyl-CoAs were such poor inhibitors.

By using computational methods, theoretical change in Gibbs free energy $(\Delta G)$ were calculated for all alkyl-CoAs. The shortest alkyl-CoAs, ethyl- and propyl-CoA, 


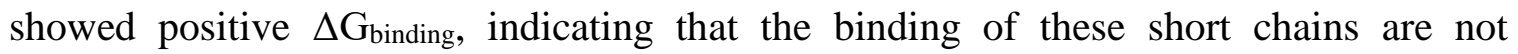
energetically favorable. One possible explanation for why the binding was so poor for the shorter chains is because these have too many degrees of freedom and consequently does not bind well within the acyl-binding pocket. Since the alkyl-chain is not locked down into the acyl-pocket, it disrupts the binding of the pantetheine linker and the CoA as well (Figure 35C). For the longer alkyl-chains, like hexyl-CoA and octyl-CoA, the binding of the alkylchain was sufficient enough to not disrupt the binding of the pantetheine linker and the CoA, which is one possibility for why these were better inhibitors than the short alkylchains. However, these alkyl-chains are too long to fit into the acyl-binding pocket, which forced them to bind to an alternative pocket (Figure 35B). This still allows for sufficient hydrophobic interactions to occur between the alkyl-chain and the hydrophobic amino acids, but it is not ideal.
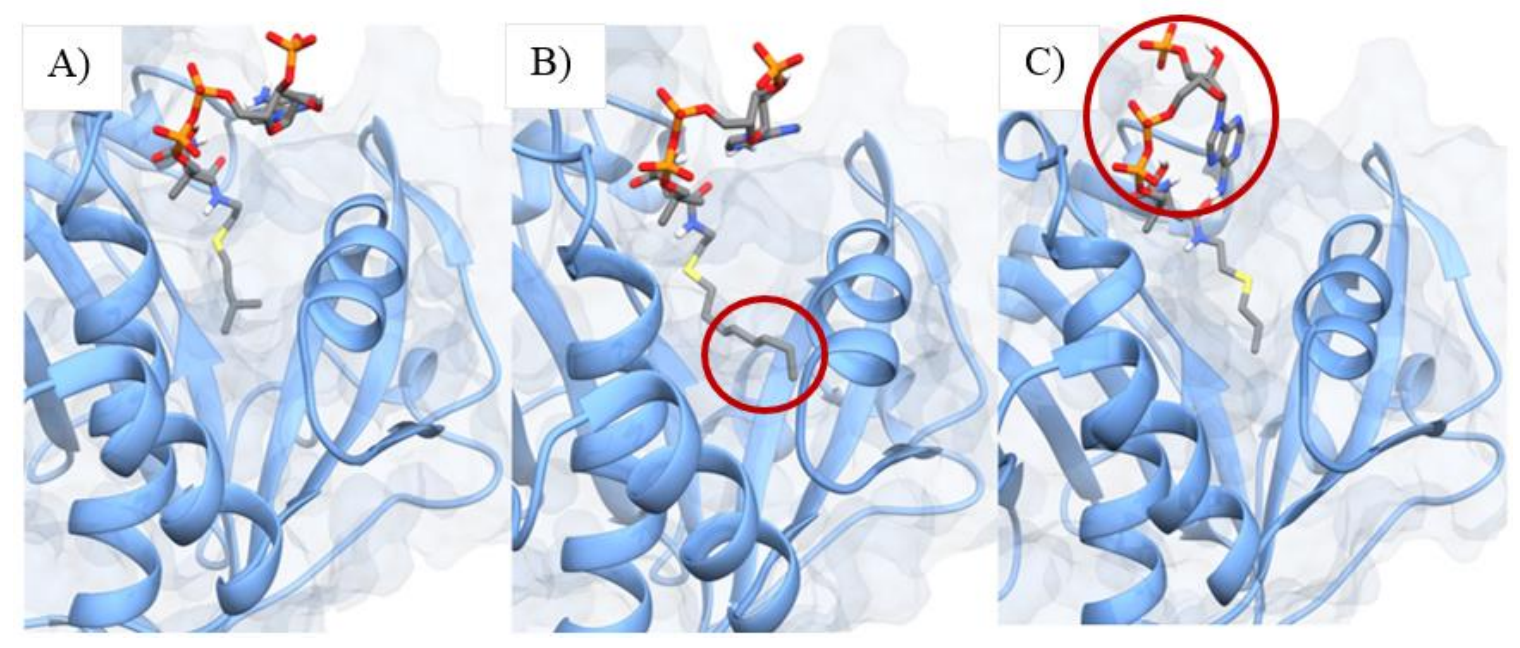

Figure 35 BjaI bound with various alkyl-CoAs. A) Isopentyl-CoA fits snug into the acyl-binding pocket of BjaI whereas $\mathrm{B}$ ) octyl-CoA is too long and finds an alternative pocket (circled), thus increasing $K_{\text {i. }}$ C) Propyl-CoA starts off in the acylbinding pocket, but because the alkyl-chain is only three carbons long, there are not enough interactions with the alkyl-chain and the binding pocket to stabilize it. This results in disrupted interactions between $\mathrm{BjaI}$ and the rest of the substrate (circled) and it eventually dissociates. 


\section{Conclusion}

In conclusion, BjaI predominately differentiates between native and non-native substrates at the binding step. Shorter chains did not bind well at all and this could be due to a lack of hydrophobic interactions occuring within the acyl-binding pocket that holds the alkyl-chain in place. Without the alkyl-chain secured in the binding pocket, this causes disruption in the binding with the pantetheine linker and CoA. Longer alkyl-chains, like hexyl- and octyl-CoA, can still bind within the pocket allowing the linker and CoA to bind well. However, the alkyl-chains have to find room in between amino acids since the pocket is not deep enough to accommodate the longer chain. For similar acyl-CoAs, it seems that BjaI uses a combination of both the binding and catalysis steps to help differentiate between acyl-CoA substrates. Even though the inhibitors are substrate analogs, all of the alkyl-CoAs showed mixed inhibition, except isobutyl-CoA. The inhibitor, SAM, MTA, and CoA all have a similar structure, the adenosine, which then allowed the inhibitor to bind to multiple enzyme forms. This is supported by substrate inhibition observed in substrate-velocity curves with IV-CoA. 


\section{THESIS CONCLUSION}

AHL synthases have potential as antibacterial therapeutics, but designing synthase inhibitors have been complicated with the lack of detailed mechanistic characterization of these enzymes. BjaI, an acyl-homoserine lactone synthase found in Bradyrhizobium japonicum, was studied for substrate recognition. Ideally, while performing these studies, it would be best to use a purer SAM sample than what is commercially available at this time. This is because AHL synthases already have low enzyme rates and, on top of that, SAM degrades into products, which may lead to unwanted product inhibition. When SAM was synthesized in our lab, there was not any difference in the enzyme rates in comparison to commercially available SAM. Therefore, substrate recognition studies were continued with Sigma SAM.

Single point BjaI active site mutants were evaluated for detrimental effects in the enzyme's ability to recognize and catalyze isovaleryl-CoA and SAM. Our studies demonstrate that the entire substrate binding pocket (both acyl-CoA and SAM) in BjaI is optimized for specific recognition of native, isovaleryl-CoA substrate. Furthermore, enzyme mutants that lead to the formation of a less-productive, nonoptimal ternary complex were found to be defective in recognizing the native isovaleryl-CoA substrate. In conclusion, the decreased catalytic efficiency for every mutant in this substrate recognition pocket signifies the importance of this amino acid cluster towards the formation of a productive enzyme-substrate ternary complex, conducive for catalysis. 
To determine if BjaI is selectively binding to its specific acyl-CoA substrate, $k_{\text {cat }}$ and $K_{\mathrm{i}}$ values were measured of various acyl-CoAs and alkyl-CoAs, respectively. For alkyl-chains that were either too short or too long, BjaI predominately differentiates between native and non-native substrates at the binding step. However, with similar acylCoAs, BjaI relies on both the binding and catalysis steps to recognize its native substrate. Even though the inhibitors are substrate analogs, all but one of the alkyl-CoAs showed mixed inhibition; this is probably due to the inhibitor, SAM, MTA, and CoA sharing a common adenosine moiety in their structures. This hypothesis is also supported by substrate inhibition that was observed in substrate-velocity curves with isovalerylCoA.This thesis is the first systematic investigation on the molecular basis of acyl-substrate recognition in an acyl-homoserine lactone synthase. The tools used in this study can be broadly applied to conduct mechanistic investigations in other AHL synthases to discover quorum sensing specific inhibitors. 


\section{REFERENCES}

1. Sharma, V. K.; Johnson, N.; Cizmas, L.; McDonald, T. J.; Kim, H., A review of the influence of treatment strategies on antibiotic resistant bacteria and antibiotic resistance genes. Chemosphere 2016, 150, 702-714.

2. Hwang, I. Y.; Koh, E.; Kim, H. R.; Yew, W. S.; Chang, M. W., Reprogrammable microbial cell-based therapeutics against antibiotic-resistant bacteria. Drug Resistance Updates 2016, 27, 59-71.

3. Waters, C. M.; Bassler, B. L., Quorum sensing: cell-to-cell communication in bacteria. Annu. Rev. Cell Dev. Biol. 2005, 21, 319-46.

4. Costerton, J. W.; Stewart, P. S.; Greenberg, E. P., Bacterial biofilms: a common cause of persistent infections. Science 1999, 284 (5418), 1318-22.

5. Parker, C. T.; Sperandio, V., Cell-to-cell signalling during pathogenesis. Cell Microbiol. 2009, 11 (3), 363-9.

6. Costerton, W.; Veeh, R.; Shirtliff, M.; Pasmore, M.; Post, C.; Ehrlich, G., The application of biofilm science to the study and control of chronic bacterial infections. J. Clin. Invest 2003, 112 (10), 1466-77.

7. Davey, M. E.; O'Toole G, A., Microbial biofilms: from ecology to molecular genetics. Microbiol. Mol. Biol. Rev. 2000, 64 (4), 847-67.

8. Smith, K. M.; Bu, Y.; Suga, H., Library screening for synthetic agonists and antagonists of a Pseudomonas aeruginosa autoinducer. Chem. Biol. 2003, 10 (6), 563 71. 
9. Reimmann, C.; Ginet, N.; Michel, L.; Keel, C.; Michaux, P.; Krishnapillai, V.; Zala, M.; Heurlier, K.; Triandafillu, K.; Harms, H.; Defago, G.; Haas, D., Genetically programmed autoinducer destruction reduces virulence gene expression and swarming motility in Pseudomonas aeruginosa PAO1. Microbiology 2002, 148 (Pt 4), 923-32.

10. Parlet, C. P.; Kavanaugh, J. S.; Crosby, H. A.; Cech, N. B.; Oberlies, N. H.; Horswill, A. R., Apicidin mediated attenuation of MRSA virulence corresponds with quorum sensing inhibition and enhanced immune effector responses. J. Immunol. 2016, 196 (1 Supplement), 206.3-206.3.

11. Finch, R. G.; Pritchard, D. I.; Bycroft, B. W.; Williams, P.; Stewart, G. S., Quorum sensing: a novel target for anti-infective therapy. J. Antimicrob. Chemother. 1998, 42 (5), 569-71.

12. Nealson, K. H.; Platt, T.; Hastings, J. W., Cellular Control of the Synthesis and Activity of the Bacterial Luminescent System. J. Bacteriol. 1970, 104 (1), 313-322.

13. Jones, B. W.; Nishiguchi, M. K., Counterillumination in the Hawaiian bobtail squid, Euprymna scolopes Berry (Mollusca: Cephalopoda). Marine Biology 2004, 144 (6), 1151-1155.

14. Visick, K. L.; Foster, J.; Doino, J.; McFall-Ngai, M.; Ruby, E. G., Vibrio fischeri lux Genes Play an Important Role in Colonization and Development of the Host Light Organ. J. Bacteriol. 2000, 182 (16), 4578-4586.

15. Fuqua, W. C.; Winans, S. C.; Greenberg, E. P., Quorum sensing in bacteria: the LuxR-LuxI family of cell density-responsive transcriptional regulators. J. Bacteriol. 1994, $176(2), 269-275$. 
16. Miller, M. B.; Bassler, B. L., Quorum Sensing in Bacteria. Annu. Rev. Microbiol. 2001, 165-199.

17. Costa, E. D.; Chai, Y.; Winans, S. C., The quorum-sensing protein TraR of Agrobacterium tumefaciens is susceptible to intrinsic and TraM-mediated proteolytic instability. Mol. Microbiol. 2012, 84 (5), 807-15.

18. Fuqua, C.; Greenberg, E. P., Listening in on Bacteria: Acyl-homoserine Lactone Signaling. Nat. Rev. Mol. Cell Biol. 2002, 3, 685-695.

19. Bassler, B. L., Small talk. Cell-to-cell communication in bacteria. Cell. 2002, 109, $421-4$.

20. Dunny, G. M.; Leonard, B. A., Cell-cell communication in gram-positive bacteria. Annu. Rev. Microbiol. 1997, 51, 527-64.

21. Rutherford, S. T.; Bassler, B. L., Bacterial quorum sensing: its role in virulence and possibilities for its control. Cold Spring Harb. Perspect Med. 2012, 2 (11), 1-26.

22. Federle, M. J.; Bassler, B. L., Interspecies communication in bacteria. J Clin Invest 2003, $112(9), 1291-9$.

23. Giles, K. L.; Atherly, A. G., Biology of the Rhizobiaceae International Review of Cytology. Elsevier Science,: Burlington, 2013, pp. 1-355. http://boisestate.eblib.com/patron/FullRecord.aspx?p=1817952http://library.boisestat e.edu/link.php?site=EBL.

24. Kaneko, T.; Nakamura, Y.; Sato, S.; Minamisawa, K.; Uchiumi, T.; Sasamoto, S.; Watanabe, A.; Idesawa, K.; Iriguchi, M.; Kawashima, K.; Kohara, M.; Matsumoto, M.; Shimpo, S.; Tsuruoka, H.; Wada, T.; Yamada, M.; Tabata, S., Complete genomic 
sequence of nitrogen-fixing symbiotic bacterium Bradyrhizobium japonicum USDA110. DNA Res. 2002, 9 (6), 189-97.

25. Zahran, H. H., Rhizobium-Legume Symbiosis and Nitrogen Fixation under Severe Conditions and in an Arid Climate. Microbiol. Mol. Biol. Rev. 1999, 63 (4), 968-989.

26. Loh, J.; Stacey, G., Nodulation Gene Regulation in Bradyrhizobium japonicum: a Unique Integration of Global Regulatory Circuits. Appl. Environ. Microbiol. 2003, 69 (1), 10-17.

27. Oldroyd, G. E. D.; Downie, J. A., Calcium, kinases and nodulation signalling in legumes. Nat. Rev. Mol. Cell Biol. 2004, 5 (7), 566-576.

28. Sanchez-Contreras, M.; Bauer, W. D.; Gao, M.; Robinson, J. B.; Allan Downie, J., Quorum-sensing regulation in rhizobia and its role in symbiotic interactions with legumes. Philosophical Transactions of the Royal Society B: Biological Sciences 2007, 362 (1483), 1149-1163.

29. Christensen, Q. H.; Brecht, R. M.; Dudekula, D.; Greenberg, E. P.; Nagarajan, R., Evolution of Acyl-Substrate Recognition by a Family of Acyl-Homoserine Lactone Synthases. PLoS ONE 2014, 9 (11), e112464.

30. Li, Z.; Nair, S. K., Quorum sensing: How bacteria can coordinate activity and synchronize their response to external signals? Protein Science : A Publication of the Protein Society 2012, 21 (10), 1403-1417.

31. Chung, J.; Goo, E.; Yu, S.; Choi, O.; Lee, J.; Kim, J.; Kim, H.; Igarashi, J.; Suga, H.; Moon, J. S.; Hwang, I.; Rhee, S., Small-molecule inhibitor binding to an N-acylhomoserine lactone synthase. PNAS USA 2011, 108 (29), 12089-12094. 
32. Chang, C.-Y.; Krishnan, T.; Wang, H.; Chen, Y.; Yin, W.-F.; Chong, Y.-M.; Tan, L. Y.; Chong, T. M.; Chan, K.-G., Non-antibiotic quorum sensing inhibitors acting against N-acyl homoserine lactone synthase as druggable target. Sci. Rep. 2014, 4, 18.

33. Gould, T. A.; Schweizer, H. P.; Churchill, M. E. A., Structure of the Pseudomonas aeruginosa acyl-homoserinelactone synthase LasI. Molecular Microbiology. 2004, 53 (4), 1135 .

34. Hoffman, J. L., Chromatographic analysis of the chiral and covalent instability of Sadenosyl-L-methionine. Biochemistry 1986, 25 (15), 4444-4449.

35. Montebello, A. N.; Brecht, R. M.; Turner, R. D.; Ghali, M.; Pu, X.; Nagarajan, R., Acyl-ACP Substrate Recognition in Burkholderia mallei BmaI1 Acyl-Homoserine Lactone Synthase. Biochemistry 2014, 53 (39), 6231-6242.

36. Taylor, J. C.; Markham, G. D., The bifunctional active site of s-adenosylmethionine synthetase. Roles of the active site aspartates. J. Biol. Chem. 1999, 274 (46), 3290914.

37. Lin, S.; Cronan, J. E., The BioC O-Methyltransferase Catalyzes Methyl Esterification of Malonyl-Acyl Carrier Protein, an Essential Step in Biotin Synthesis. J. Biol. Chem. 2012, 287 (44), 37010-37020.

38. Shin, D.; Frane, N. D.; Brecht, R. M.; Keeler, J.; Nagarajan, R., A Comparative Analysis of Acyl-Homoserine Lactone Synthase Assays. ChemBioChem 2015, 16 (18), 2651-2659. 
39. Watson, W. T.; Minogue, T. D.; Val, D. L.; von Bodman, S. B.; Churchill, M. E. A., Structural Basis and Specificity of Acyl-Homoserine Lactone Signal Production in Bacterial Quorum Sensing. Molecular Cell 2002, 9 (3), 685-694.

40. Gould, T. A.; Herman, J.; Krank, J.; Murphy, R. C.; Churchill, M. E. A., Specificity of Acyl-Homoserine Lactone Synthases Examined by Mass Spectrometry. $J$. Bacteriol. 2006, 188 (2), 773-83.

41. Dong, S.-H.; Frane, N. D.; Christensen, Q. H.; Greenberg, E. P.; Nagarajan, R.; Nair, S. N., Molecular Basis for the Substrate Specificity of Quorum Signal Synthases. Science, submitted and under review.

42. Hess, B.; Kutzner, C.; van der Spoel, D.; Lindahl, E., GROMACS 4: Algorithms for Highly Efficient, Load-Balanced, and Scalable Molecular Simulation. J. Chem. Theory Comput. 2008, 4 (3), 435-47.

43. Van Der Spoel, D.; Lindahl, E.; Hess, B.; Groenhof, G.; Mark, A. E.; Berendsen, H. J., GROMACS: fast, flexible, and free. J. Comput. Chem. 2005, 26 (16), 1701-18.

44. Berendsen, H. J. C.; van der Spoel, D.; van Drunen, R., GROMACS: A messagepassing parallel molecular dynamics implementation. Comput. Phys. Comm. 1995, 91 (1), 43-56.

45. Sorin, E. J.; Pande, V. S., Exploring the Helix-Coil Transition via All-Atom Equilibrium Ensemble Simulations. Biophys. J. 2005, 88 (4), 2472-2493.

46. DePaul, A. J.; Thompson, E. J.; Patel, S. S.; Haldeman, K.; Sorin, E. J., Equilibrium conformational dynamics in an RNA tetraloop from massively parallel molecular dynamics. Nucleic Acids Res. 2010, 38 (14), 4856-4867. 
47. Duan, Y.; Wu, C.; Chowdhury, S.; Lee, M. C.; Xiong, G.; Zhang, W.; Yang, R.; Cieplak, P.; Luo, R.; Lee, T.; Caldwell, J.; Wang, J.; Kollman, P., A point-charge force field for molecular mechanics simulations of proteins based on condensedphase quantum mechanical calculations. J. Comput. Chem. 2003, 24 (16), 1999-2012.

48. Jorgensen, W. L.; Chandrasekhar, J.; Madura, J. D.; Impey, R. W.; Klein, M. L., Comparison of simple potential functions for simulating liquid water. J. Chem. Phys. 1983, 79 (2), 926-935.

49. Bussi, G.; Donadio, D.; Parrinello, M., Canonical sampling through velocity rescaling. J. Chem. Phys. 2007, 126 (1), 014101.

50. Parrinello, M.; Rahman, A., Polymorphic transitions in single crystals: A new molecular dynamics method. J. Appl. Phys. 1981, 52 (12), 7182-7190.

51. Nosé, S.; Klein, M. L., Constant pressure molecular dynamics for molecular systems. Mol. Phys. 1983, 50 (5), 1055-1076.

52. Hess, B., P-LINCS: A parallel linear constraint solver for molecular simulation. $J$. Chem. Theory Comput. 2008, 4 (1), 116-122.

53. Darden, T.; York, D.; Pedersen, L., Particle mesh Ewald: An N· $\log (\mathrm{N})$ method for Ewald sums in large systems. J. Chem. Phys. 1993, 98 (12), 10089-10092.

54. Essmann, U.; Perera, L.; Berkowitz, M. L.; Darden, T.; Lee, H.; Pedersen, L. G., A smooth particle mesh Ewald method. J. Chem. Phys. 1995, 103 (19), 8577-8593.

55. Wang, J.; Wang, W.; Kollman, P. A.; Case, D. A., Automatic atom type and bond type perception in molecular mechanical calculations. J. Mol. Graph. Model. 2006, 25 (2), 247-260. 
56. Wang, J.; Wolf, R. M.; Caldwell, J. W.; Kollman, P. A.; Case, D. A., Development and testing of a general amber force field. J. Comput. Chem. 2004, 25 (9), 1157-1174.

57. da Silva, A. W. S.; Vranken, W. F., ACPYPE-Antechamber python parser interface. BMC research notes 2012, 5 (1), 367.

58. Pettersen, E. F.; Goddard, T. D.; Huang, C. C.; Couch, G. S.; Greenblatt, D. M.; Meng, E. C.; Ferrin, T. E., UCSF Chimera--a visualization system for exploratory research and analysis. J. Comput. Chem. 2004, 25 (13), 1605-12.

59. Beutler, T. C.; Mark, A. E.; van Schaik, R. C.; Gerber, P. R.; van Gunsteren, W. F., Avoiding singularities and numerical instabilities in free energy calculations based on molecular simulations. Chem. Phys. Lett. 1994, 222 (6), 529-539.

60. Pham, T. T.; Shirts, M. R., Identifying low variance pathways for free energy calculations of molecular transformations in solution phase. J. Chem. Phys. 2011, 135 (3), 034114.

61. Bennett, C. H., Efficient estimation of free energy differences from Monte Carlo data. J. Comput. Chem. 1976, 22 (2), 245-268.

62. Montebello, A. N., Mechanistic and substrate specificity studies on Burkholderia mallei quorum sensing signal synthesis enzyme. Master's Dissertation, Boise State University, Boise, ID. 2014. 


\section{SUPPLEMENTAL INFORMATION}

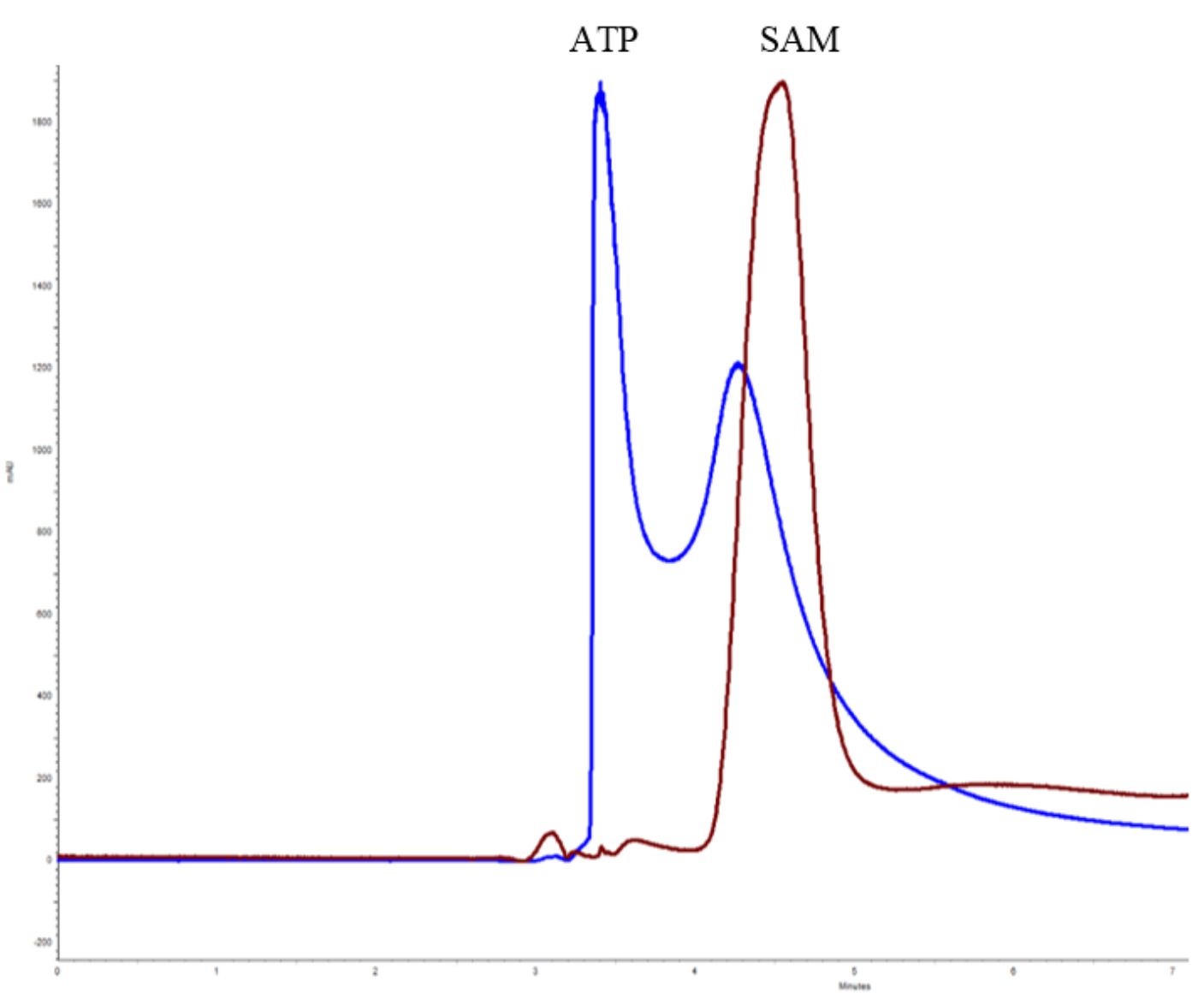

Figure S1 HPLC spectra of ATP and SAM separation. Both ATP and SAM are charged compounds, which makes it difficult to separate on the HPLC. A method was optimized for the separation of the two compounds, where the first peak is ATP (split into two peaks) and the second peak is SAM. 
Mass spectroscopy data was obtained to confirm the expected alkyl-CoA was synthesized (Figures S1 - S8). The expected weights were calculated using ChemDraw.

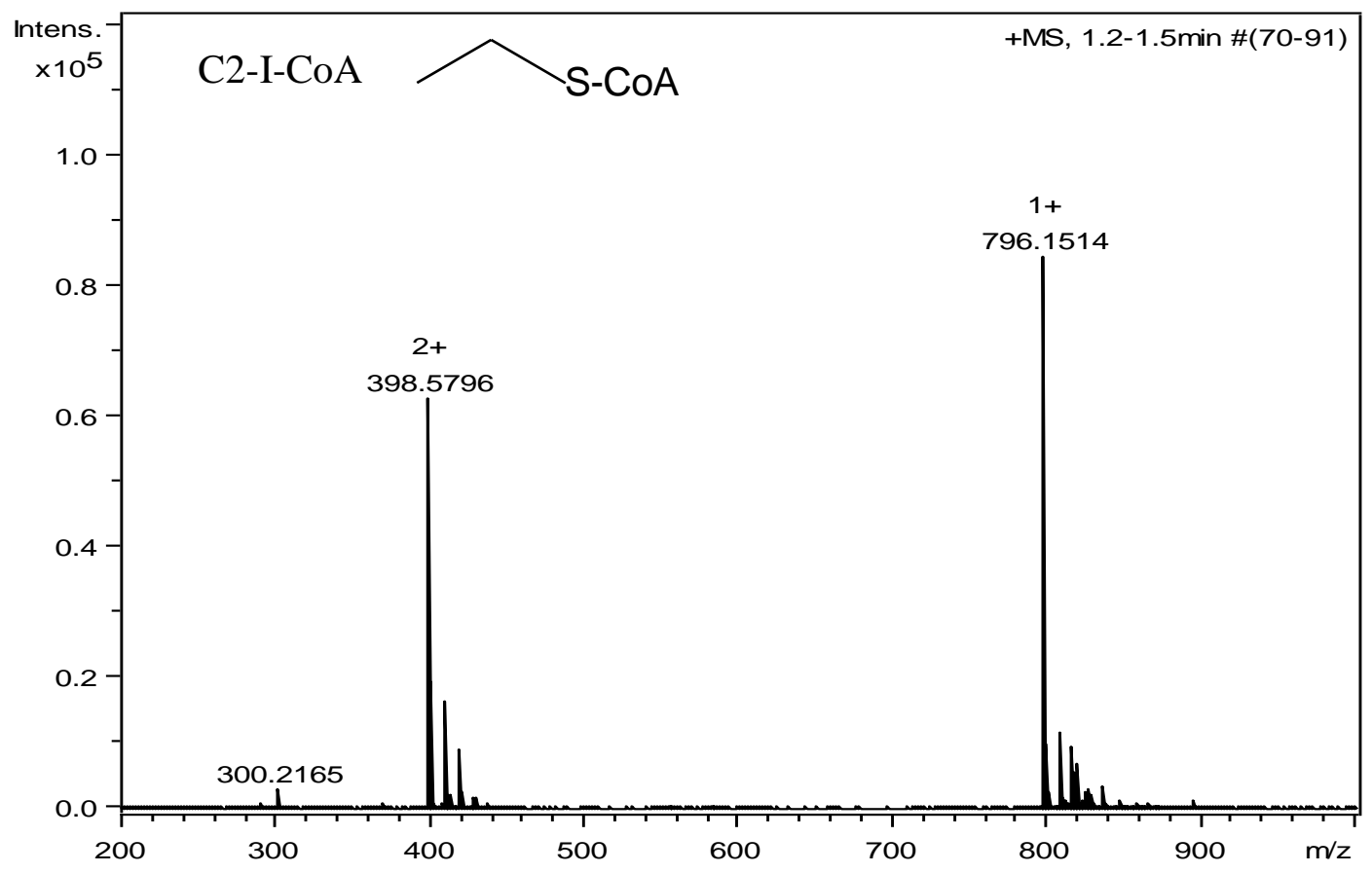

Figure S2 Mass Spec of ethyl-CoA. Expected mass was 796.1465g $/ \mathrm{mol}$.

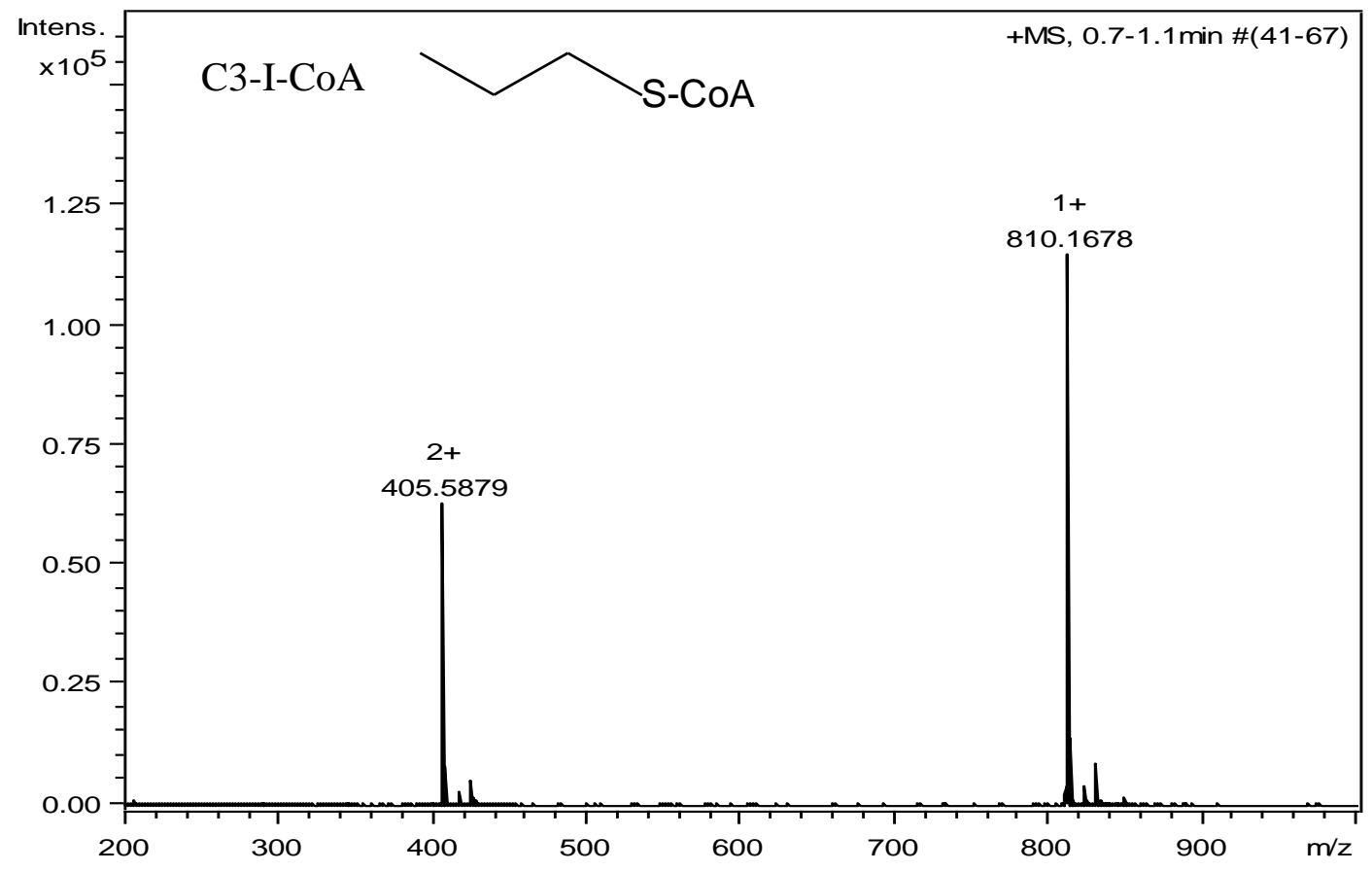

Figure S3 Mass Spec of propyl-CoA. Expected mass was 810.1622 g /mol. 


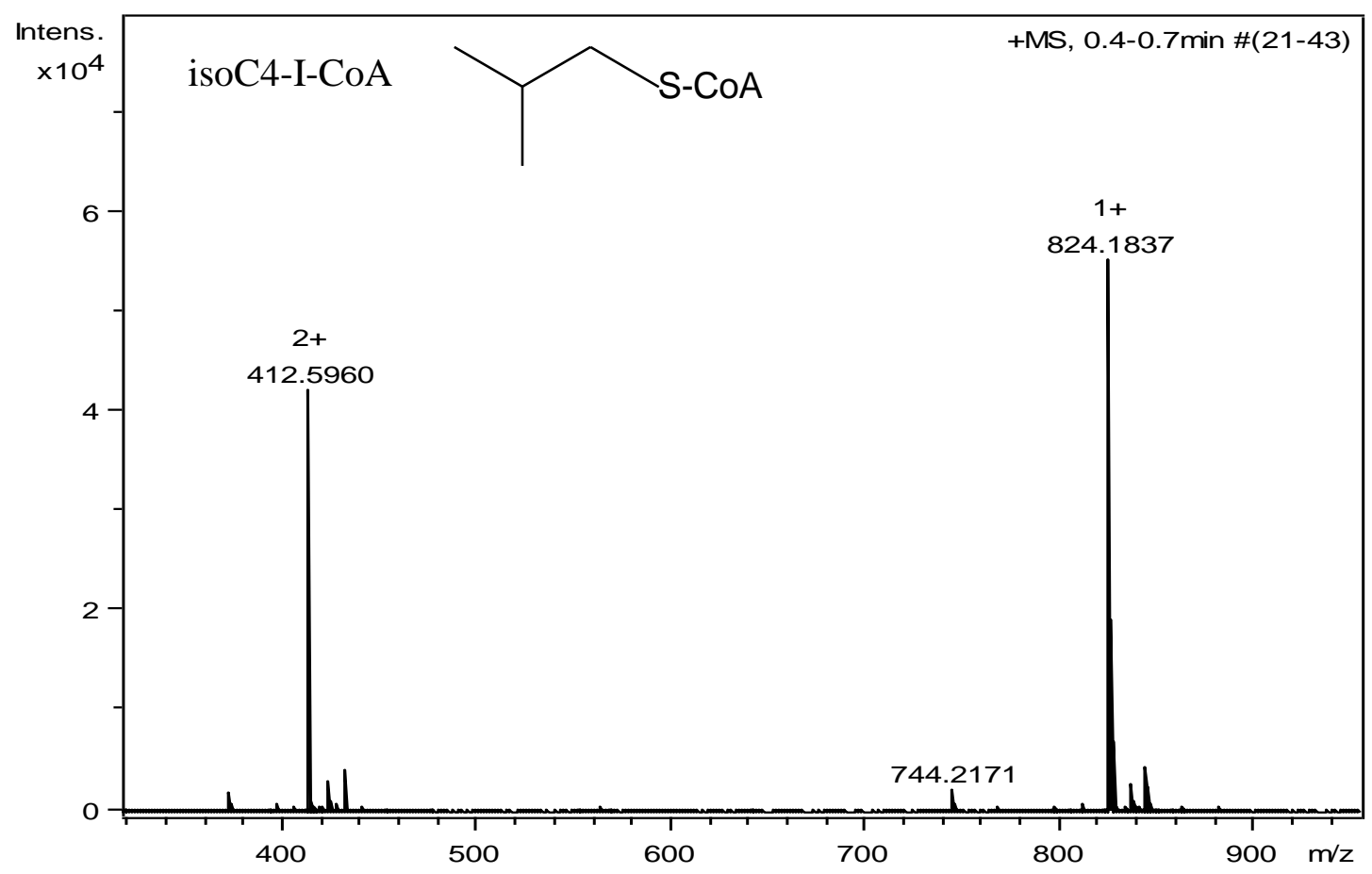

Figure S4 Mass Spec of isobutyl-CoA. Expected mass was $824.1778 \mathrm{~g} / \mathrm{mol}$.

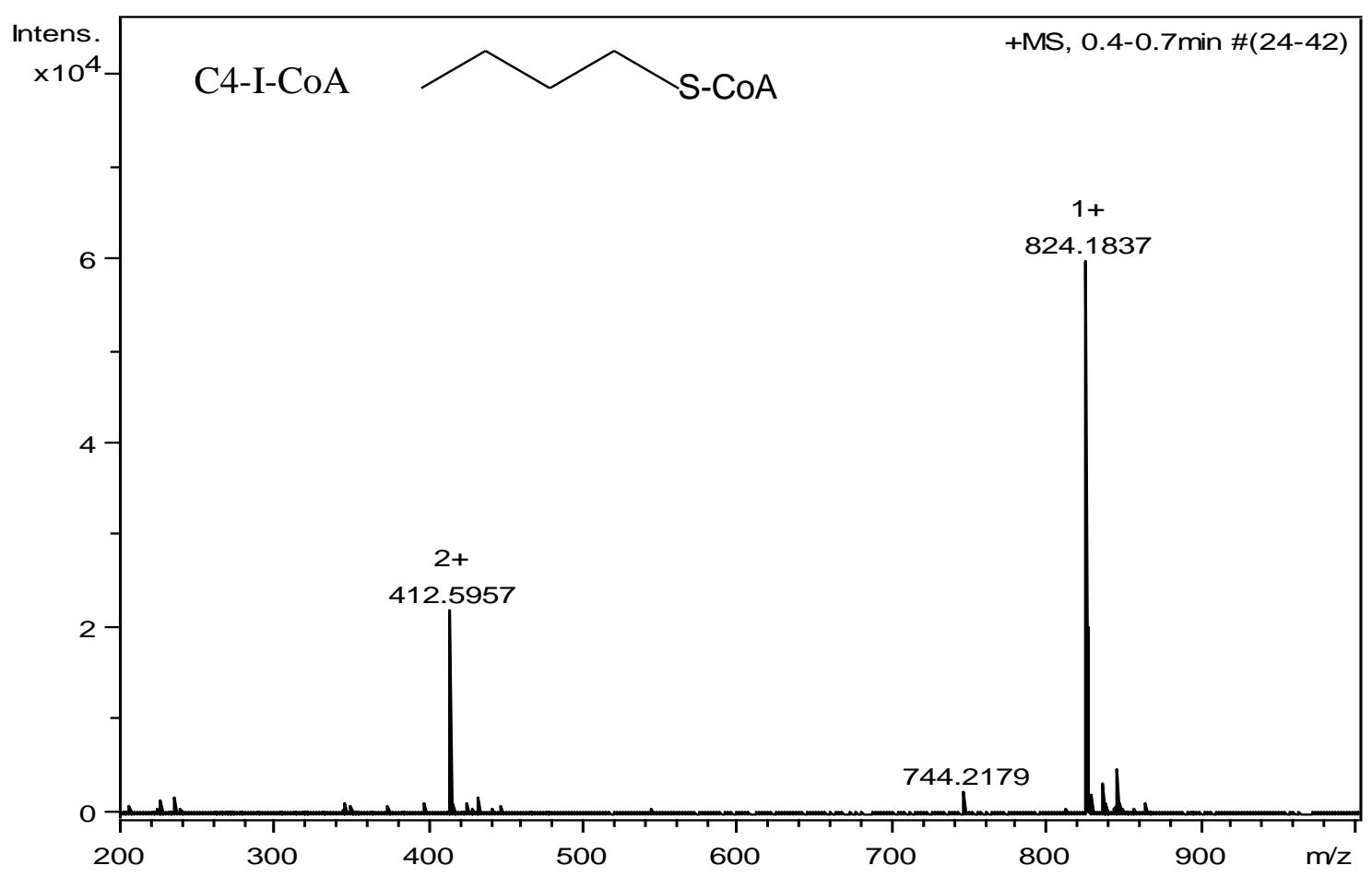

Figure S5 Mass Spec of butyl-CoA. Expected mass was 824.1778 g $/ \mathrm{mol}$. 


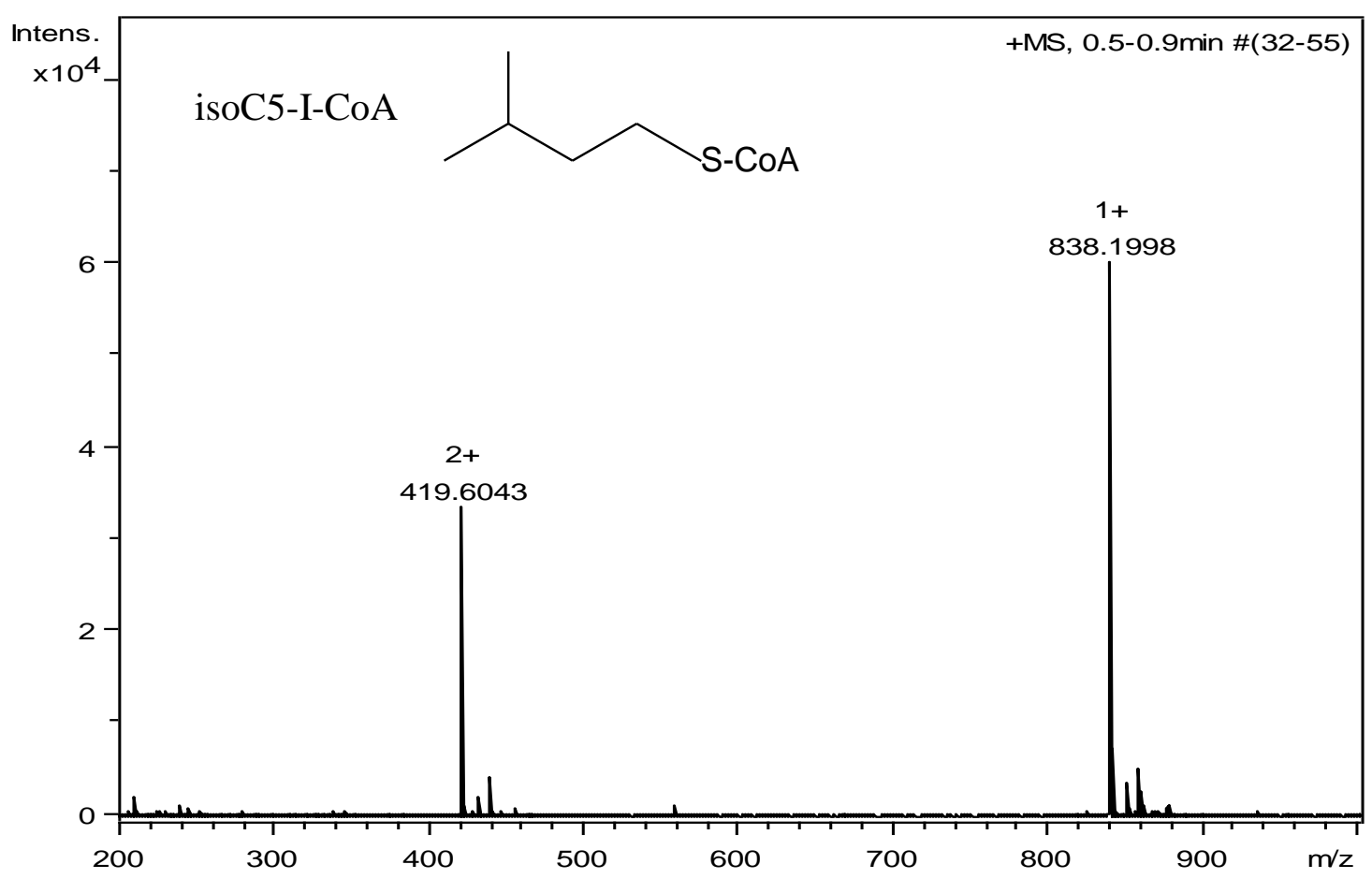

Figure S6 Mass Spec of isopentyl-CoA. Expected mass was $838.1935 \mathrm{~g} / \mathrm{mol}$.

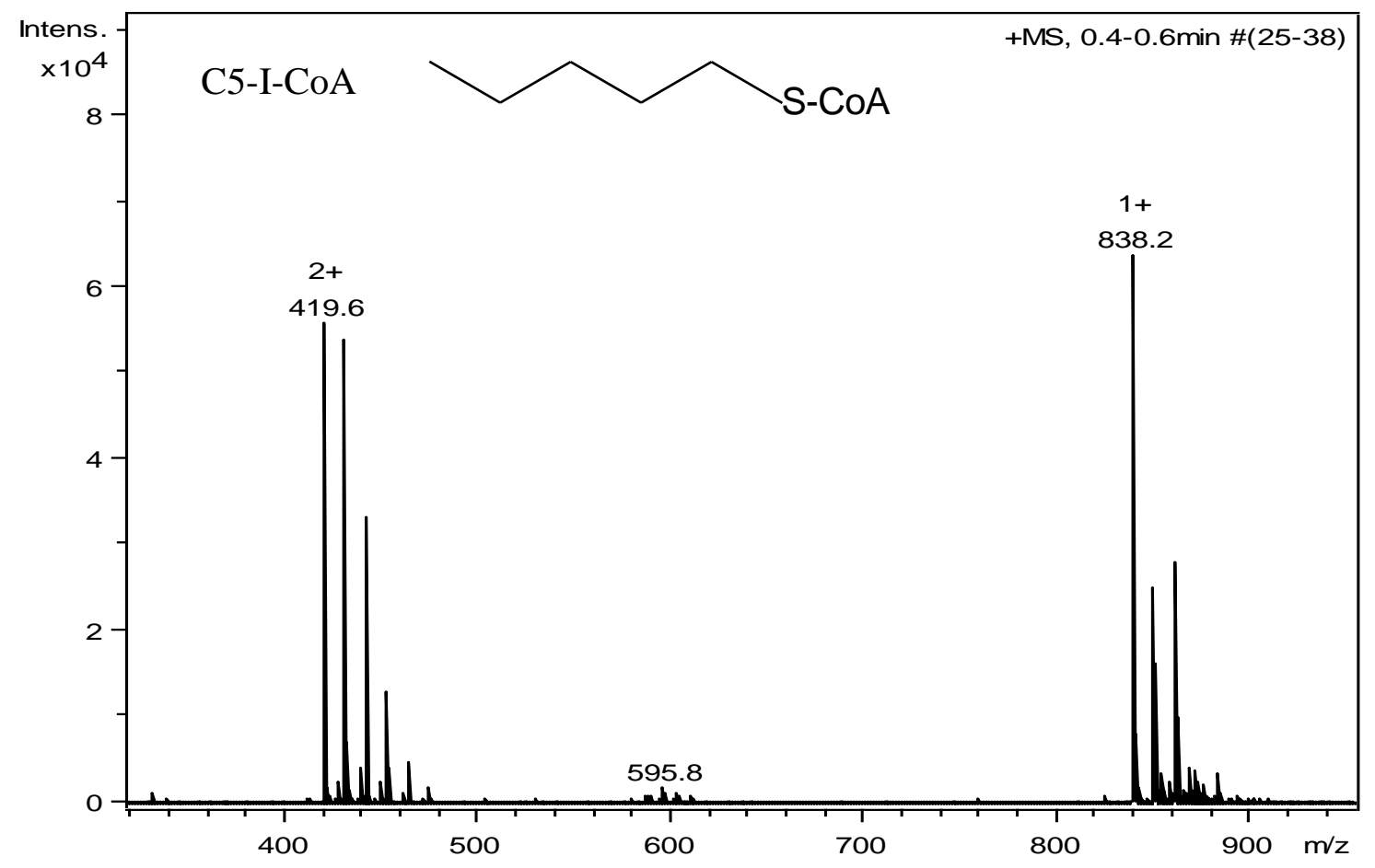

Figure S7 Mass Spec of pentyl-CoA. Expected mass was 838.1935 g /mol. 


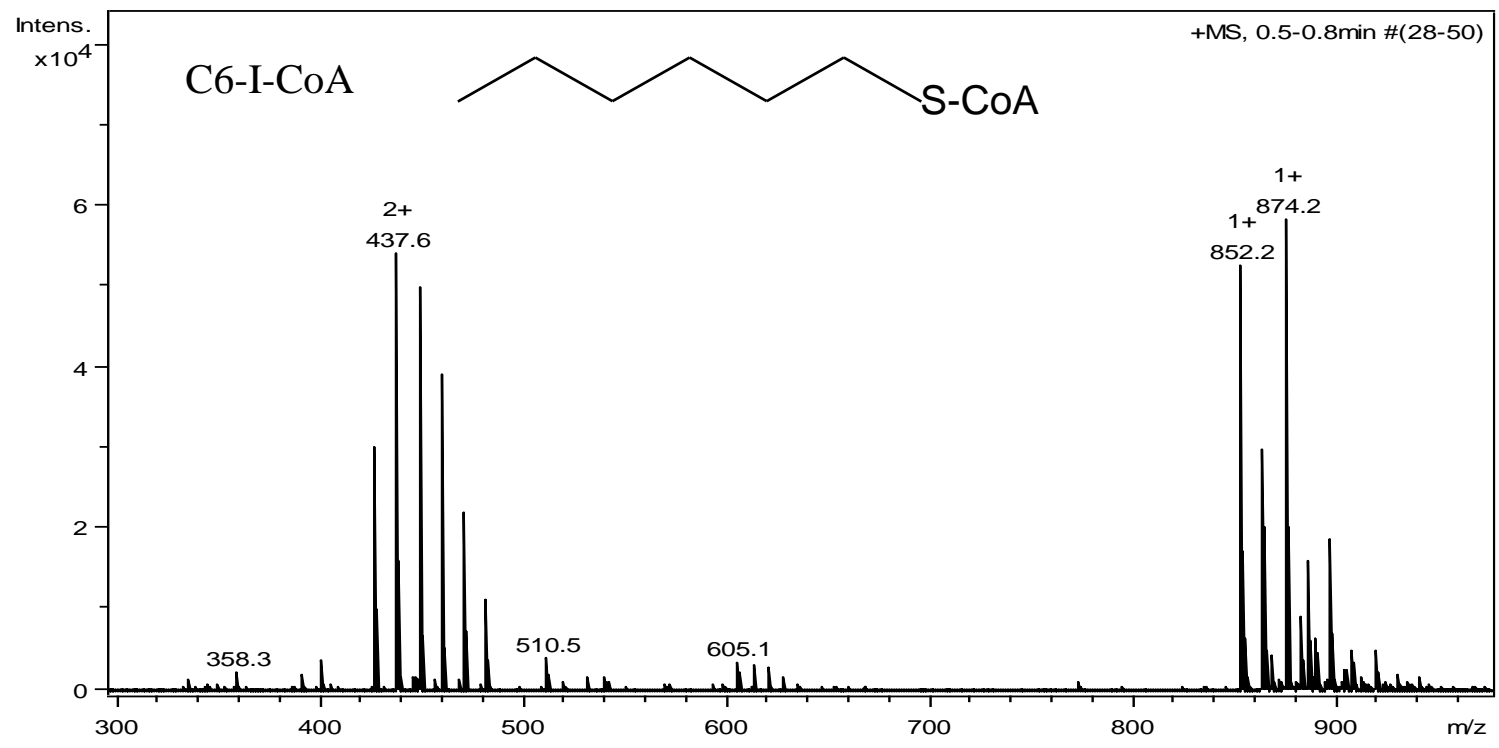

Figure S8 Mass Spec of hexyl-CoA. Expected mass was $852.2163 \mathrm{~g} / \mathrm{mol}$.

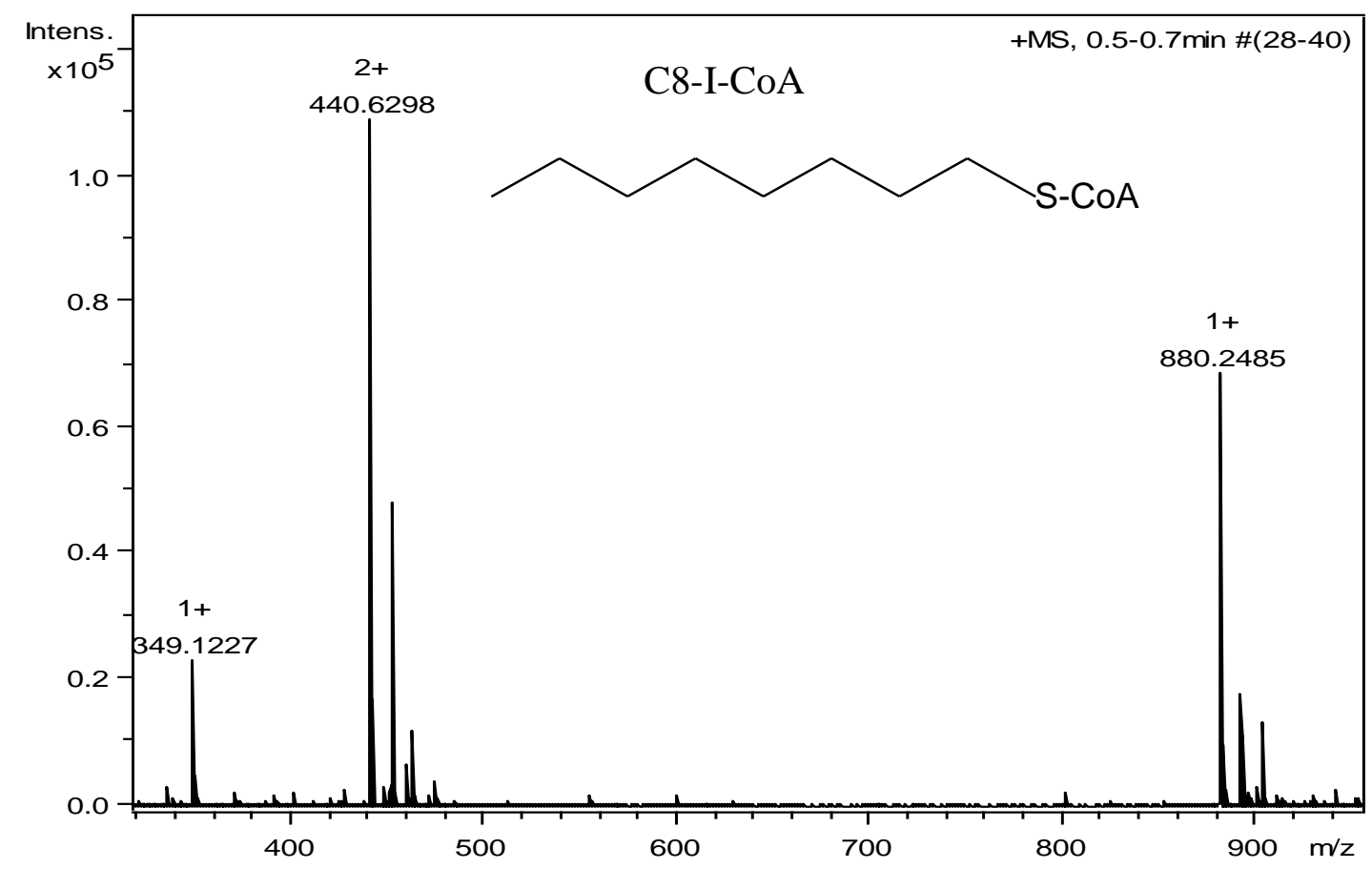

Figure S9 Mass Spec of octyl-CoA. Expected mass was 880.2476 g /mol. 


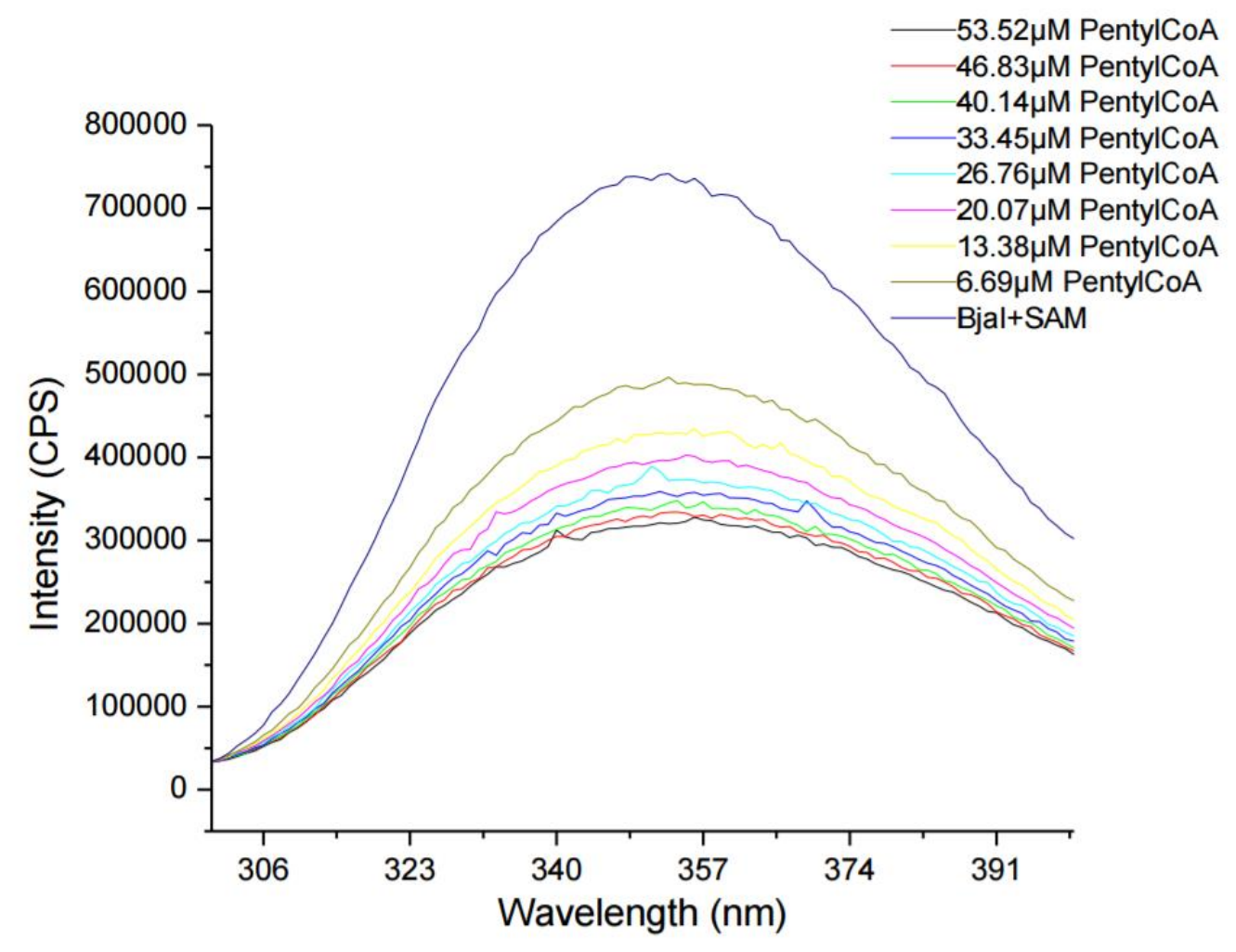

Figure S10 Fluorescence quenching with pentyl-CoA and BjaI. Fluorescence data is currently being collected to determine if SAM or alkyl-CoA is binding first based on their $K_{d}$ values. Collected by John Taffin. 